\title{
Dynamics in Mode Choice Behaviour
}

\author{
Marie-José Olde Kalter
}

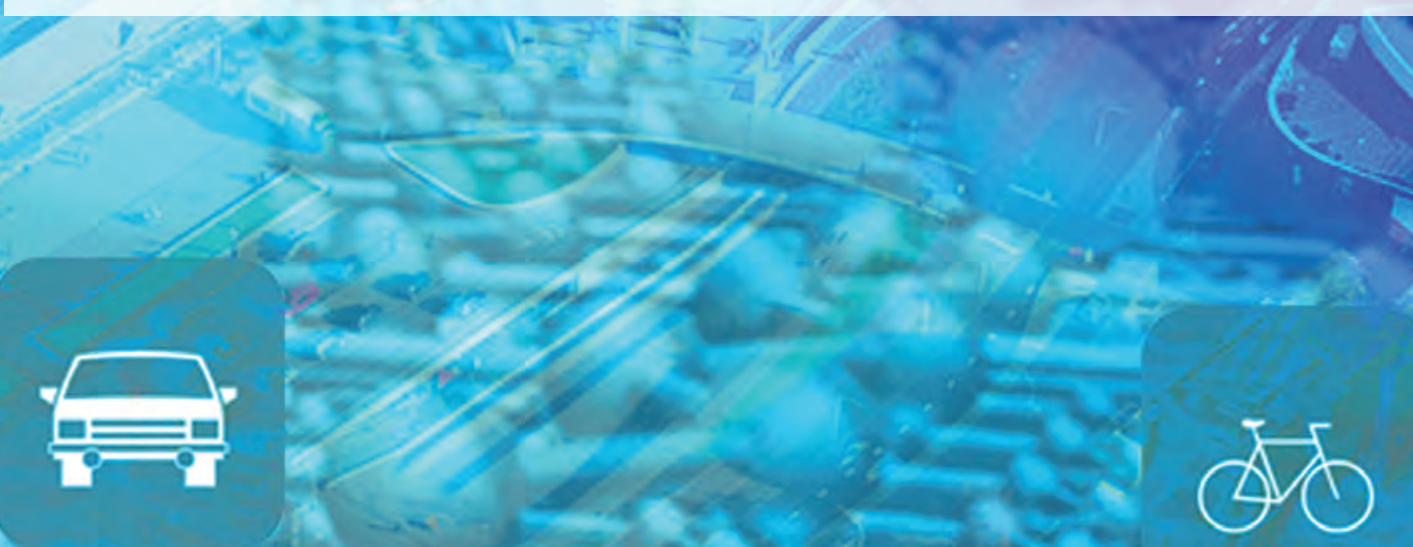




\title{
Dynamics in Mode Choice Behaviour
}

\author{
Marie-José Olde Kalter
}

University of Twente 


\section{Graduation Committee:}

Prof. Dr. Ir. H.F.J.M. Koopman

Prof. Dr. Ing. K.T. Geurs

Prof. Dr. Ir. E.C. van Berkum

Prof. Dr. Ir. J. Henseler

Prof. Dr. H.J. Meurs

Prof. Dr. S. Rasouli

Dr. Ir. M. Kroesen
University of Twente, chairman

University of Twente, promotor

University of Twente

University of Twente

Radboud University

Eindhoven University of Technology

Delft University of Technology

TRAIL Thesis Series No. T2020/27, the Netherlands TRAIL Research School

TRAIL Research School

P.O. Box 5017

2600 GA Delft

The Netherlands

E-mail: info@rsTRAIL.nl

DSI Ph.D. Thesis Series No. 21-009

Digital Society Institute

P.O. Box 217

7500 AE Enschede

The Netherlands

ISBN: 978-90-5584-302-2

ISSN: $2589-7721$

DOI: 10.3990 .1 .9789055843022

This dissertation is the result of a PhD research carried out from 2014-2021 at the University of Twente, Faculty of Engineering Technology, Centre for Transport Studies. This research has been funded by Goudappel and partly supported by the KIM Netherlands Institute for Transport Policy Analysis.

\section{G(O)U (d) (P) (ㄴ) UNIVERSITY DIGITAL SOCIETY

Cover illustration: Carina Kroeze (www.kroezekunst.nl)

Copyright (C) 2021 by Marie-José Olde Kalter

All rights reserved. No part of the material protected by this copyright notice may be reproduced or utilized in any form or by any means, electronic or mechanical, including photocopying, recording or by any information storage and retrieval system, without written permission from the author.

Printed in the Netherlands 


\title{
Dynamics in Mode Choice Behaviour
}

\author{
Proefschrift \\ ter verkrijging van de graad van doctor \\ aan de Universiteit Twente, \\ op gezag van de Rector Magnificus Prof. dr. ir. A. Veldkamp, \\ voorzitter van het College voor Promoties, \\ in het openbaar te verdedigen op 5 november 2021 om 12:45 uur \\ door \\ Marie-José Theresia OLDE KALTER \\ geboren op 16 augustus 1974 \\ te Oldenzaal
}


This dissertation is approved by:

Prof. Dr. Ing. K.T. Geurs [promotor] 


\section{Voorwoord}

Kennen jullie het gevoel dat je na een beslissende wedstrijd om het kampioenschap juichend op het veld staat, dolgelukkig dat na een zenuwslopende strijd de titel binnen is, maar je tegelijkertijd ook beseft dat iets moois voorbij is? Dat gevoel heb ik nu. Het schrijven van mijn proefschrift voelde als een spannende, maar soms ook slopende wedstrijd. Nu het laatste fluitsignaal heeft geklonken, ben ik blij, opgelucht en trots dat de eindstreep in zicht is. Maar tegelijkertijd vind ik het ook jammer dat aan een bijzondere en leerzame periode een einde is gekomen. Het proefschrift is gedrukt. De voetbalschoenen hangen aan de wilgen. Wat blijft zijn de mooie en waardevolle herinneringen aan deze speciale 'wedstrijd'.

In 2009 kwamen Karst en Paul met het plan om een nieuw longitudinaal onderzoek naar het mobiliteitsgedrag in Nederland te starten. Het idee werd verder uitgewerkt en mondde uit in een mooie samenwerking tussen de Universiteit Twente, Goudappel en het Kennisinstituut voor Mobiliteitsbeleid (KIM). Het Mobiliteitspanel Nederland (MPN) was geboren en de eerste dataverzameling vond in 2013 plaats. In datzelfde jaar ontstond het volgende idee: een promotieonderzoek naar de dynamiek in mobiliteitsgedrag op basis van de MPN-data. Een jaar later begon ik als deeltijd-promovendus aan deze spannende wedstrijd.

Zonder goede sponsoren is het tegenwoordig bijna onmogelijk om op topsport niveau te presteren. Dat geldt ook zeker voor een deeltijd-promovendus. Ik ben Goudappel en het KIM dan ook zeer dankbaar voor hun bijdrage aan mijn onderzoek. Een speciaal woord van dank voor de (voormalige) directeuren van Goudappel: Jaap, Jos en Wim. Het is een voorrecht om bij een bedrijf als Goudappel te mogen werken en ik hoop dat het investeren in kennis- en productontwikkeling altijd hoog op de agenda blijft staan.

Karst, ik ben blij dat jij mijn promotor bent. Een betere promotor had ik me niet kunnen wensen. Sporters presteren beter als ze het vertrouwen hebben van de trainer. Dat geldt zeker ook voor promovendi. Ondanks dat deze wedstrijd iets langer duurde dan vooraf gepland, heb je mij altijd het gevoel gegeven dat het goed zou komen. Ik heb erg veel van je geleerd. Er zijn niet veel coaches en trainers die spelers beter maken. Als het gaat om hoogleraren kan ik 
dat minder goed beoordelen, maar voor mij hoor je thuis in het rijtje Michels, Cruyff en Wiegman. Dank!

In het laatste kwartier van de wedstrijd zat ik er een beetje doorheen. Gelukkig zijn er dan altijd teamgenoten die voor je opstaan. Paul en Luc, bedankt dat jullie er mede voor hebben gezorgd dat ik niet zelf achter alle ballen aan hoefde te rennen en in de laatste fase van het onderzoek extra tijd kreeg om mij volledig te concentreren op het afronden van mijn proefschrift. Luc bedankt voor je altijd scherpe en waardevolle suggesties en tips. Je gaf me het vertrouwen om niet altijd voor het balletje breed te gaan, en dat heeft absoluut gezorgd voor meer diepgang in mijn onderzoek.

Ik wil ook graag dit voorwoord benutten om de leden van mijn promotiecommissie - Eric van Berkum, Jorg Henseler, Maarten Kroesen, Henk Meurs en Soora Rasouli - te bedanken voor het lezen van mijn proefschrift, de verbetersuggesties en alvast voor de ongetwijfeld interessante en uitdagende vragen tijdens de verdediging.

Uiteraard wil ik ook mijn collega's bij Goudappel bedanken. Dat zijn er te veel om bij naam te noemen. In de afgelopen twintig jaar heb ik met heel veel fijne en leuke collega's mogen samenwerken. Iedereen bedankt daarvoor. En natuurlijk dank voor de talloze gezellige momenten buiten het werk, met de jaarlijkse pub quiz en het ski-weekend als hoogtepunten. Ook de collega's van het Ministerie van Infrastructuur en Waterstaat wil ik graag bedanken. Mijn werkzaamheden voor het Ministerie hebben mij tijdens het schrijven van mijn proefschrift enorm geholpen om vaker stil te staan bij de vraag achter de vraag.

Een speciaal woord van dank voor mijn paranimfen Anouk en Lucas. Anouk, we kennen elkaar nu meer dan 30 jaar en het verveelt nooit om samen iets te ondernemen. Ik hoop dat we onze tradities de komende 30 jaar voortzetten en nog heel veel samen lachen en mooie gesprekken voeren. Met jouw humor en ratio aan mijn zijde durf ik de verdediging zeker aan. Lucas, we leerden elkaar in 2006 kennen. Onze tijd samen op de "pretkamer" bij het KIM was zonder twijfel een van de leukste perioden in mijn werkzame leven. Jouw altijd positieve houding en uitstraling loodsen me vast en zeker door de moeilijke momenten van de verdediging heen.

Het is fijn om mensen om je heen te hebben waarmee je veel en hard kunt lachen, waarmee je gezellig kunt borrelen, waarmee je lange wandelingen kunt maken, waarmee je concerten kunt bezoeken en nog heel veel meer. Shelly, Carina, Henriette, Simone, Stefanie en iedereen die ik vergeten ben, bedankt voor alle mooie momenten. Moeten we vaker doen.

Je familie heb je niet voor het uitkiezen. Gelukkig niet, want ik had zelf geen betere keuze kunnen maken. Jan-Willem, Bart, Cesarine, Annemarie, Ab, Ageniet, Agnes, Chris, Mats, Totte, Pip, Sophie, Phileine en Lott, jullie zijn een goed stel!

Papa, mijn trouwste supporter. Jij en mama hebben Jan-Willem, Bart en mij een superfijne jeugd gegeven waarin jullie altijd voor ons klaar stonden. Zo reisde mama met mij het hele land door voor trainingen en wedstrijden met Jong Oranje en het Nederlands Elftal. De ervaringen die ik in die periode heb opgedaan blijf ik koesteren. Lieve papa, ik vind het mooi om te zien hoe jij je nog steeds met veel enthousiasme en energie inzet voor onze samenleving en hoe je je zelfs hard maakt voor een autoluw winkelcentrum in ZuidBerghuizen. Ik weet dat je trots bent op mij, maar je weet niet half hoe trots ik op jou ben. 
Een laatste woord van dank voor mijn drie favoriete teamgenoten. Lieve Tieme en Arwen, jullie hebben je ontwikkeld tot twee zeer talentvolle en onmisbare spelers in ons team. Dankzij jullie is elke dag een feest. Blijf alsjeblieft altijd zo nieuwsgierig en veel vragen stellen (ook als ik zeg "nu even niet"). En maak vooral jullie dromen waar! Tenslotte "my husband' Erwin. Twee deeltijd-promovendi in hetzelfde team, dat kan niet goed gaan hoor je het publiek denken. Maar wij hebben het tegendeel bewezen. Jij bent mijn rots in de verdediging. Zonder jou was dit een kansloze en uitermate saaie wedstrijd geweest. Lieve Erwin, Tieme en Arwen. Ik kijk er naar uit om samen met jullie nog heel veel nieuwe en mooie herinneringen te maken.

Marie-José Olde Kalter

November, 2021 


\section{Content}

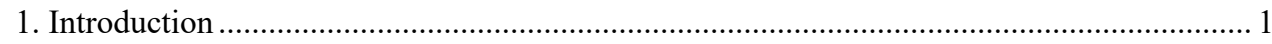

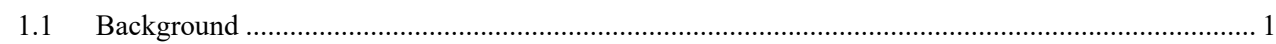

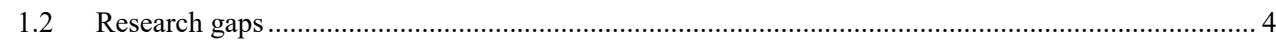

1.3 Research scope and methodology ..................................................................................

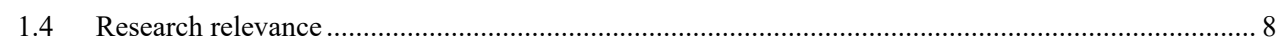

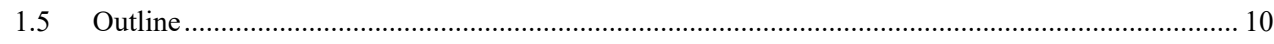

2. Impact of household interactions on mode choice ………………………………........... 13

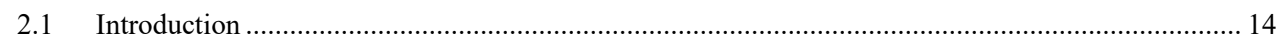

2.2 Literature on household interactions and travel behaviour................................................................ 15

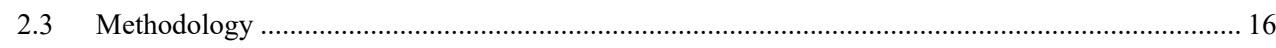

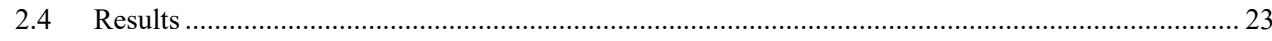

2.5 Conclusions and further research ........................................................................................... 26

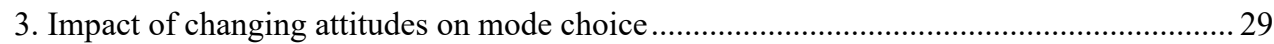

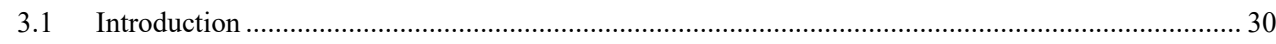

3.2 Attitudes and travel mode choice ......................................................................................

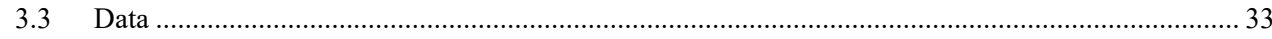

3.4 Method

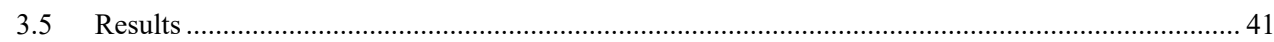

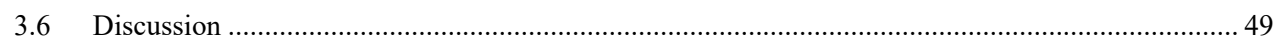

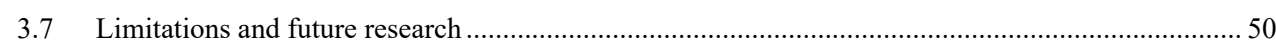

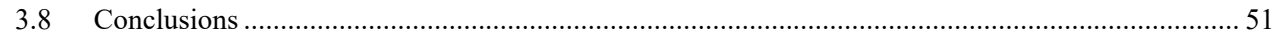


4. Impact of life events on mode preference and mode use of young adults ........................... 53

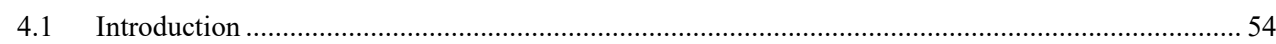

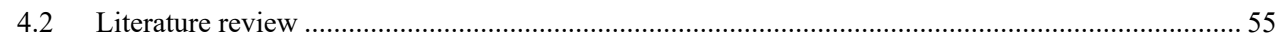

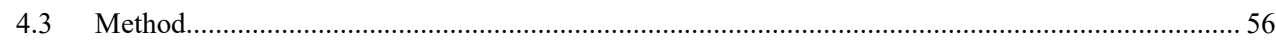

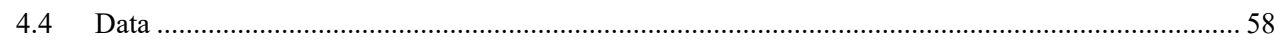

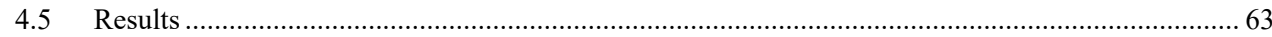

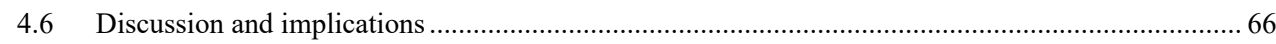

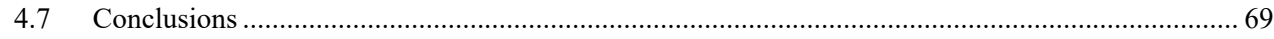

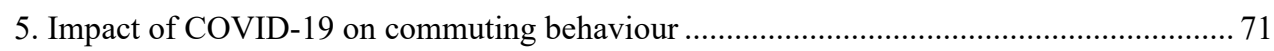

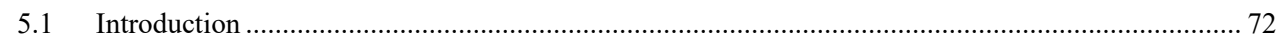

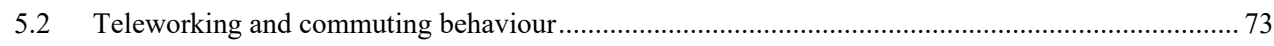

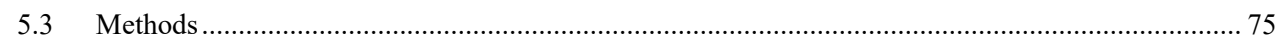

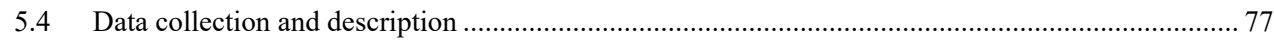

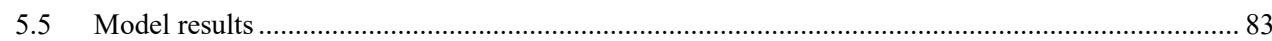

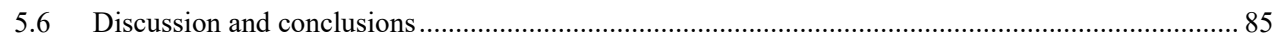

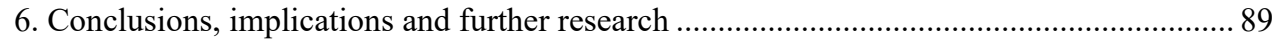

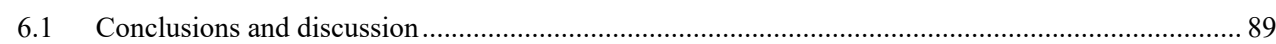

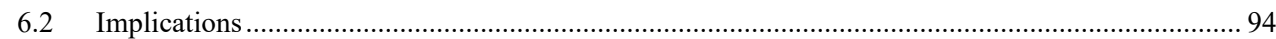

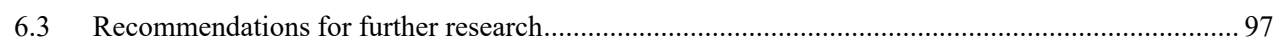

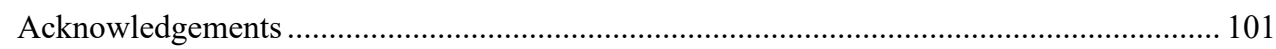

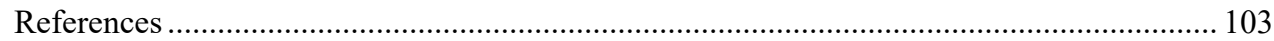

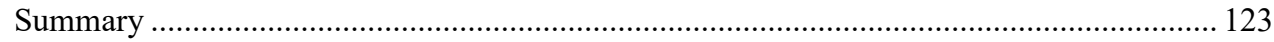

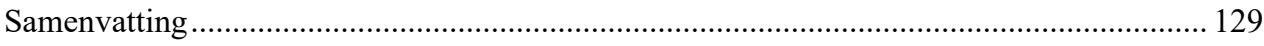

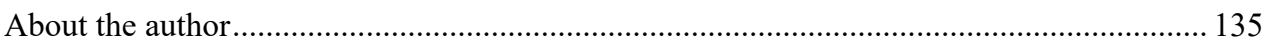

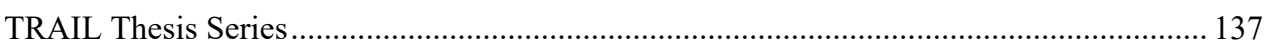




\section{Introduction}

\subsection{Background}

Encouraging sustainable modes of transport is a major policy issue for nearly every local and regional authority as well as the national government in many countries, including the Netherlands. To reverse the worrying long-term trends of growing mobility, such as congestion, increasing oil consumption, greenhouse gas (GHG) emissions, air pollution and the inefficient use of public spaces, policymakers try to encourage people cycle, walk and use public transport more often, instead of the car. Better insight is therefore needed into the motivations and barriers of different modes of transport and the underlying reasons for behavioural changes. Knowledge of the factors determining mode choice is necessary to design effective interventions and move towards the desired behavioural changes. The factors that influence our mode choice behaviour have been the subject of travel behaviour research for decades (e.g., Bailey, 1984; Buehler, 2011; Chatterjee et al., 2016; Miskeen et al., 2014; Müller et al., 2008; Niemeier and Mannering, 1994). However, there are still significant research challenges, especially regarding changes in mode choice behaviour over time. In recent years, the availability of new panel data sources have created new opportunities to study these dynamics in mode choice behaviour.

The aim of this thesis is to provide empirical evidence for the different factors that influence the dynamics in mode choice, the causal relationships between these factors and the directions of these relationships over time, based on large-scale panel data from the Netherlands. A better understanding of what influences our behaviour will help decision-makers develop and implement a better and more effective policy approach to (desired) behavioural changes. 


\section{Factors influencing mode choice behaviour}

In general, research on mode choice behaviour focuses on the following groups of determinants:

- individual and household characteristics: e.g., age, gender, educational level, car ownership;

- motivational factors: e.g., attitudes towards transport modes;

- built environment variables: e.g., characteristics of the spatial and transport infrastructure;

- trip characteristics: e.g., trip distance, travel time and travel cost and

- ICT use: e.g., e-shopping, teleworking, teleconferencing.

Studies on mode choice behaviour typically do not include determinants from all of the groups mentioned above as that would put high demands on the data. The choice and detail in the operationalisation of determinants typically depends on the academic discipline. In general, three domains in travel behaviour research are distinguished, i.e. the fields of geography, economics and psychology (Dijst et al., 2013). Geographers typically focus on built environment factors, economists concentrate on an individual's travel costs and preferences, and psychologists are particularly interested in the motivational factors that influence travel behaviour (Dijst et al., 2013). In recent years, attitudes and preferences of the traveller and ICT use have received increasing attention (Arroyo et al., 2020; de Vos and Alemi, 2020; Elldér, 2020; Swiers et al., 2017). However, information about attitudes and ICT use is another aspect that imposes specific requirements on the data, particularly regarding changes in attitudes and ICT use over time.

To examine the dynamics in mode choice behaviour - intra- and interpersonal changes in mode preferences and mode choice during the life course - it is essential to consider all the different factors that affect mode choice and the changes in these factors over time. Therefore, panel data is needed to provide insight into the changes in these factors over time and the relationship between these changes and mode choice behaviour.

\section{Panel data}

In most countries, including the Netherlands, the understanding of people's travel behaviour is based on one-day (repeated) cross-sectional travel surveys, with or without retrospective elements. Repeated cross-sectional surveys show changes over time on an aggregated level, for example, decreasing car use by young adults or an increase in the number of cycling trips by higher educated people. However, analysis of changes over time on an aggregated level may lead to the wrong conclusions. Ortúzar et al. (2011) claim that cross-sectional travel surveys are not sufficient to understand the dynamics in travel behaviour properly. Besides, the validity and reliability of retrospective surveys to obtain information about changes from the past are questioned because of the complexity and commitment of the respondents (Axhausen, 2008; Sourd and Calastri, 2020).

Panel data offer the opportunity to describe and understand the dynamics in mode choice behaviour. A panel survey means that data is collected from a sample of respondents (panel) at different time points. The most apparent and essential benefit of panel surveys is that it allows measurements of behavioural change over time at the individual level of respondents, information that cannot be obtained in a cross-sectional survey (Tourangeau et al., 1997). This is illustrated by a hypothetical example of the impact of a new railway on the modal split (see Figure 1.1). 
Suppose only data from a repeated cross-section survey before and after finishing a new railway is available. In that case, the results suggest no significant change in car use, and $17 \%$ of the travellers switch from the bus to the train. However, when the same persons were asked which mode they used both before and after the intervention, as in panel surveys, the conclusion looks very different. In that case, the results show that about $5 \%$ of the former car users switched to the train, while $12 \%$ of the former bus users switched to the car and $41 \%$ to the train. Underlying explanations for these changes on the individual level, such as disposing of the car, can be obtained from panel surveys. Moreover, day-to-day information about traveller's mode choice provides an even better insight into behavioural changes at the individual level (e.g., Xianyu et al., 2017).
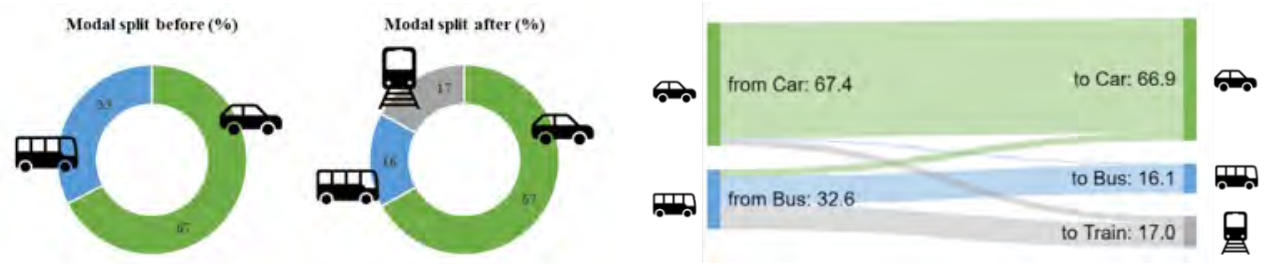

Figure 1.1 A hypothetical example to show the modal split before and after finishing a new railway, based on a repeated cross-section survey (left) and panel survey (right) (Source: authors' creation)

\section{Inter- and intrapersonal mode use variation}

In most travel surveys, only one day is surveyed for each respondent, and intrapersonal dynamics, such as variation in mode use during the week, cannot be derived (e.g., Thomas et al., 2019). Since its inception, most travel demand models, which form the basis of transport policymaking in many countries, are based on these one-day travel surveys (e.g., Stopher and Zhang, 2011). The models implicitly assume that behaviour adjusts instantaneously to new circumstances (i.e., the behaviour is supposed to be in equilibrium, fully adjusting to the prevailing values of contributing factors), and travel is highly repetitive in the short term. Neither assumption holds, however. The literature has often reported all sorts of factors that contribute to travellers not adapting immediately to new situations (e.g., Fujii, 2010; Meurs, 2007). In line with this, recent work shows significant differences between the outcome of cross-sectional and longitudinal models (e.g., van de Coevering et al., 2021). Also, new mobility concepts that target the use of different alternatives, such as shared mobility and mobility-as-a-service, require insight into day-to-day variation in travel behaviour at the individual level to determine its potential and effects. To that end, longitudinal data is needed to analyse the inter- and intrapersonal dynamics in mode use variation. 


\subsection{Research gaps}

The observations in the previous section highlight the need for more longitudinal studies to examine the causal relationship between the different determinants that affect changes in mode choice over time, and to disentangle intrapersonal- and interpersonal variation in travel behaviour. Despite the vast amount of studies conducted to analyse transport mode choice, there are still significant knowledge gaps related to dynamics in mode choice behaviour.

\section{Household interactions}

Although the importance of household interactions in travel behaviour research has been recognised (e.g., Auld and Zhang, 2013; Bhat and Pendyala, 2005; Timmermans and Zhang, 2009), most studies on mode choice behaviour are typically based on individual travel behaviour decisions. Arrangements between individuals within the same household (e.g., vehicle allocation, joint activities) are not considered (Ho and Mulley, 2015b). For instance, in a two-adult household with only one car, individual mode choice models do not include the decision-making process regarding the car's allocation. Previous research showed that household interactions affect mode choice behaviour at the individual level (e.g., Ho and Mulley, 2013; Ho and Mulley, 2015a; Miller et al., 2005). Also, Kroesen (2015) found that travel behaviour of the male household head influences travel behaviour of the female household head and vice versa over time. However, the impact of changes in personal and household characteristics on household interactions and travel behaviour over time has hardly been investigated. Probably because of the lack of longitudinal household surveys, most studies focus on the individual decision-making process.

\section{Temporal dynamics in attitudes}

According to existing research findings, travel mode choice is determined and influenced by the attitudes people have towards the car, public transport and inactive modes (e.g., Anable, 2005; Donald et al., 2014; Molin et al., 2016; Paulssen et al., 2014; Steg et al., 2001). The Theory of Planned Behaviour (Ajzen, 1991) and Swartz's Norm Activation Model (Schwartz, 1977) are two of the most widely used models to study the effects of attitudes on behaviour. These models have been applied in different studies to improve our understanding of travel behaviour (e.g., Bamberg et al., 2015; Donald et al., 2014; Kaewkluengklom et al., 2017). They provide insight into the relationship between attitudes, social norms, intention and behaviour. Although it is recognised that behaviour may influence attitudes (e.g., Ajzen, 2015; Kroesen et al., 2017), most research assumes that attitudes affect behaviour. This follows from the basic principle that people's behaviour can be derived from their intentions, and attitudes determine intentions (Ajzen, 1991). Consequently, the impact of temporal dynamics in attitudes on transport mode choice has been much less studied, particularly the extent to which changes in attitudes are caused by changes in time-dependent variables such as life events (e.g., childbirth, new job, moving home).

\section{Life events and mode preferences}

In recent years, changes in travel behaviour over the life course of an individual and the impact of different life course stages on these changes has been the subject of intensive research (e.g., Busch-Geertsema and Lanzendorf, 2017; Clark et al., 2016; Janke and Handy, 2019). The mobility biography approach suggests that life-course events, such as the birth of a child or starting a new job, lead to travel behaviour changes (Müggenburg et al., 2015). Much work has already been done to understand behavioural changes from this perspective (e.g., Lanzendorf, 2003; Rau and Manton, 2016; Scheiner et al., 2016). However, there is still a clear need for a better understanding of the impact of life events on changes in mode choice behaviour based on empirical data. Although previous studies examined the impact of life 
events and an individual's preference for transport modes on travel behaviour (e.g., Chatterjee and Scheiner, 2015; Susilo et al., 2019; Zhang et al., 2014), most of these studies assume that mode preferences do not simultaneously change during the life event. However, mode preferences may also change over time, and these changes may affect travel behaviour as well (Susilo et al., 2019). For instance, van de Coevering et al. (2021) found that moving to an environment with different characteristics, such as living closer to PT facilities, affects mode preferences and travel behaviour over time. Besides, based on cognitive theory, we might expect that life events affect travel behaviour by influencing preferences (Andersen and Chen, 2002).

\section{Teleworking and commuting behaviour}

The impact of teleworking on commuting behaviour has been the subject of many studies. In the short term, teleworking reduces commuting trips (e.g., Andreev et al., 2010; Elldér, 2020). However, the positive impact might disappear in the long term because of so-called rebound effects, such as induced travel demand for other purposes (e.g., Choo et al., 2005; de Abreu e Silva and Melo, 2018; Kim, 2017). The COVID-19 virus outbreak at the beginning of 2020 had an enormous impact on daily mobility patterns in the Netherlands. Since the outbreak of the COVID-19 virus, employees were strongly advised to work from home as much as possible. The share of teleworking has never been so high as during the first lockdown. Existing research provides insight into teleworking adaption and the relationship with mode choice for commuting before the virus outbreak. However, less is known about the influence of the behavioural changes during the COVID-19 pandemic on intentions concerning teleworking and mode choice for commuting. In this respect, the COVID-19 pandemic provides new insights into the impact of experiences with teleworking for a more extended period.

\subsection{Research scope and methodology}

The main objective of this research is 'to provide empirical evidence of the different factors that influence dynamics in mode choice, the causal relationships between these factors and the directions of these relationships over time, based on large-scale panel data from the Netherlands'.

\subsubsection{Conceptual model}

Research on travel behaviour covers a large variety of topics, concerning mainly the factors that influence people's travel choices, building new or improving analytical modelling approaches for forecasting travel behaviour, and analysing the impacts of future scenarios on travel behaviour. This thesis focuses on the factors that influence people's travel mode choices and changes in mode choice behaviour over time. Figure 1.2 shows the conceptual model used to explore how mode choice behaviour over time is affected by changes in the built environment, personal and household situation, attitudes and preferences, trip characteristics and ICT use. This conceptual model is based on Geurs' dynamic research approach (Geurs, 2014). The framework shows the different groups of determinants that affect mode choice behaviour. A change in one of these factors at time $t$ might affect mode choice behaviour at time $t$, but might also affect the determinants and mode choice behaviour at time $t+1$. Between the different periods, life events may occur and affect travel behaviour. Longitudinal data are needed to examine these so-called lagged effects (e.g., Lee et al., 2017; Kroesen and Goulias, 2016; McBride et al., 2016; Oakil et al., 2011; Golob and Meurs, 1986). This thesis focusses on examining the role of lagged effects. Lead effects (i.e. the impact of one variable at time $t$ on the other variable at time $t-1)$ are potentially also possible and relevant but beyond 
the scope of this thesis. In addition, at the individual and household level, intra- and interpersonal dynamics in mode choice behaviour can be distinguished at different time points and covering different periods. Other elements in the dynamic analysis of travel behaviour are the effects of habit formation (i.e. it takes time to change) (e.g., Kitamura, 1990; Kitamura and van der Hoorn, 1987). The data used in this thesis covers behavioural changes at most for three consecutive years. Habit formation over a longer period is beyond the scope of this thesis.

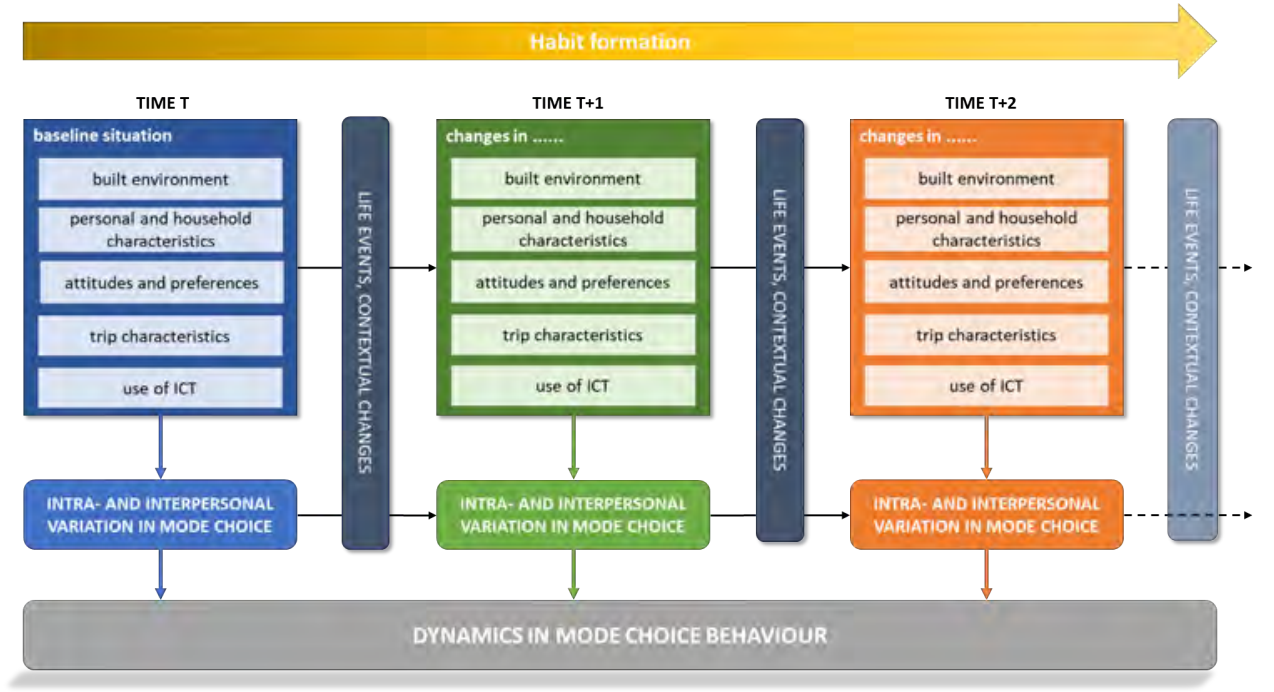

Figure 1.2 Conceptual framework

\subsubsection{Data}

In the 1980s, the Netherlands was one of the first countries to set up a mobility panel survey, the Dutch Longitudinal Travel Survey (in Dutch: Longitudinaal Verplaatsings Onderzoek, LVO), which involved keeping a seven-day trip diary by 1,500 households (about 3,500 persons aged 12 and over) (Meurs et al., 1989). However, the costs of collecting the data proved prohibitive and the survey was discontinued. Since then, one of the most important data sources for understanding people's travel behaviour in the Netherlands is the Dutch National Travel Survey (in Dutch: Onderweg in Nederland, ODIN), a yearly cross-sectional travel survey (CBS, 2019). Because of the large sample (i.e., more than 40,000 persons), ODIN offers the possibility to derive mobility trends on an aggregated level. However, individual variation and changes in travel behaviour cannot be determined. For precisely this reason, the University of Twente, Goudappel and the KIM Netherlands Institute for Transport Policy Analysis initiated the Mobility Panel Netherlands (in Dutch: Mobiliteitspanel Nederland, MPN). The MPN comprises a yearly three-day trip diary among 2,000 Dutch households (4,500 persons aged 12 and over). The first data collection started in the fall of 2013. Hoogendoorn-Lanser et al. (2015) provide more information about the setup of the MPN. Also, recently, travel information from big data such as GSM and smartphone GSMtracking has become available. A targeted GPS-tracking travel survey is the new Dutch Travel Panel (in Dutch: Nederlands Verplaatsingspanel, NVP), started in 2019 as an initiative of KANTAR, Mobidot and DAT.Mobility with an expectation of continuously recording travel 
information through smartphones of about 10,000 participants whose household and demographic characteristics are also known. More details on the NVP can be found in van der Drift et al. (2021) and Thomas et al. (2018b).

The availability of recent and large-scale panel data in the Netherlands, in particular the MPN and NVP as described above, provides new opportunities to examine the identified research gaps and to increases our understanding of the temporal dynamics in mode choice behaviour. Data from the MPN and NVP are used to explore these dynamics from different perspectives, and individual and contextual determinants that affect mode choice behaviour can be studied simultaneously. The results improve our knowledge about changes in mode choice behaviour, the underlying explanations for these changes and the causal relationships over time.

\subsubsection{Research questions}

In this thesis, the following research questions are addressed:

1. To what extent do household interactions and changes in household and personal characteristics affect car use for home-based tours?

2. Do travellers' profiles based on their attitudes towards the car change over time, and are these changes related to life events?

3. How do the life events of young adults affect mode preferences and mode use over time?

4. Did changes in teleworking and travel behaviour during the lockdown influence car use for commuting after COVID-19?

The research scope and methodology of each topic will be discussed in detail below.

\section{Impact of household interactions on car use}

In this thesis, the impact of intra- and inter-household variation on car use is examined. Household interactions can be distinguished into three main categories: resource and allocation usage, task and time allocation, and joint activity allocation (Timmermans and Zhang, 2009). In this thesis, the focus relies on the last category, i.e., joint activity allocation. This analysis contributes to understanding the effect that (changes in) relations between household members has on travel mode choice, with special focus on which part of the variation in mode choice is due to differences among households and individuals, and which part is due to the interaction between household members.

The decision to use the car is modelled for home-based tours, based on MPN data. Also, the impact of time-varying variables on household interactions and travel behaviour, such as life events, is considered. Because the MPN is a longitudinal household panel, which means that travel data is collected from every household member, both the impact of household interactions and changes in individual and household characteristics over time are included. A multilevel framework is used to investigate mode choice behaviour at the tour, individual and household level. Also, within this framework, the impact of individual and household characteristics on travel mode choice, interdependencies between household members and variation in individual travel mode choice and other characteristics over time are considered.

\section{Impact of changing attitudes on car use and ownership}

In this thesis, the effects of changes in attitudes towards car use and car ownership over time on mode use are investigated. This analysis provides a better insight into changes in attitudes over time as well as the effect of these changes on car use. Moreover, the impact of life events on transitions between attitude-based segments is tested, providing more insight into the relationship between life events and dynamics in attitudes. 
Based on the 2014 and 2016 waves of the MPN, a latent transition model is estimated to investigate the transitions between different segments based on travellers' attitudes towards car use and ownership. The latent transition probabilities are used to predict changes in mode use. In this analysis, it is assumed that changes in traveller attitudes towards car use and ownership precede mode choice and not vice versa. The identification of differences in attitudes towards car use and ownership between sub-groups, and the stability in these attitudes, can help policymakers to develop specific policy strategies for these sub-groups.

\section{Impact of life events on mode preference and mode use}

In this thesis, the bi-directional feedback effects between mode use and mode preference over time are examined, as well as the mediating effects of mode preference between life events and mode use and of mode use between life events and mode preference. This analysis contributes to a better understanding of the direction of the relationship between life events and changes in mode preferences and the frequency of mode use. Moreover, the Netherlands is an interesting case study area to examine changes in mode preferences given the quality and role of alternatives to the car.

The focus is on three life events (i.e., the birth of a child, moving home, and a new job) and young adults, as they experience life events more frequently than other age groups. A random-intercept cross-lagged panel model (RI-CLPM) is estimated to explore the relationships between mode preference, mode use, and life events based on three waves of the MPN. Within the RI-CLPM framework it is possible to examine both the causal relation between several variables and the magnitude of change in behaviour under various conditions, distinguishing between- and within-person effects.

\section{Impact of COVID-19 on mode choice for commuting}

During the lockdown in the Netherlands, the strong advice for employees to work from home created an unintended break in daily routines, such as cycling to work every morning. The focus in this thesis is on how employees changed their commuting behaviour (i.e. teleworking and car use for commuting) due to a 'forced' intervention aimed at this behaviour. This analysis provides insight into the relationship between the observed changes in commuting behaviour during the lockdown and the intended changes afterwards. Also, the impact of moderating effects such as experiences with teleworking and the impact of policy measures on teleworking intentions are included.

The conceptual model for the analysis is based on the different factors that affect teleworking and mode choice for commuting from a dynamic perspective. It suggests that changes in teleworking and travel behaviour during the lockdown impact the intention to change behaviour after COVID-19, controlling for sociodemographic characteristics. Large-scale smartphone GPS-data and survey data of Dutch employees are used to analyse actual and intended changes in behaviour. Ordinal and binominal logistic regression models are estimated to examine the odds to change teleworking during the lockdown and the intention to change teleworking and car use after COVID-19. Also, intended changes in commuting behaviour are related to policy interventions, both by the government and employers.

\subsection{Research relevance}

\subsubsection{Scientific relevance}

In recent years, there has been renewed interest in panel analyses, as new and cheaper data collection methods have become available, such as online surveys and GPS-data. The availability of panel data enables a greater focus on the longitudinal analysis of travel behaviour changes and the causal relationships over time (Scheiner and Rau, 2020). This 
thesis utilises this development and contributes to the literature on dynamics in mode choice behaviour as follows.

Since the late 1980s, when the well-known LVO ended, there has been an extended period with no recent longitudinal data regarding travel behaviour in the Netherlands. In this research, I had the unique opportunity to use two new sophisticated and large-scale panel data sources: the MPN and the NVP (see section 1.3.2). Both the MPN and NVP are amongst the world's largest ongoing mobility panels. The unique combination of travel behaviour, household and personal characteristics, and the large sample sizes allow for advanced statistical techniques. For instance, a latent transition analysis is used to examine changes in attitudes and the causal relationship with mode use over time. Furthermore, a randomintercept cross-lagged panel model is estimated to explore the causal relationship between mode preference, mode use and life events over time. Only a few studies have applied a crosslagged panel model to investigate changes in travel behaviour previously (e.g., van de Thøgersen, 2006; van de Coevering et al., 2021; de Haas et al., 2021). Moreover, the longitudinal data enables the examination of causal relations over time, which is impossible with repeated cross-sectional data. In addition, the data includes information on various background characteristics of the participants. Alongside sociodemographic characteristics such as household composition, educational level, and income which are collected annually, also attitudes and preferences towards transport modes for different purposes, life events and the spatial characteristics of the origin and destination of every trip. With this, I was able to examine the causal relationship between changes in factors that influence mode choice and changes in mode use over time.

The impact of life events was included in all the analyses that used MPN data. Life events are considered as windows of opportunity for policymakers, both from the mobility life cycle approach (e.g., Rau and Manton, 2015; Schoenduwe et al., 2015) and the habit-discontinuity theory (e.g., Haggar et al., 2019; Zarabi et al., 2019). In this thesis, the impact of life events on changes in mode choice behaviour is explored from these different theories, focusing on the Dutch situation. Furthermore, the COVID-19 pandemic offered a unique chance to investigate the changes in mode choice behaviour from another perspective. Whereas the mobility life cycle approach and the habit-discontinuity theory state that life-changing moments trigger people to reconsider their behaviour, the COVID-19 pandemic, which can be seen as a "disruptive life event," caused behavioural changes without time for reconsideration, in particular regarding teleworking. Also. most research on teleworking is based on the situation pre-COVID-19. To this end, this thesis provides new insights into the factors that determine working from home and the relationship between teleworking and car use. Moreover, I was able to use a combination of smartphone and survey data of the same persons and to analyse day-to-day variation in mode use both before and during the COVID-19 pandemic.

Overall, this thesis provides empirical evidence on the dynamics in mode choice behaviour from different perspectives, using novel panel data sources (i.e., survey and smartphonebased) and applied advanced statistical techniques to model the causal relationships over time and analyse inter- and intrapersonal mode use variation.

\subsubsection{Societal relevance}

Stimulating more sustainable modes of transport not only reduces travel-related emissions but also has a positive impact on congestion, health, and liveability and is one of the key issues for national, regional and local authorities. In the Netherlands, for instance, stimulating 
sustainable modes such as cycling and walking is high on the agenda of policymakers. In this regard, the National Climate Agreement ${ }^{1}$ includes more than 100 policy measures to stimulate more sustainable modes of transport. Also, the current plan "A National Vision for the Future of Cycling", contains a first inventory of possible investments in cycling throughout the Netherlands in the coming years (Ministerie van Infrastructuur en Waterstaat, 2021). In addition, several municipalities aim to create low-traffic urban areas (e.g., Gemeente Amsterdam, 2020; Gemeente Enschede, 2021; Gemeente Utrecht, 2021). On the regional level, in co-operation with local authorities and employers, many policies and instruments have been implemented ${ }^{2}$. Regional and local mobility programs (e.g., Provincie Drenthe, 2020; Provincie Utrecht, 2019) also have their own climate, accessibility, traffic safety and health targets, and have translated these targets into several actions to improve accessibility, to stimulate clean urban transport and to encourage the use of active modes (i.e., cycling and walking).

For all these policy programmes and measures, it is essential to know how people behave, the underlying reasons for (changes in) their behaviour and possible adjustments towards achieving the desired behavioural change. A better understanding of the dynamics in mode choice behaviour provides insight into the behavioural changes needed to tackle the major societal challenges, such as climate change and health issues. More awareness of these aspects could be crucial to the success of these programmes. These new insights help policymakers to understand the underlying explanations for behavioural changes, and this knowledge might be crucial in the implementation of new or improving current policy measures to achieve structural changes in travel behaviour. As such, the findings in this thesis help to determine the effectiveness of policy measures and emphasise the societal relevance of this research.

\subsection{Outline}

This thesis is organized as follows (see Figure 1.3).

Chapter 2 provides empirical insights into the impact of inter- and intrahousehold interaction and changes in individual and household characteristics, such as life events and changing preferences, on car use for home-based tours.

Chapter 3 presents how changes in travellers' attitudes towards car use and ownership changes over time and how these changes influence car use.

Chapter 4 provides insight into the relationship between frequency of mode use and mode preference over time and the impact of life events on mode preference and mode use frequency.

Chapter 5 provides evidence from large-scale GPS-tracking and survey data on the relationship between changes in teleworking and daily travel behaviour during the first lockdown and the intention to change commuting behaviour after COVID-19 in the Netherlands.

\footnotetext{
${ }^{1}$ https://www.klimaatakkoord.nl

${ }^{2}$ https://www.zowerkthet.nl
} 
Chapter 6 starts with the answers to the research questions and discusses the main conclusions. Based on the findings in this thesis, research implications for transport policy are formulated. This chapter ends with a discussion of directions for future research.

CHAPTER 1: BACKGROUND, SCOPE AND METHODOLOGY

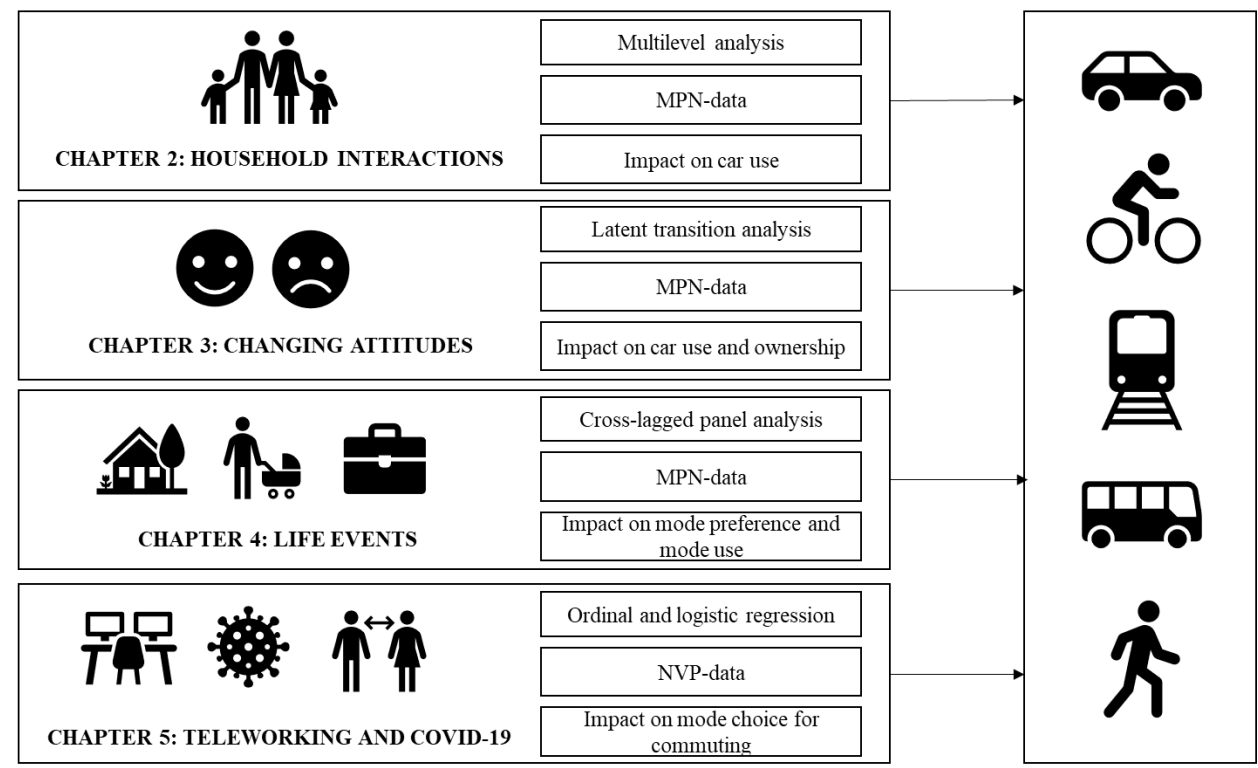

CHAPTER 6: CONCLUSIONS, IMPLICATIONS AND FURTHER RESEARCH

\section{Figure 1.3 Thesis structure}




\title{
2. Impact of household interactions on mode choice
}

This chapter is based on: Olde Kalter, M.J.T. \& Geurs, K.T. (2016). Exploring the impact of household interactions on car use for home-based tours. A Multilevel analysis of mode choice using data from the first two waves of the Netherlands Mobility Panel. European Journal of Transport and Infrastructure Research, 16(4), 698-712.

\begin{abstract}
While most studies on mode choice behaviour and households are typically based on individual travel behaviour decisions, less is known about how relations inside households affect mode choice. This study addresses this topic by examining intra- and inter-household variation in car use. The decision to use the car is modelled for home-based tours, based on data from the 2013 and 2014 waves of the Netherlands Mobility Panel. A multilevel framework is used to investigate mode choice behaviour at tour, individual and household level to account for the impact of individual and household characteristics on travel mode choice, interdependencies of individuals within their households and variation in individual travel mode choice and other characteristics over time. The results show that variability between households and individuals accounts for more than one third of the total variation in the mode choice of home-based tours. In dual-income households, intra-household interactions have a larger effect on car use than inter-household interactions. Although only two panel waves are used, the model results show significant time effects on mode choice: if the same tour was also conducted in the previous year and one person changed working hours or work location, car use is less likely.
\end{abstract}




\subsection{Introduction}

The overarching aim of transport policies in most countries is to increase accessibility and at the same time reduce the externalities created by transport. To achieve these aims, transport policies are developed and implemented to promote a modal shift from car use towards more sustainable modes such as public transport, cycling and walking. Knowledge about the factors that determine mode choice is therefore essential, and this has been a major topic in travel behaviour research in recent decades. There is a huge body of literature on mode choice behaviour. However, like other activity-travel behaviour studies, most of these studies are typically based on individual travel behaviour decisions. The existence of intra-household interactions giving rise to joint activity participation and interdependencies in travel decisions has long been acknowledged, yet empirical studies of household interactions still remain limited (Ho and Mulley, 2015b).

There are numerous facets to intra-household interactions and group decision-making that have important implications for mode choice behaviour. For instance, in a multi-driver household with only one car available, agreements about car use have to be made. Also, timevarying personal or household-level factors may influence household interactions and affect travel behaviour. Important life events, such as changing jobs or having children, can prompt reconsideration of routine behaviours, break habits and form a trigger for changes in travel behaviour (Bamberg et al., 2003). Probably because of the lack of panel data, most studies on household interactions and travel behaviour (see Ho and Mulley (2015b) for an overview) do not take changes in individual or household characteristics into account.

Bhat and Pendyala (2005) concluded that there has been a great leap forward in understanding and modelling intra-household interactions and group decision-making. However, much remains to be explored and learnt. In particular, there is little literature about the impact of household interactions on travel mode choice, with the work by Miller et al. (2005) and Ho and Mulley (2013, 2015a) among the few recent studies. Ho and Mulley (2015a) found that mode choices differ significantly across joint tour patterns, with public transport being less likely to be used for joint travel. Miller et al. (2005) developed a disaggregated tour-based mode choice model, which predicts the mode choice of individual trip makers and takes within-household and inter-personal interactions into account. However, most studies investigate interdependencies between household members by defining household characteristics at the individual level, like household size or the number of children.

An examination of the existing research shows that less is known about how relations inside households affect mode choice. Consequently, there is little knowledge about which part of variation in mode choice is due to differences among households and which part is due to interactions between household members. In this study, we examine intra- and interhousehold variation in mode choice. We used data from the first two waves from the Netherlands Mobility Panel (in Dutch: Mobiliteitspanel Nederland, MPN). The MPN is specifically designed for examining changes in travel behaviour, both at the individual and the household level and the analysis in this study addresses the following research question: to what extent do household interactions affect home-based car tours, and how do changes in household and individual characteristics affect home-based car tours?

The remainder of this chapter is organized as follows. Section 2.2 provides a short review of the literature on the influence of household interactions on travel behaviour. Section 2.2 describes the methodology and data used for the analysis. Section 2.4 details the estimation results and Section 2.5 presents the conclusions and discusses directions for further research. 


\subsection{Literature on household interactions and travel behaviour}

Most research on mode choice behaviour is based on individual behaviour and, therefore, on the individual decision-making process. In general, research on mode choice behaviour focuses on the following group of determinants at the personal level: individual and household characteristics, attitudes and preferences, built-environment variables, and trip characteristics (Olde Kalter et al., 2014). Although the importance of representing group decision-making mechanisms of household behaviour has been recognized since the 1980s, studies about group behaviour in transportation are new and remain limited (Timmermans and Zhang, 2009).

Household interactions can be divided in three main categories: resource and allocation usage, task and time allocation, and joint-activity allocation (Timmermans, 2009). All three categories have their own effect on travel behaviour. With regards to the first category (resource and allocation usage), some households may have limited resources (for example, one car in a multi-driver household), which in turn can affect individual travel patterns. Most studies that take resource and allocation usage into account focus on the relationship between car ownership and/or car availability and mode choice (e.g., Anggraini et al., 2008; Gliebe and Koppelman, 2005). Maat and Timmermans (2009) examined whether the decision to commute by car is influenced by built-environment characteristics, taking interdependencies between household partners into account. They found that for cases of dual earners with only one car, the partner with the greatest commuting distance and the lowest-density work location is likeliest to commute by car.

Task and time allocation decisions may also affect travel behaviour. Not all (household) tasks have to be carried out by all household members, such as grocery shopping and taking the children to school. Ettema et al. (2007) investigated the role of location factors in task and time allocation at the household level. The results of that study indicate the existence of various intra- and interpersonal linkages in activity choice and time allocation. Wang and $\mathrm{Li}$ (2009) developed a model of time allocation in a household and found that time allocation of males contributes more heavily to household utilities than time allocation of females and that optimal time allocation patterns depend on household income, number of children, car ownership and type of housing. Schwanen et al. (2007) investigated the distribution of out-ofhome household tasks between spouses. The results show that women perform the bulk of out-of-home household activities and that the distribution of household tasks between partners is more even in higher-density, higher-diversity neighbourhoods.

Concerning joint-activity allocation, decisions about joint activities will have a synchronizing effect on the activity and travel patterns of household members. Vovsha et al. (2007) found that joint travel constitutes a significant share (40-50 percent) of total travel. Ho and Mulley (2013) established that joint household travel accounts for about 60 percent of all home-based tours at weekends and for about 50 percent on weekdays. They also showed that arrangements of joint household travel are highly associated with travel purpose, social and mobility constraints and household resources. Especially the presence of children is important in household interactions and joint travel. Vovsha and Petersen (2005) and Yarlagadda and Srinivasan (2008) found that chauffeur characteristics (gender, employment status and age), the children's ages, household car ownership, household income and relative distance between home, school and workplace had a significant effect on the decision about who takes the children to school. 
The present study contributes to the understanding of the effect that (changes in) relations between household members has on travel mode choice, with a special focus on joint activities by household members as well as with non-household members. Our expectation was that mode choice is not only the outcome of individual decisions. Our analysis of how relations between household members affect car use also addresses the effects of different household types and changes in individual and household characteristics on mode choice.

\subsection{Methodology}

A multilevel binary logit model was developed to examine the impact of interactions between household members on car use. We used a binary mode choice variable as dependent variable: auto driver mode (1) and other means of transport (0). We decided to use a binary mode choice model as we were interested in the effect of household interactions and the influence of changes in household interactions on the decisions of household members to drive a car or not to drive a car. The results of the model serve as a starting point for investigating more complicated mode choice models in follow-up studies.

\subsubsection{Multilevel analysis}

It is fair to expect that individual household members interact with each other, meaning that individual persons are influenced by the household to which they belong. Although it is generally known that individuals within a specific household type may have different travel patterns, most research does not take these differences into account. A common specification error in travel behaviour research is that variables at the household level, for example household size and car availability, are disaggregated into explanatory variables at the individual level. The opposite occurs as well; sometimes individual characteristics are aggregated to explain differences between households, for instance by assigning to a household the mean trip rate for all household members. Disaggregation and aggregation cause incorrect assumptions of independence at different levels. Multilevel analysis is one of the best approaches to deal with this variation at different levels.

In multilevel analysis, the grouping of participants, which results from either the sampling scheme (for example, selection of neighbourhoods followed by selection of individuals within neighbourhoods) or the social groupings of participants (for example, being in the same classroom, department, organization or political district), is the focus of the theory and conceptual model, as proposed by Kreft and De Leeuw (1998). Multilevel analysis is a suitable approach for taking the social contexts as well as the individual respondents or subjects into account. Multilevel analysis is a statistical technique, which can be applied to hierarchical nested data. Multilevel models open up opportunities not only to examine relationships at multiple levels of a data hierarchy but also to incorporate a time dimension into the analysis. Longitudinal data, or repeated measures data, can be viewed as multilevel data, with repeated measurements nested within individuals (Hox, 2010). However, at least three time points are required to model patterns of change over time (Liu, 2016).

Multilevel analysis carried out in relation to travel behaviour falls into two categories of approach (Lipps and Kunert, 2005). The first approach takes the hierarchy in the data into account. Most of these studies focus on the relation between travel behaviour and spatial factors. For example, Schwanen et al. (2004) investigated the impact of metropolitan structure on commute behaviour of urban residents in the Netherlands. In this study, multilevel regression was applied to allow for interdependencies among a variety of levels of analysis ranging from the individual worker to the metropolitan region. The results show that the 
variation in mode choice among individual workers within residential zones is much larger than the variation between such geographical units. Another example comes from the work by (Borgoni et al., 2002). They focused on the influences of household characteristics and one regional variable on car ownership and use and concluded that there exists some regional clustering of specific household types in Austria. Klöckner and Friedrichsmeier (2011) used a two-level structural equation model to model the decision to use the car in contrast with alternative travel modes. This brief analysis shows that the multi-level approach adds information about interactions between both the levels and the amounts of variance present at each level.

The second approach regarding multilevel analysis accounts for repeated measurements from longitudinal surveys with a nested structure at the individual or household level. In this way, multilevel analysis helps understand the individual variation of travel behaviour. To the authors' knowledge, the literature contains only one longitudinal study concerning household interactions. Goulias (2000) used data from the first five waves of the Puget Sound Panel Survey, the first general-purpose travel panel survey in the United States, which was in operation between 1989-2002 and comprised 1,700 households. Goulias (2000) examined not only the variation between persons and households, but also the variation in travel behaviour over several years. The most important findings in the analysis are the large variance contributions by each level and the lack of symmetry in change over time. Another example of the use of a time variable in multilevel analysis is the study of Cherchi and Cirillo (2008). They estimated a mode choice model that accounts for systematic and random heterogeneity over individual preferences and responses and correlation across individuals over three time periods. The results of that study show that accounting for correlation between individuals in panel data improves model results enormously. In another study, Cherchi and Cirillo (2014) used a six-week travel diary survey to study the intrinsic variability in the individual preferences for mode choices, the effect of long-term plans and habitual behaviour in daily mode choices. They found that there is a strong inertia effect in mode choice that increases with (or is reinforced by) the number of times the same tour is repeated.

\subsubsection{Model specification}

The multilevel framework allows us to investigate mode choice behaviour at different levels. In this study, we decomposed the total variation in car use into variations at three different levels: household level, individual level, and tour level ${ }^{3}$ :

1. Tours form the first level at which the dependent variable (car use) is measured.

2. The second level is taken up by the individuals within the households.

3. The households represent the third level. This is the basic unit of demand in which activities are organized, budgets and goods (for example, cars) are shared, similar attitudes are prevalent, and the socio-economic status of the members is generally comparable (Lipps and Kunert, 2005).

We created explanatory variables for each level (see Table 2.1). These variables served to explain the variation in car use between and within different individuals and households. Different explanatory variables from the common group of determinants (individual and household characteristics, attitudes and preferences, built environment and trip characteristics)

\footnotetext{
${ }^{3}$ We also examined a fourth level: municipality of the home location. Probably because of the small number of households within each municipality, this level showed no significant effect and was therefore omitted from the study.
} 
and also variables related to ICT use were tested. Only variables that showed a statistically significant effect or variables that are related to household interactions were included in the final model. For this reason, for example ICT use such as telework and accessibility of the home location were excluded. Previous analyses with MPN data showed a significant effect of ICT use on commuting mode choice (Olde Kalter et al., 2014). By contrast, ICT use is not a significant variable in the present study, probably because all trip purposes were included.

\section{Table 2.1 Explanatory variables for different levels}

\begin{tabular}{cc}
\hline Level & Explanatory variables \\
\hline $1-$ Tours & Purpose \\
Distance & Joint activity \\
& Accessibility of destination \\
Same tour in 2013 \\
Same tour in 2014 \\
\hline $2-$ Individuals & PT season ticket holder \\
& Car license holder \\
& Preferences for cycling (for different purposes) \\
Changed working hours \\
Changed work location \\
Changed preference for car use \\
\hline Children $<12$ years in household \\
Car availability \\
Single-income or dual-income households
\end{tabular}

A multilevel model consists of a fixed part and a random part. The fixed part represents the systematic relationship between the dependent variable and explanatory variables at different levels. For example, at level 1 (tour level), car use may be affected by main purpose and distance. At level 2 (individual level), variability in car use can be the result of differences in preference. At level 3 (household level) the focus is on differences between various household structures, for example single-income or dual-income households. The random part allows for variation around this fixed part (Bullen et al., 1997).

Because our dependent variable is discrete, we specified a generalized linear model consisting of a set of linear predictors and a nonlinear link function, with is typically a logit function in the case of a binary response variable. The resulting model is the multilevel equivalent of the traditional logistic regression or logit model. The level-1 model for mode choice of a tour $\mathrm{y}_{\mathrm{ijk}}$ as outcome variable and tour $i$ nested in individual $j$ and household $k$ with one explanatory variable $\mathrm{X}_{\mathrm{ij}}$ is of the general form:

$\eta_{i j k}=\log \left(\frac{\pi_{i j k}}{1-\pi_{i j k}}\right)=\beta_{0 j k}+\beta_{1 j k} X_{i j}$

No residual variance term is included for level 1 because the underlying probability distribution associated with $\mathrm{y}_{\mathrm{ijk}}$ is not normally distributed. For level 2, we specified an individual variable $W_{j k}$ (individual $j$ within household $k$ ): 
$\beta_{0 j k}=\gamma_{00 k}+\gamma_{01 k} W_{j k}+\mu_{0 j k}$

For level 3, we specified a household covariate:

$\gamma_{00 k}=\gamma_{000}+\gamma_{001} Z_{k}+\mu_{00 k}$

We also specified the tour level predictors as fixed at level $2\left(\beta_{1 \mathrm{jk}}=\gamma_{10 \mathrm{k}}\right)$ and individual-level predictors to be fixed at level $3\left(\gamma_{01 \mathrm{k}}=\gamma_{010}\right)$. The $\mu$-terms are (random) residual-error terms at the individual and household level. These residual errors are assumed to have a mean value of zero. Combining this information into a single equation gives:

$\mathrm{\eta}_{i j k}=\gamma_{000}+\gamma_{100} X_{i j}+\gamma_{010} W_{j k}+\gamma_{001} Z_{k}+\mu_{00 k}+\mu_{0 j k}$

If there are no explanatory variables at the tour, individual and household level, Eq. (4) reduces to:

$\eta_{i j k}=\gamma_{000}+\mu_{00 k}+\mu_{o j k}$

This is the so-called intercept-only or unconditional model, where $\gamma_{000}$ represents the intercept at household level, $\mu_{00 \mathrm{k}}$ represents the household level random effect for the intercept, and $\mu_{\mathrm{ojk}}$ represents the random effect for intercepts at individual level. The intercept-only model can be used to produce an estimate of the intra-class correlation $\rho$. This parameter tells us if the probability of choosing the car is generally more alike for household members than for nonhousehold members, which violates the assumption of independence of all observations (Hox, 2010). The intra-class correlation describes the proportion of variance that lies between households and individuals ( $\sigma$ between) relative to the total variance ( $\sigma^{2}$ between $\left.+\sigma^{2}{ }_{\text {within }}\right)$. We can define the intra-class correlation $\rho$ of a logistic distribution, as follows (Hedeker, 2007; Hox, 2002):

$\rho=\frac{\sigma_{\text {between }}^{2}}{\sigma_{\text {between }}^{2}+\frac{\pi^{2}}{3}}$

To investigate the variation in car use at the household and individual level, we estimated different multilevel models. We started with an intercept-only model (M1), to examine the extent of variability of car use across individuals (level 2) and households (level 3). Next, we estimated a full model with fixed and random effects at each level (M2). To gain a better understanding of the interactions between household members within different household types, we estimated two models. We selected all multiple-person households with single and dual incomes (M3) and developed a separate model for dual-income households only (M4). As our main objective was to examine to which extent interactions between household members affect car use, we also added a random 'slope' effect to the models to investigate the variation between households in the influence of joint activity patterns on mode choice.

\subsubsection{Data}

The analyses in this study are based on data from the first and second wave of the MPN. Socio-economic attributes for households and their members were collected for each household through individual questionnaires. Participants with a completed questionnaire were invited to keep a three-day online trip diary for three successive days (including weekend days). The MPN was set up to study short-run and long-run dynamics in the travel behaviour of Dutch individuals and households, and to determine how changes in personal 
and household characteristics and in other travel-related factors (for example economic crisis, reduced taxes on sustainable transport or changes in land use) correlate with (changes in) travel behaviour. The publication by Hoogendoorn-Lanser et al. (2015) contains a description of the overall set-up and design of the MPN and of the philosophy behind the innovative design approach of the MPN's web-based diary.

In the present study, home-based tours are the unit of analysis. All trips with home as starting and end point form one tour. Every trip, called a trip segment, is considered one part of a tour. If one or more trip segments are made jointly, with one or more other persons, we speak of a joint tour. A joint tour can be made 'fully joint' (two or more persons travelling together, leaving home and returning together) or 'partly joint' (two or more persons travelling together, but leaving home or returning separately). A distinction is made between tours with household members and tours with non-household members. Each tour is assigned a main purpose based on a hierarchy, in which work has the highest priority, followed by education, shopping and personal services, and social and leisure, after Stopher et al. (1996). Similarly, tours involving more than one travel mode are assigned a main mode, which is the mode with the highest share of travel time.

Only 'frequent' daily trips were selected, which means that holiday trips, trips abroad and occupational trips were excluded. Also, we only included individuals aged over 17 (the age at which it is legal to drive a car in the Netherlands) in the analysis. From other analyses (see for example, Ho and Mulley, 2013), we know that travel mode choice and joint activities are very different at weekends. Other research also shows that these differences cannot easily be captured in one model by using weekday dummies (see Chlond and Lipps, 2000; Kloas and Kunert, 1994). Therefore, we restricted our analysis to working days (Monday to Friday) and to persons who reported at least one tour on one of these days. As we were interested in intrahousehold interactions, we selected only 'complete' multiple-person households. 'Complete' means that each household member completed the travel diary. This gave us the ability to distinguish between tours accompanied by household members and tours accompanied by non-household members. Finally, we selected all individuals who participated in the first and second wave. In total, we used data from 514 households and 960 individuals. The final dataset consists of 3,266 home-based tours in 2014 and 3,343 home-based tours in 2013. The 2104 dataset served as baseline in the analysis.

Repeated tours may indicate a preference for specific travel modes (Yang and Timmermans, 2015). To examine the impact of repeating tours, two variables were constructed, namely a variable that measures if the same home-based tour occurred in the previous year and a variable that measures if the same home-based tour occurred on another day in the same year. Furthermore, we constructed several 'change' variables to examine the effect of changes between 2013 and 2014 in individual, household and spatial characteristics. Several life events were also included in the analysis.

\subsubsection{Sample description}

Table 2.2 shows car use, according to the selected sample, by various tour and individual characteristics. Of all home-based tours considered, 48 percent were made by car in 2014 . The average distance of a home-based tour by car is 33.9 kilometres. The average distance travelled by public transport is 81.4 kilometres, and 4.7 kilometres for cycling or walking. The average distance of all other modes together is 11.2 kilometres. Work and business tours have by far the highest share of car use ( 60 percent), while fewer than half of all tours for other purposes were made by car. This suggests that particularly in dual-income households 
with one car, where both workers would like to use the car for commuting, agreements on car use are necessary. To examine the impact of spatial characteristics, we used a variable commonly used in urban planning in the Netherlands, representing the accessibility typology of trip destinations (Hilbers et al., 2005). Typology depends on the location relative to public transport facilities and access to a highway (see Table 2.3). A-locations are easily accessible by public transport, regardless of their distance to a highway, and consequently have the lowest share of car use ( 35 percent). C-locations, not easily accessible by public transport but close to a highway, have the highest share of car use. Furthermore, Table 2.2 indicates no great differences between 2013 and 2014 in tour and individual characteristics, probably because of the relatively short time period. These changes are therefore not used in explaining variation in car use.

Table 2.2 Car use by tour and individual characteristics

\begin{tabular}{ccccc}
\hline Level & Variable & Values & $\mathbf{2 0 1 3}$ & $\mathbf{2 0 1 4}$ \\
\hline $\begin{array}{c}\text { Home-based tour } \\
(\mathrm{n}=3,266)\end{array}$ & Distance tour $(\mathrm{km})$ & Mean distance car & 34.9 & 33.9 \\
& & Mean other modes & 11.4 & 11.2 \\
& Purpose tour (\%) & Work, business & 64 & 60 \\
& & Education & 43 & 49 \\
& & Shopping and personal services & 50 & 47 \\
& Accessibility of & Social and leisure & 41 & 40 \\
& destination (\%) & A-location & 43 & 35 \\
& & B-location & 52 & 53 \\
& & C-location & 55 & 54 \\
& & D-location & 48 & 43 \\
& & R-location & 50 & 49 \\
\hline Individual (n=960) & PT season & No & 62 & 56 \\
& ticket holder & Yes & 31 & 32 \\
& Car licence & No & 13 & 10 \\
& holder & Yes & 58 & 54 \\
\hline
\end{tabular}

Table 2.3 Typology of accessibility

\begin{tabular}{ccc}
\hline & $\begin{array}{c}\text { Distance to } \\
\text { highway }<\mathbf{2} \mathbf{~ k m}\end{array}$ & $\begin{array}{c}\text { Distance to } \\
\text { highway }>\mathbf{2} \mathbf{~ k m}\end{array}$ \\
\hline Distance to main railway station $<3 \mathrm{~km}$ & $\mathrm{~A}$ & $\mathrm{~A}$ \\
Distance to secondary railway station $<2 \mathrm{~km}$ or metro $<1 \mathrm{~km}$ & $\mathrm{~B}$ & $\mathrm{D}$ \\
Other & $\mathrm{C}$ & $\mathrm{R}$ \\
\hline
\end{tabular}

Table 2.4 shows household characteristics of the sample. Of all households considered, 51 percent always have a car available. This means that the number of cars in the household is the same as or greater than the number of persons with a driving license in the household. The majority have no children younger than 12 years old. Single- and dual-income households have a higher share of car use than no-income households (i.e. none of the household members have income from paid employment or self-employment). Also, at the household level, we see hardly any differences between 2013 and 2014. 
Table 2.4 Household characteristics

\begin{tabular}{ccccc}
\hline Level & Variable & Values & $\mathbf{2 0 1 3}$ & $\mathbf{2 0 1 4}$ \\
\hline Household & Car availability (\%) & Not always car available & 47 & 49 \\
$(\mathrm{n}=514)$ & & Always car available & 53 & 51 \\
& Children $<12$ years (\%) & No & 70 & 71 \\
& & Yes & 30 & 29 \\
& Income type (\%) & No-income household & 25 & 25 \\
& & Single-income household & 27 & 30 \\
& & Dual-income household & 49 & 45 \\
\hline
\end{tabular}

\section{Joint-activity patterns}

As our focus is the effect of household interactions on car use, we take a closer look at jointactivity patterns. Table 2.5 compares individual and joint tours for different travel purposes. Most work and business tours are individual tours (76 percent), whereas shopping and personal service, and social and leisure tours are more likely to be joint tours. The latter two are also more frequently undertaken with a household member (more than 30 percent), while educational tours are more likely to be accompanied by non-household members ( 27 percent).

Table 2.5 Distribution of joint tours (\%) by purpose in 2014

\begin{tabular}{ccccc}
\hline tour type & work, business & education & $\begin{array}{c}\text { shopping and } \\
\text { personal services }\end{array}$ & $\begin{array}{c}\text { social and } \\
\text { leisure }\end{array}$ \\
\hline individual & 76 & 57 & 51 & 43 \\
fully joint with hh & 1 & 13 & 23 & 17 \\
fully joint without hh & 4 & 19 & 11 & 11 \\
partly joint with hh & 9 & 3 & 9 & 16 \\
partly joint without hh & 10 & 8 & 5 & 13 \\
\hline
\end{tabular}

Figure 2.1 shows the share of joint tours by car. Most joint tours are made by car, with the highest share for fully joint tours with a household member (64 percent). Individual tours are more frequently undertaken by other means of transport. This suggests that travelling together and joint activities increase car use. Fully joint tours have a larger share of car use compared with partly joint tours, although the difference between fully joint tours with non-household members and partly joint tours with household members is small.

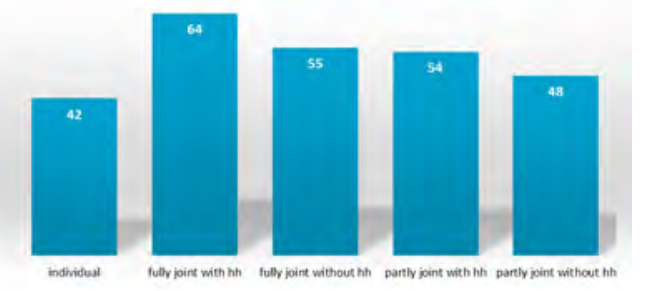

Figure 2.1 Share of joint tours (\%) by car in 2014 


\section{Changes in individual, household and spatial characteristics and life events}

The analysis presented in this chapter concerns the 2013 and 2014 waves of the MPN. As this is a relatively short period of time, there are no major changes in individual and household characteristics at the aggregate level, as expected. For example, only 6 percent of the households increased in size and about 4 percent had a lower income in 2014. The accessibility type of the residential locations obviously did not change much for the sample either, although the perceived accessibility of the living environment by car, public transport and bicycle on individual level was more positive in 2014. The greatest changes occurred in the stated mode preferences. Individual respondents were asked to state their preferred mode(s) of transport for specific trip motives (i.e. commuting, business, school, shopping or leisure trips). Significant shifts in stated preference are found for the car and bicycle modes. For example, 7 percent of the respondents preferred the car for commuting trips in 2014 and did not in 2013. Also, 10 percent preferred cycling to and from work in 2014 but did not in 2013. We see similar changes for other trip purposes. To examine the influence of changing household interactions, we also took the impact of different life events that are measured in the MPN into account (Figure 2.2). A change in working hours, a new job and the birth of a child are the most frequent life events in the selected sample for the period 2012-2014. Some life events are very rare, such as 'household member passed away' and 'divorced / broke up'.

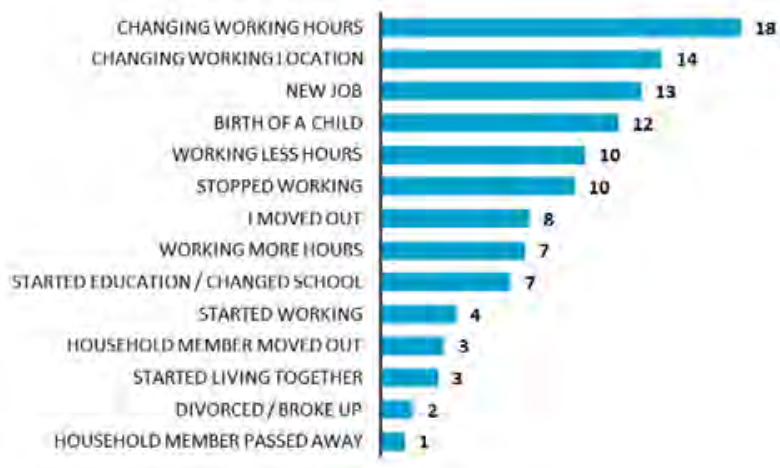

Figure 2.2 Frequency of life events (\%) in the selected sample in the years 2012-2014

\subsection{Results}

Table 2.5 lists the estimation results. The random variables in the intercept-only model (M1) show that the intercept varies significantly across individuals as well as across households. The significant degree of variation among individuals and among households justifies the application of multilevel modelling (in this case, a three-level model). The intra-class correlation $\rho$ for M1 shows that 23.4 percent of the variability of mode choice for home-based tours is between-household variation and 14.5 percent is between-person variation.

Next, we estimated a full model with both fixed and random effects (M2). By adding explanatory variables at each level (fixed effects) ${ }^{4}$, the variations between households and individuals on average (random 'intercept' effects) and among households in the impact of joint activity patterns on mode choice (random 'slope' effect) reveal some interesting results concerning household interactions. First, we see that joint tours were more frequently

\footnotetext{
${ }^{4}$ All categorical variables were included as dummy variables. Table 2.5 shows the reference category.
} 
undertaken by car compared with individual tours. For partly joint tours with non-household members, car use is increased by about 57 percent and for fully joint tours with household members, the odds ratio of using the car is even about 4.2 times higher. For similar tours conducted in the previous year, car use was less likely. This probably means that cyclists show stronger habitual behaviour than car drivers and may suggest less involvement of household members. Two life events have a statistically significant impact on car use; both a change in working hours in 2012 and a change of work location in 2014 decreased car use. These results indicate a delayed effect of changing working hours on mode choice, whereas a change of work location immediately affects mode choice. Furthermore, individuals who stated a change in commuting mode preference towards the car for home-to-work trips were more likely to travel by car. No significant association was found between the birth of a child and car use, although a relatively large share in the selected sample became parent and transition to parenthood is often associated with an increase in car use. A possible explanation for why we did not find a significant difference is that it was not possible to make a distinction between first-time parents and others. It is obvious that the birth of a first child is more likely to lead to the purchase of a car and an increase in car use.

Variability among individuals accounts for 11.8 percent and variability among households accounts for 23.4 percent of the total variation in mode choice of home-based tours. Compared with the intercept-only model, random variation at individual level is slightly lower. This means that the explanatory variables capture part of the behavioural differences in mode choice. However, including the explanatory variables only increases the correct prediction by 4 percent. The random effects at household level show that the variation in mode choice among households occurs because on average (i.e. random intercept) and because the impact of joint activities on mode choice differs between households (i.e. random slope). The latter accounts for 13.0 percent of the total variation in mode choice. This finding indicates that interactions between household members, resulting in joint (or not) activity patterns, have significantly different outcomes for car use.

Because work and business tours have a higher share of car use, we expected that particularly dual-income households with one car need agreements on car use. Therefore, we estimated separate models for single-income and dual-income households. Most interestingly, the household random effect shows no significant effect for the intercept when only singleincome and dual-income households are selected (M3). This indicates that for multiple-person households with single or dual incomes, the variability between individuals is much greater than the variability between households, and hence interactions between household members have a larger effect on mode choice. The variation between households in the effect of joint activity patterns on mode choice is still significant and accounts for 13.6 percent of the total variation. Shopping and personal services and preference for shopping trips have an insignificant coefficient in model M3, probably because single-income and dual-income households have less time for these activities compared with households without paid jobs (e.g., retired, unemployed). Partly joint tours with non-household members also have an insignificant coefficient in model M3. This confirms the finding that in single-income and dual-income households, interactions with household members have a larger effect on mode choice. The fixed effects for other types of joint tours are still significant, although the magnitude is smaller than in model M2.

The next model shows the fixed and random effects for dual-income households only (M4). In this model, the household level accounts for 17.2 percent and the individual level for 16.2 percent of the total variation in car use. Compared with model M3, dual-income households 
show more variation in mode choice between households than between individuals. This larger variation between households is fully explained and is greater than in model M3 as a result of the random 'slope' effect of joint activity patterns. This indicates that in dual-income households, interactions between household members have a greater impact on car use. In addition, dual-income households show larger fixed effects for the accessibility of the destination. This means that accessibility determines the odds ratio of using the car for a home-based tour to a greater extent and suggests more household interactions. On the other hand, the magnitude of the fixed effects for joint tours is smaller in model M4 and only significant for fully joint tours with household members. This indicates less coordination between household members and is not according to a priori expectation, as we hypothesized that joint tours with household members would suggest stronger intra-household interactions. Repeating tours, life events and changing preferences show the same effect compared with model M3.

Table 2.5 Binary choice modelling results

\begin{tabular}{|c|c|c|c|c|c|c|c|c|c|}
\hline & & \multicolumn{8}{|c|}{ Multiple-person households } \\
\hline & & \multicolumn{2}{|c|}{ All hh } & \multicolumn{2}{|c|}{ All hh } & \multicolumn{2}{|c|}{$\begin{array}{l}\text { Single and dual } \\
\text { income } h h\end{array}$} & \multicolumn{2}{|c|}{ Dual income hh } \\
\hline & & M1 & & M2 & & M3 & & M4 & \\
\hline Parameters & & $\operatorname{Exp}(B)$ & Sign. & $\operatorname{Exp}(B)$ & Sign. & $\operatorname{Exp}(B)$ & Sign. & $\operatorname{Exp}(B)$ & Sign. \\
\hline \multicolumn{10}{|l|}{ Fixed part } \\
\hline Intercept & & 1.016 & 0.822 & 0.123 & 0.000 & 0.107 & 0.000 & 0.130 & 0,010 \\
\hline Purpose tour & Social and leisure & & & 0.442 & 0.000 & 0.412 & 0.000 & 0.341 & 0.000 \\
\hline \multirow[t]{2}{*}{ (work=reference) } & Shopping, personal & & & 0.656 & 0.030 & 0.783 & 0.251 & 0.799 & 0.396 \\
\hline & Education & & & 0.339 & 0.003 & 0.385 & 0.019 & 0.404 & 0.068 \\
\hline Distance tour & & & & 1.019 & 0.000 & 1.016 & 0.002 & 1.017 & 0.002 \\
\hline Joint activity & Partly joint without hh & & & 1.571 & 0.030 & 1.388 & 0.149 & 1.227 & 0.459 \\
\hline \multirow[t]{3}{*}{ (individual=reference) } & Partly joint with hh & & & 2.149 & 0.000 & 2.017 & 0.001 & 1.491 & 0.136 \\
\hline & Fully joint without hh & & & 2.742 & 0.000 & 2.177 & 0.001 & 1.585 & 0.131 \\
\hline & Fully joint with hh & & & 4.179 & 0.000 & 4.002 & 0.000 & 4.218 & 0,000 \\
\hline Accessibility destination & R-location & & & 2.094 & 0.019 & 1.966 & 0.049 & 3.067 & 0.013 \\
\hline \multirow[t]{3}{*}{ (A-location=reference) } & D-location & & & 1.648 & 0.103 & 1.527 & 0.203 & 2.372 & 0.047 \\
\hline & C-location & & & 2.537 & 0.004 & 2.986 & 0.002 & 3.851 & 0.002 \\
\hline & B-location & & & 2.283 & 0.006 & 2.191 & 0.019 & 3.368 & 0.004 \\
\hline PT season ticket & Yes vs. no & & & 0.464 & 0.000 & 0.344 & 0.000 & 0.307 & 0.000 \\
\hline Car licence holder & Yes vs. no & & & 7.050 & 0.000 & 9.867 & 0.000 & 7.181 & 0.000 \\
\hline Preference for cycling & Work trips & & & 0.561 & 0.000 & 0.479 & 0.000 & 0.452 & 0.000 \\
\hline \multirow[t]{3}{*}{$($ no=reference $)$} & Business trips & & & 0.549 & 0.080 & 0.519 & 0.051 & 0.584 & 0.148 \\
\hline & Daily grocery trips & & & 0.571 & 0.000 & 0.582 & 0.000 & 0.674 & 0.032 \\
\hline & Shopping trips & & & 0.741 & 0.034 & 0.768 & 0.104 & 0.732 & 0.106 \\
\hline Always car available & Yes vs. no & & & 2.935 & 0.000 & 2.509 & 0.000 & 2.375 & 0.000 \\
\hline Children $<12 \mathrm{yr}$ in $\mathrm{hh}$ & Yes vs. no & & & 0.750 & 0.071 & 0.740 & 0.064 & 0.824 & 0.350 \\
\hline Income household & Single income & & & 0.953 & 0.825 & & & & \\
\hline (no income=reference) & Dual income & & & 0.996 & 0.986 & 1.003 & 0.984 & & \\
\hline Same tour in 2013 & Yes vs. no & & & 0.638 & 0.001 & 0.682 & 0.009 & 0.619 & 0.008 \\
\hline Same tour in 2014 & Yes vs. no & & & 0.814 & 0.093 & 0.824 & 0.157 & 0.805 & 0.203 \\
\hline Changing working hours & In 2014 & & & 1.070 & 0.755 & 1.134 & 0.581 & 0.786 & 0.366 \\
\hline \multirow[t]{2}{*}{ (no=reference) } & In 2013 & & & 0.842 & 0.444 & 0.862 & 0.520 & 0.704 & 0.149 \\
\hline & In 2012 & & & 0.379 & 0.012 & 0.383 & 0.017 & 0.304 & 0.005 \\
\hline Changing work location & In 2014 & & & 0.559 & 0.017 & 0.581 & 0.031 & 0.585 & 0.053 \\
\hline \multirow[t]{2}{*}{$($ no $=$ reference $)$} & In 2013 & & & 1.258 & 0.394 & 1.253 & 0.401 & 1.589 & 0.118 \\
\hline & In 2012 & & & 0.766 & 0.623 & 0.755 & 0.603 & 0.994 & 0.992 \\
\hline $\begin{array}{l}\text { Changing preference car } \\
\text { (no=reference) }\end{array}$ & For work trips & & & 2.000 & 0.019 & 2.175 & 0.009 & 1.767 & 0.103 \\
\hline \multicolumn{10}{|l|}{ Random part } \\
\hline Level 1 - between tours & & 1.000 & & 1.000 & & 1.000 & & 1.000 & \\
\hline Level 2 - between indiv. & & 0.765 & 0.000 & 0.598 & 0.001 & 0.937 & 0.000 & 0.798 & 0.004 \\
\hline Level 3 - between hh & & 1.239 & 0.000 & 0.524 & 0.008 & 0.159 & 0.453 & 0.029 & 0.903 \\
\hline Level 3 - joint activity & & & & 0.662 & 0.000 & 0.667 & 0.001 & 0.849 & 0.002 \\
\hline $\mathrm{N}$ (tours) & & 3266 & & 3266 & & 2.496 & & 1.575 & \\
\hline$\rho$ (level 2) & & $14.5 \%$ & & $11.8 \%$ & & $19.1 \%$ & & $16.2 \%$ & \\
\hline$\rho$ (level 3) & & $23.4 \%$ & & $23.4 \%$ & & $13.6 \%$ & & $17.2 \%$ & \\
\hline Correctly predicted & & $83.2 \%$ & & $87.8 \%$ & & $87.5 \%$ & & $87.3 \%$ & \\
\hline
\end{tabular}




\subsection{Conclusions and further research}

The main objective of this study was to explore the influence of household interactions on car use for home-based tours, using data from the first two waves of the MPN. We estimated multilevel binary logit models to investigate to what extent relations between household members affect car use. We created a set of explanatory variables for three different levels, namely the household, individual and tour level. These variables were used to explain variation in car use between and within these levels (i.e. random effects and fixed effects). We added repeating tours in the same and previous year and life events to the model to analyse the impact of changes in household and individual characteristics over time on car use.

The results show that variation in mode choice can be explained by variability between household and individuals and justifies a multilevel modelling approach. Variability between households and individuals accounts for about one third of the total variation in mode choice of home-based tours. The first important conclusion is, therefore, that multilevel analysis is able to add knowledge about intra- and inter-household variation in car use. Joint tours are more frequently undertaken by car than individual tours and the impact of joint activities on mode choice differs between households. This finding indicates that interactions between household members, resulting in joint (or not) activity patterns, have significant different outcomes in terms of car use. For dual-income households only, the variability between individuals is greater than the variability between households. This indicates that intrahousehold interactions have a greater effect on car use in dual-income households, probably because there are more aspects to consider that impact car use (for example, having two work locations instead of one, with different accessibility types). Different explanatory variables show a significant impact of household interactions on car use. Firstly, fully joint tours form the strongest predictor in a given situation: if somebody travels together with a household member, he or she is much more likely to use the car. The purpose of a trip is another significant predictor. Work and business tours have a higher likelihood of car use. This is confirmed at the individual level, where fulltime workers are more likely to use the car. This implies that in the case of two or more employees in a one-car-household, decisions have to be made about who gets to use the car. Furthermore, the results indicate a delayed effect of changing working hours on mode choice, whereas a change of work location immediately affects mode choice.

The results provide us with a better understanding of intra- and inter-household interactions and their impact on car use. Policymakers should take into consideration that in multi-person and specifically in dual-income households, car use is more strongly affected by relationships between household members. For example, encouraging specific types of commute mode change is not just about commuting distance at the individual level. Decisions on car use also depend on agreements about who will take the children to school before going to work, who will do the groceries after work or commuting distance of the spouse.

There are several directions for future research. A first direction is to widen the scope of the analysis. For example, the models can be expanded with interaction effects, mode choice alternatives, and other random 'slope' effects or can be evaluated for different distance classes. It would be also very informative to explore if results and conclusions differ for weekend activities Another worthwhile extension of the analysis could be to include explanatory variables representing features of one or more household members, such as commuting distance of the spouse or parallel activities. As stated before, it would also be interesting to focus on home-based work tours, to determine if other variables such as ICT use are significant. Finally, analysing more dimensions than only mode choice, for example tour 
distance, travel time and activity duration, would be a challenging and interesting task for future research. A second direction for future research is to examine the dynamics in household interactions over a longer time period and the influence of these changes on mode choice behaviour. It is intriguing that we found already significant temporal effects when analysing only two waves; once data for subsequent years become available, more sophisticated panel analyses can be conducted. Within the multilevel approach, this means that repeated measures nested within individuals can be added to the model specification. Van Acker and Witlox (2010) raised the question whether car availability is just a predictor of car use or a result of a decision-making process itself. Exploring this kind of causal relations in both research directions using panel data is a third interesting research topic for the future. 


\title{
3. Impact of changing attitudes on mode choice
}

This chapter is based on: Olde Kalter, M.J.T., La Paix Puello, L. \& Geurs, K.T. (2020). Do changes in travellers' attitudes towards car use and ownership over time affect travel mode choice? A latent transition approach in the Netherlands. Transportation Research Part A: Policy and Practice, 132, 1-17.

\begin{abstract}
This study examines how changes in travellers' attitudes towards car use and ownership change over time and how these changes influence car use, based on the 2014 and 2016 waves of the Netherlands Mobility Panel $(\mathrm{N}=1,640)$. A latent transition model was estimated to investigate transitions between different segments based on travellers' attitudes towards car use and ownership, and the latent transition probabilities were used to predict changes in mode use. Four latent classes were found to reflect the participants' attitudes: cost-sensitive, car-minded, environmentally aware and social-conscious travellers. Most of the participants remained in the same class between 2014 and 2016, which suggests that attitudes towards car use and ownership are stable over time. Also, the results indicate that car use and car ownership may be less widespread among younger adults. Only when younger adults face life events, such as moving, starting a job or become parents, transitioning to more car-oriented profiles appears more likely. Changes in attitudes towards car use and car ownership do not significantly affect car use (number of trips per day), except for the social-conscious travellers who switched to the car-minded class. This suggests that, in most cases, a more positive or negative attitude towards car use and ownership does not directly affect the frequency of car use.
\end{abstract}




\subsection{Introduction}

In the Netherlands, like in other industrialised countries, car use is dominant. In 2016, almost half of all trips were by car $(47 \%)$, and at $73 \%$, the share of distance travelled by car was even higher (CBS, 2016). Between 1995 and 2005, the number of car trips increased by 5\% and the number of car kilometres by $12 \%$. Since 2005 , car use has approximately remained the same. Considerable differences in the development of car use exist by age group (Jorritsma, 2017). For older adults (i.e., 65 years or older), both the number of trips and the distance travelled by car strongly increased, while people aged 40 and younger did not drive as much as before. This decrease in car use among young adults and the increase in car use among older adults do not merely reflect a change in population size, but also changes in behaviour and the household situation.

Explanations for a change in car use are related to various factors, such as social characteristics or residential location (Jorritsma, 2017). For example, nowadays, young people in the Netherlands tend to live in urban areas and remain enrolled at university longer. As a result, young people more frequently use public transport and the bicycle, rather than the car. Differences in the development of car use by age are not unique to the Netherlands. For example, Kuhnimhof et al. (2012) found a reduction in car use among young travellers in six industrialised countries (i.e., Germany, France, Great Britain, Japan, Norway and the USA). Also, a recent study of the travel patterns of older adults in England, Germany, USA and Japan showed a significant increase in car use (Zmud et al., 2017). To understand these increases and decreases in car use, and changes in other modes of transport, more insight is required into the processes and determinants affecting mode choice behaviour.

According to existing research findings, travel mode choice is determined and influenced by attitudes people have towards the car, public transport and inactive modes (e.g., Anable, 2005; Donald et al., 2014; Molin et al., 2016; Paulssen et al., 2014; Steg et al., 2001). The Theory of Planned Behaviour (Ajzen, 1991) and Swartz's Norm Activation Model (Schwartz, 1977) are two of the most widely used models to study the effects of attitudes on behaviour, and have been applied in different studies to improve our understanding of travel behaviour (Bamberg et al., 2015; Donald et al., 2014; Kaewkluengklom et al., 2017). These models provide insight into the relationship between attitudes, social norms, intention and behaviour. Although it is recognized that behaviour may influence attitudes (Ajzen, 2015), in most research, it is assumed that attitudes affect behaviour. This follows from the basic principle that people's behaviour can be derived from their intentions, and attitudes determine intentions (Ajzen, 1991). However, the impact of temporal dynamics in attitudes on transport mode choice has been much less studied, in particular the extent to which changes in attitudes are caused by changes in time-dependent variables such as life events (e.g. childbirth, new job, moving home).

The main aim of this study is to examine the effects of changes in attitudes towards car use and ownership over time on mode use. We identify different profiles or population segments based on attitudes towards specific modes and investigate how these profiles tend to change over time as well as how these changes relate to car use. This study addresses the following research questions:

- Which travellers' profiles can be defined based on their attitudes towards car use and ownership?

- Do these travellers' profiles change over time, and if so, are these changes related to life events?

- Are changes in attitudes towards car use and ownership related to changes in mode use? 
To answer these research questions, we used panel data from the Netherlands Mobility Panel (in Dutch: Mobiliteitspanel Nederland, MPN), the largest ongoing mobility panel in the world. This panel is specifically designed to examine annual changes in travel behaviour and contains individual and household characteristics, questions on mode attitudes and preferences as well as life events, and the actual travel behaviour recorded in a three-day trip diary. To allow a detailed analysis of the dynamics in attitudes towards car use and ownership, and the relationship with individual mobility, an additional dedicated survey was designed and conducted for this study in the 2014 and 2016 waves of the MPN.

This research is novel for three reasons. First, to our knowledge, this is the first study analysing changes in attitudes towards car use and ownership over time for a large panel of individuals, as well as the effects of these changes on car use. Although segmentation of travellers based on attitudes has been the subject of many studies, most of those studies were based on cross-sectional data of only one year. The dynamics of attitude change have hardly been investigated due to the lack of longitudinal data. The 2014 and 2016 waves of the MPN provided us with data about attitudes and travel behaviour of the same people at different time points, enabling us to study the dynamics in attitude-based segments over time. Second, because also data was collected about several life events, the MPN allowed testing the impact of life events on changes between attitude-based segments. Although the effects of life events on changes in travel behaviour have been the subject of many studies, still little is known about the relationship between life events and changes in attitudes. Third, the MPN comprises a three-day trip diary which enabled us to link changes in attitudes with actual travel behaviour, and therefore to examine to what extent these changes affected mode use.

We organised the remainder of this chapter as follows. Section 3.2 reviews the existing research on attitudes and travel mode choice. Next, Section 3.3 describes the data and measures we used for the analysis and some descriptive statistics for the selected sample. Section 3.4 defines model specification and model selection, followed by the results in Section 3.5. Section 3.6 discusses the results and ends with directions for further research. Finally, Sections 3.7 wraps up this chapter with the main conclusions.

\subsection{Attitudes and travel mode choice}

Various factors influence travel mode choice, such as sociodemographic characteristics at the individual and household level, characteristics of the built environment, and trip characteristics. Gaining knowledge about factors that determine mode choice is a major topic in transportation research (Feng et al., 2014; Paulssen et al., 2014; Vij et al., 2013). In recent years, the effects of the attitudes of the individual traveller on his or her travel mode choice have received increasing attention. Most of these studies refer to the Theory of Planned Behaviour (Ajzen, 1991) to show that individual travel behaviour is a result of attitude, subjective norm, perceived behaviour control and intention (Abrahamse et al., 2009; Donald et al., 2014). To facilitate shifts from car use towards more sustainable means of transportation, a better understanding of travellers' motivations is needed. Steg and Kalfs (2000) argued that individual mode choices are primarily determined by personal values, feelings, preferences and social norms, much more than, for example, by the availability of alternatives. However, little is known about the cause of changes in travel behaviour from the dynamics of attitudes. For example, concerning car use, there are widespread indications of a declining popularity of the car among young adults (Davis and Dutzik, 2012; Delbosc and Currie, 2013; Dutzik and Baxandall, 2013). However, these indications mostly rely on 
declining trends in car use based on cross-sectional surveys. There is no empirical evidence that changes in attitudes towards car use and ownership causes this decrease in car use.

To examine the differences between individual travellers, the concept of market segmentation is widely used to divide the population into meaningful subgroups of individuals. Traditionally, sociodemographic characteristics, such as gender, age and car ownership, were used as a basis for segmentation (e.g., de Jong et al., 2004). Recently, to capture behavioural components, segments have been based on frequency of mode use (Kroesen, 2014; Molin et al., 2016; Prillwitz and Barr, 2011), characterised as 'strictly car users' or 'multimodal users', for example. However, segmentation based on either sociodemographic characteristics or mode use does not explain attitudes towards transport modes and, therefore, does not provide insight into potential changes (Semanjski and Gautama, 2016). Segmentation based on attitudes helps gain more insight into mode choice behaviour (Anable, 2005). However, those attitudes might also change over time, so mode choice decisions might change as well, and vice versa. Analysing attitudes based on longitudinal data is therefore crucial.

Most research findings on the relationship between attitudes and mobility choices have certain limitations. First, the results are usually based on a stated preference survey, which means that respondents are presented with a limited number of choices and settings. The theoretical choices respondents make, based on the provided information, can be entirely different from the decisions they make in daily life. Monitoring of attitudes and travel behaviour is needed to examine the relationship between changes in attitudes and travel behaviour. Second, most research on mode attitudes is based on cross-sectional survey data, which does not provide insights into changes at the individual level. For example, Molin et al. (2016) found that travel mode use and attitudes are strongly correlated for four of the five identified travel groups. However, because this analysis was based on a dataset from one year, it is not clear if and to what extent a change in attitude affects travel mode use. Just a few studies have examined the relationship between attitudes and mode choice behaviour over time. For example, Thøgersen (2006) showed that past behaviour is the main predictor of current behaviour, and when accounting for past behaviour, the influence of attitudes on public transport use decreases. Recently, Kroesen et al. (2017) investigated the bi-directional relationship between attitude and behaviour over time and found that attitudes and mode use influence each other in both directions. However, we still know little about changes in attitudes and the effect of these changes on travel behaviour. 


\subsection{Data}

\subsubsection{Survey and sample selection}

The analyses in this study are based on data from the 2014 and 2016 waves of the Netherlands Mobility Panel (MPN). The MPN was set up to study short-run and long-run dynamics in travel behaviour of Dutch individuals and households, and to study how changes in personal and household characteristics and other travel-related factors correlate with (changes in) travel behaviour (Hoogendoorn-Lanser et al., 2015). Socio-economic attributes for households and their members were collected for each household through individual questionnaires. Participants who completed questionnaires were invited to keep a three-day online trip diary for three successive days. In 2014 and 2016, additional questions were added about attitudes towards car use and ownership.

A total of 3,622 individuals aged 18 years and older completed the additional survey in the fall of 2014 and 2016. From this sample, missing values were deleted list-wise and respondents without completed household questionnaire were removed. The final sample contained 2,484 individuals, of who 1,640 completed the three-day trip diary. To examine changes in attitudes towards car use and ownership with actual mode use, as highlighted in previous sections, we used the sample with individuals who completed both the questionnaire and the trip diary.

Panel data may contain possible attrition biases. Regarding our main variables of interest, we found insignificant differences in respondents' attitudes between participants who completed the additional survey and the trip diary in 2014 and 2016, and those who dropped out. For mode use, we detected no significant differences for bicycle and bus, tram and metro (BTM) use. However, those who dropped out used the car more often and the train less frequently relative to those who participated in both waves. Although the differences are small, this indicates a small attrition bias. More information on the impact of non-random attrition (between and within waves) in the MPN data on travel behaviour can be found in La Paix Puello et al. (2017).

\subsubsection{Measures}

To analyse travellers' attitudes towards car use and ownership and the relationship with travel behaviour, we developed a construct to measure car attitudes and derived mode use from the MPN trip diary.

Car attitudes. To examine the travellers' car attitudes towards car use and car ownership, sixteen statements were formulated in an additional dedicated survey, conducted at the same time as the individual questionnaires were collected in 2014 and 2016. We used five-point Likert scales ranging from (1) completely disagree to (5) completely agree as response scales for all statements. We conducted a common factor analysis (principal components analysis with oblimin rotation ${ }^{5}$ ) to explore if there were unobserved (latent) variables that describe the variation in sixteen statements. In 2014 we identified five underlying factors (based on eigenvalues $>1$ ) reflecting travellers' attitudes towards car use and ownership: car-minded (F1), cost-sensitive (F2), status-sensitive (F3), environmental awareness (F4) and social consciousness (F5). These factors explain $47 \%$ of the total variance in the statements. Table

\footnotetext{
5 This rotation technique can be used when some correlation among the factors is assumed or expected. For example, we observed that the factors 'environmental awareness 'and 'social consciousness' can be correlated.
} 
3.1 presents a list of all statements and the corresponding factor loadings in 2014. To determine the internal consistency reliability, we calculated Cronbach's alpha and found all factors within an acceptable range, i.e. between 0.65 and 0.80 (Nunnally, 1978).

Furthermore, in longitudinal research, measurement invariance is an important issue, and testing for measurement invariance across the two waves is a necessary stage (Chung et al., 2011). Regarding factor analysis, this means that there should be no differences in the number of underlying factors and the sizes of the factor loadings between both waves (Lanza et al., 2010). We calculated Tucker's coefficient of congruence to examine the two-factor structures for 2014 and 2016 (Lorenzo-Seva and ten Berge, 2006). As can be seen in Table 3.1, all coefficients are higher than 0.95 , and, therefore we concluded that the factor loadings were invariant and the factor model applied across both waves (Lorenzo-Seva and ten Berge, 2006). We saved each respondents' latent factor scores on each of the five factors reflecting their attitudes towards car use and ownership in the database.

Table 3.1 Factor loadings from factor analysis in 2014 and reliability scores $(\mathrm{N}=\mathbf{1 , 6 4 0})$

\begin{tabular}{|c|c|c|c|c|c|c|}
\hline \multirow{2}{*}{$\begin{array}{l}\text { Factors } \\
\text { Car-minded }\end{array}$} & Statements & \multicolumn{5}{|c|}{ Factor loadings } \\
\hline & Owning a car allows me to do whatever I want & \multicolumn{5}{|c|}{0.684} \\
\hline & $\begin{array}{l}\text { Travelling by car offers a lot of advantages } \\
\text { compared with other modes }\end{array}$ & \multicolumn{5}{|l|}{0.630} \\
\hline & I can't live without a car & \multicolumn{5}{|l|}{0.599} \\
\hline & Nearly every time I travel, I use the car & \multicolumn{5}{|l|}{0.529} \\
\hline & Driving a car is fun & \multicolumn{5}{|l|}{0.436} \\
\hline \multirow[t]{3}{*}{ Cost-sensitive } & $\begin{array}{l}\text { Because of the costs, I'm using the car less } \\
\text { frequently }\end{array}$ & & 0.831 & & & \\
\hline & $\begin{array}{l}\text { My financial situation is a reason to postpone } \\
\text { buying a (new) car }\end{array}$ & & 0.722 & & & \\
\hline & Owning a car is difficult because of the expenses & & 0.541 & & & \\
\hline \multirow[t]{2}{*}{ Status-sensitive } & A car represents someone's taste & \multicolumn{5}{|c|}{0.769} \\
\hline & A car represents someone's position in society & & & 0.682 & & \\
\hline \multirow[t]{3}{*}{$\begin{array}{l}\text { Environmental } \\
\text { awareness }\end{array}$} & $\begin{array}{l}\text { It makes no sense to care about the environment; } \\
\text { you can't change it by yourself }\end{array}$ & & & \multicolumn{3}{|c|}{-0.845} \\
\hline & $\begin{array}{l}\text { It makes no sense to use the car less frequently } \\
\text { because others keep driving }\end{array}$ & & & \multicolumn{3}{|c|}{-0.743} \\
\hline & The environment would benefit from less car use & & & \multicolumn{3}{|c|}{0.588} \\
\hline \multirow[t]{6}{*}{$\begin{array}{l}\text { Social } \\
\text { consciousness }\end{array}$} & $\begin{array}{l}\text { My friends think you should only use the car } \\
\text { when there is no other option }\end{array}$ & & & & & 0.647 \\
\hline & I only use the car when it is necessary & & & & & 0.611 \\
\hline & $\begin{array}{l}\text { Because of the environment, I tried to use the car } \\
\text { less frequently }\end{array}$ & & & & & 0.584 \\
\hline & \multicolumn{6}{|l|}{ Reliability scores } \\
\hline & Cronbach's alpha & 0.734 & 0.748 & 0.694 & 0.740 & 0.709 \\
\hline & Tucker's coefficient of congruence & 0.994 & 0.994 & 0.991 & 0.997 & 0.989 \\
\hline
\end{tabular}


Mode use. Mode use was derived from the three-day trip diary and was operationalised as the number of trips and distance travelled per person per day by mode (Table 3.2). The number of trips per person per day in our sample is comparable with the average number of trips of the total sample of the MPN. Compared with the Dutch National Travel Survey (NTS), a yearly cross-sectional survey, the number of trips per person per day was substantially higher, mostly because short walking and cycling trips and locations not regularly visited are underreported in the NTS (Hoogendoorn-Lanser et al., 2015). Between 2014 and 2016, we observed a slight decrease in the total number of trips, and a small increase in the distance travelled for the same respondents. This suggests that the distance per trip increased, in particular, the distance of car trips.

Table 3.2 Mode use based on the three-day trip diary in 2014 and $2016(\mathrm{~N}=1,640)$

\begin{tabular}{lllll}
\hline & \multicolumn{2}{l}{$\mathbf{2 0 1 4}$} & \multicolumn{2}{l}{$\mathbf{2 0 1 6}$} \\
\cline { 2 - 5 } & \multicolumn{2}{l}{ Per person per day } & \multicolumn{2}{l}{ Per person per day } \\
\cline { 2 - 5 } & Trips & Km's & Trips & Km's \\
\hline Total & 3.2 & 36.7 & 3.0 & 37.6 \\
Car & 1.5 & 26.2 & 1.5 & 27.7 \\
Train & 0.1 & 5.3 & 0.1 & 4.8 \\
Bus, tram, metro & 0.1 & 1.0 & 0.1 & 0.8 \\
Bicycle & 1.0 & 2.8 & 0.8 & 2.5 \\
\hline
\end{tabular}

\subsubsection{Sample characteristics}

Table 3.3 shows individual, household and spatial characteristics of the sample used in the analyses for both years. Relative to the overall Dutch population, older adults and individuals without a driving licence were somewhat underrepresented and single households and people living in rural areas overrepresented. Of all selected participants, $75 \%$ were between 25 and 64 years old. More than half were female and had a personal income of between $€ 1,000$ and $€ 3,000$. More than 9 out of 10 people had a driving licence, whereas a third had a public transport season ticket. Most people in the selected sample were living in urban regions, and almost two-third thought that the accessibility of their neighbourhood by public transport was good.

As the analysis presented in this study concerns the 2014 and 2016 waves of the MPN, which covers a relatively short period, there were no major changes in individual, household and spatial characteristics at the aggregated level, as expected. For example, only $1 \%$ of the participants obtained their driving licence in 2016, and about $2 \%$ reported a higher income class for 2016. The most considerable changes occurred in the urbanisation level of the residential location. There was a significant shift from suburban towards urban; however, this does not mean that participants moved towards more urban regions. For example, because of a change in the number of inhabitants per $\mathrm{km}^{2}$, the level of urbanisation changed for several municipalities in the Netherlands between 2014 and 2016. 
Table 3.3 Individual, household and spatial characteristics of the sample $(N=1,640)$

\begin{tabular}{|c|c|c|c|}
\hline & & MPN & \\
\hline & & 2014 & 2016 \\
\hline Individual level & Categories & $\%$ & $\%$ \\
\hline Age group & $18-29$ yrs & 21 & 17 \\
\hline & $30-39$ yrs & 17 & 18 \\
\hline & $40-49$ yrs & 22 & 19 \\
\hline & $50-64$ yrs & 28 & 31 \\
\hline & $>64$ yrs & 13 & 15 \\
\hline Gender & Male & 45 & 45 \\
\hline & Female & 55 & 55 \\
\hline Educational level & No or low & 10 & 10 \\
\hline & Medium & 48 & 47 \\
\hline & High & 42 & 43 \\
\hline PT season ticket holder & Yes & 35 & 35 \\
\hline & No & 65 & 65 \\
\hline Driving licence holder & Yes & 91 & 92 \\
\hline & No & 9 & 8 \\
\hline Employment status & $>12$ hrs paid work per week & 60 & 61 \\
\hline & Self-employed & 4 & 5 \\
\hline & Student & 8 & 6 \\
\hline & No paid work & 28 & 29 \\
\hline Personal income & No personal income & 7 & 6 \\
\hline & Less than $€ 1,000$ per month & 19 & 19 \\
\hline & Between $€ 1,000$ and $€ 2,000$ & 36 & 35 \\
\hline & Between $€ 2,000$ and $€ 3,000$ & 21 & 22 \\
\hline & $€ 3,000$ or more & 6 & 7 \\
\hline & Missing & 11 & 11 \\
\hline Household level & & & \\
\hline Household composition & Single & 24 & 22 \\
\hline & Couple without children & 28 & 29 \\
\hline & Couple with children & 42 & 43 \\
\hline & Other & 6 & 6 \\
\hline Spatial level & & & \\
\hline Residential location & Urban $\left(\geq 1,500\right.$ inhabitants $\left./ \mathrm{m}^{2}\right)$ & 49 & 55 \\
\hline & Suburban $\left(1,000-1,500\right.$ inhabitants $\left./ \mathrm{m}^{2}\right)$ & 25 & 20 \\
\hline & $\operatorname{Rural}\left(\leq 1,000-1,500\right.$ inhabitants $\left./ \mathrm{m}^{2}\right)$ & 26 & 26 \\
\hline Attitude PT accessibility & Negative & 19 & 20 \\
\hline & Not negative, not positive & 17 & 17 \\
\hline & Positive & 64 & 63 \\
\hline
\end{tabular}

As our research questions primary focus on changes in attitudes and travel behaviour over time, we compared the individual scores for the five factors reflecting travellers' attitudes towards car use and ownership and mode use between 2014 and 2016. Car-minded was the most stable factor between 2014 and 2016, followed by social consciousness and environmental awareness. About one-third of the participants stated to have become less costsensitive in 2016, which might be related to greater optimism about the country's economy (smaller chance of losing one's job). Although we did not find any significant changes in mode use (measured in trips per person per day) for the total sample, at the individual level, we did. The percentage of individuals in our sample that showed changes in trip rate by mode ranged from $47 \%$ (train) to $69 \%$ (car). This means that a substantial number of people changed their chosen mode of transport between 2014 and 2016. 
The MPN uses questionnaires to collect a large amount of mobility-related and background information on households and their members, including information about different life events. There is evidence from several studies that life events form a trigger for changes in travel behaviour (Clark et al., 2014; Oakil et al., 2016b; Rau and Manton, 2016). In our analysis, we were also interested in the impact of life events on changes in travellers' attitudes towards car use and ownership. For our sample, we asked retrospective questions about 14 different life events in the past 12 months and the influence of these life events on people's travel behaviour. The most frequently reported life events in the selected sample between 2014 and 2016 were a change in working hours (19\%), a new job (18\%), and a change in work location (14\%). Some life events were rare, such as 'household member passed away' $(1 \%)$ and 'divorced/broke up' (2\%). Included life events in our analysis were moving home, a change in the number of children in a household and starting or changing jobs. These three life events are identified in the literature as influential travel behaviour factors (Clark et al., 2014; Rau and Manton, 2016). In the selected sample, $28 \%$ of the respondents reported one or more of these three life events.

\subsection{Method}

\subsubsection{Model specification}

We estimated a latent transition model to explore changes in attitude-based segments over time. Latent transitions models are cluster models for longitudinal data in which persons can switch between clusters (Vermunt et al., 2008). The 'repeated' nature of the MPN data allows distinguishing persons whose attitudes changed over time from those whose attitudes stayed the same. Because we were also interested in the relationship with travel behaviour, we related the latent classification scores to the observed number of trips from the travel diary. In our approach, we assumed changes in travellers' attitudes towards car use and ownership precede mode choice behaviour and not vice versa.

Figure 3.1 shows the path diagram we used to study changes in patterns between 2014 and 2016. Examples of the application of latent transition models in travel behaviour research can be found in (Kroesen, 2014) and de Haas et al. (2018).

In the present study, the latent transition model is formulated in two parts that are estimated simultaneously. The first part is known as the measurement model and explains how the five factors reflecting travellers' attitudes towards car use and ownership (car-minded, costsensitive, status-sensitive, environmental awareness and social consciousness) are associated. The second part, known as the structural model, explains how the latent classes are related over time. Thus, the latent transition analysis aims to estimate parameters corresponding to the proportion of individuals in each latent class at both time points, and the probability of moving from one class to another, conditional on prior membership status (Collins et al., 2000; Collins and Lanza, 2010). We used the Latent Gold software with maximum likelihood estimation with robust standard errors for model estimation. See Vermunt et al. (2008) for a detailed discussion of latent transition analysis with Latent Gold.

We let $y_{i t j}$ denote the response of each participant $i$ at time $t$ to response variable $j$. In our study, the total number of response variables is 5 (i.e., car-minded, cost-sensitive, statussensitive, environmental awareness, social consciousness). The vector of responses for a person, i at time t, is denoted as $\boldsymbol{y}_{i t}$ and the vector of responses at all occasions as $\boldsymbol{y}_{i}$. The vector of the exogenous covariates and time-varying covariates is denoted by $\mathbf{Z}_{\mathrm{i}}$. We can then make $x_{0}$ a latent class variable for 2014 and $x_{1}$ for 2016. Hence, individual scores on the five 
response variables are each classified into 1 of the $k$ latent classes in 2014 and 2016. Latent class membership is explained by exogenous covariates (e.g., age, education and household composition). The initial state probabilities and latent transition probabilities also depend on these covariates. The latent transition probabilities represent movement from a latent class in 2014 to a latent class in 2016. Transition probabilities also depend on time-varying covariates that do not explain class membership in 2014, such as major life events (for example childbirth, moving or changing job) between 2014 and 2016. These are represented in the path diagram (Fig. 1) by an arrow from the box with time-varying covariates to the transition probabilities. Latent classes in 2016 can be explained both by exogenous covariates and timevarying covariates.

Additionally, we used the new three-step approach in Latent Gold in which the latent classification scores are related to mode use, correcting for the classification error to prevent bias (Bakk et al., 2013; Vermunt, 2010). If we performed this analysis separate from the latent transition model, any conclusions about the relationship between latent class membership and variables of interest might be incorrect because the uncertainty related to class membership is not considered and parameter estimates are underestimated (Lanza et al., 2013).

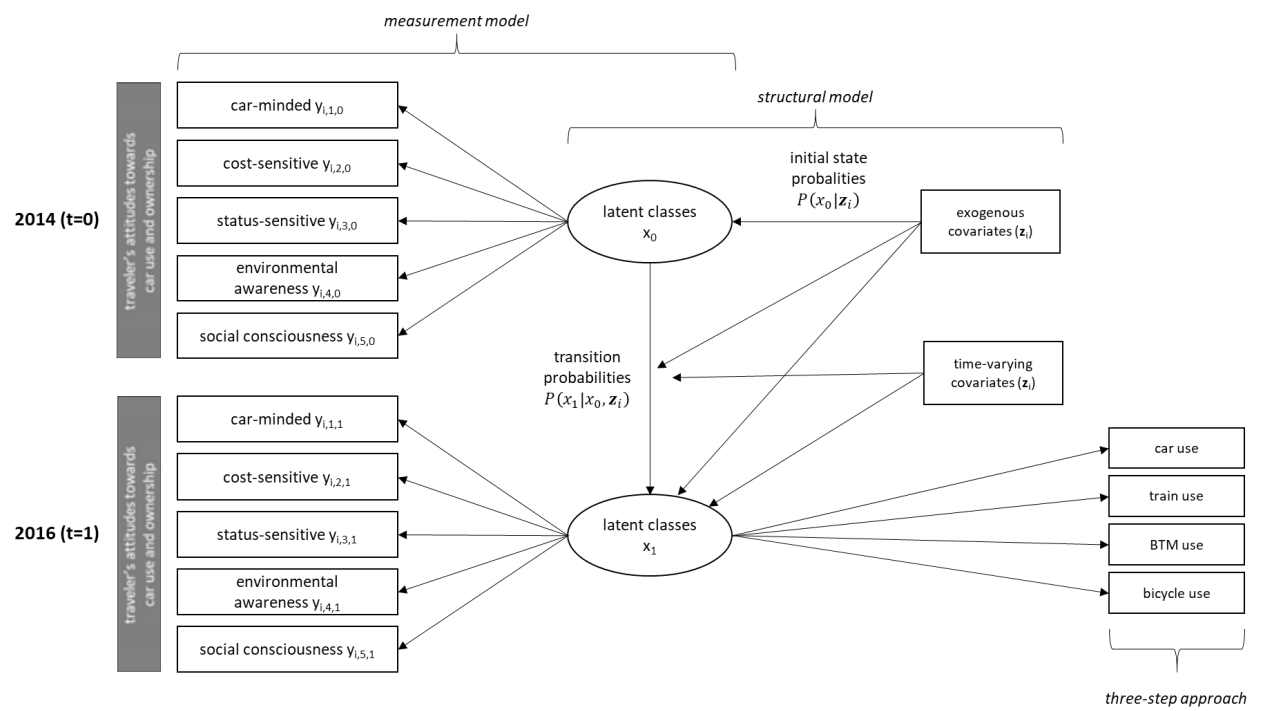

Figure 3.1 Path diagram for the latent transition model to study changes in latent classes between 2014 and 2016. Ovals represent latent (i.e., unobserved) variables, rectangles represent observed variables, and arrows represent causal relationships. 
The general model describes the probability density associated with $\mathbf{y}$ responses of individual i with covariates $\mathbf{z}$, and is expressed as follows (Magidson, 2013):

$P\left(\boldsymbol{y}_{i} \mid \mathbf{z}_{i}\right)=\sum_{x_{0}=1}^{K} \sum_{x_{1}=1}^{K} P\left(\left(x_{0}, x_{1} \mid z_{i}\right) P\left(\boldsymbol{y}_{i} \mid x_{0}, x_{1}, \mathbf{z}_{i}\right)\right.$

Eq. 2 defines the first part of Eq. 1, the class membership probabilities:

$$
P\left(x_{0}, x_{1} \mid z_{i}\right)=P\left(x_{0} \mid z_{i 0}\right) P\left(x_{1} \mid x_{0}, z_{i}\right)
$$

In the second part of Eq. 1, the measurement sub-model, the conditional response probabilities are estimated as follows:

$$
P\left(y_{i} \mid x_{0}, x_{1}, \mathbf{z}_{i}\right)=\prod_{t=0}^{1} P\left(\boldsymbol{y}_{i t} \mid x_{t}, \mathbf{z}_{i}\right)=\prod_{t=0}^{1} \prod_{j=1}^{5} P\left(y_{i t j} \mid x_{t}, \mathbf{z}_{i}\right)
$$

In summary, we estimated three sets of parameters:

- $P\left(x_{0} \mid z_{i o}\right)$ is an initial-state probability, namely the probability of having a particular latent initial state conditional on covariate values at $t=0$.

- $P\left(x_{1} \mid x_{0}, z_{i}\right)$ is a latent transition probability, namely the probability of being in a particular state at time point $t=1$ conditional on the latent state occupied at time point $t=0$ and covariate values.

- $P\left(y_{i t j} \mid x_{t}, z_{i t}\right)$ is a response probability, which is the probability of having a particular observed value on response variable $j$ at time point $t$ conditional on the latent state occupied at time point $t$ and covariate values.

\subsubsection{Model selection}

In this study, we performed the following three steps:

1. Assessing the optimal number of latent classes

2. Specification of the latent transition model

3. Relating latent classification scores to mode attitude and mode use.

The results of each step are described in the following sections.

\section{Step 1: Assessing the optimal number of classes}

The first step was to find the optimal number of latent classes (LC) in the data, a process commonly known as latent class enumeration (Masyn, 2013). The five latent factor scores reflecting travellers' attitudes towards car use and ownership are used to examine the number of underlying latent classes. Each latent class consists of respondents who share similar patterns of latent factor scores. Both for 2014 and 2016, we estimated alternative models separately. Table 3.4 presents the fit indices of eight subsequent models with a different number of classes. Various approaches exist to evaluate which number of latent classes is appropriate (Magidson and Vermunt, 2004). A common approach is the chi-square goodnessof-fit test. However, in situations involving sparse data, as is the case in our study, the chisquare distribution should not be used (Magidson and Vermunt, 2004). An alternative approach to assessing model fit in the case of sparse data utilises an information criterion weighting both model fit and parsimony. Most widely used in LC analysis is the Bayesian information criterion (BIC) statistic, which definition is based on the log-likelihood (LL) and the number of parameters (Npar). Log-likelihood values alone cannot be used as an index of 
fit because they are a function of sample size. The BIC(LL) statistic determines whether a change in the log-likelihood fails to decrease by a significant amount, for which lower values indicate a better fit (Raftery, 1995). According to the BIC values in Table 3.4, a four-class model is preferred for both the 2014 and 2016 data.

Table 3.4 Model fit of the latent class models in 2014 and $2016(\mathrm{~N}=1,640)$

\begin{tabular}{|c|c|c|c|c|c|c|}
\hline & $\mathbf{N}$ classes & LL & BIC(LL) & Npar & df & p-value \\
\hline \multirow[t]{8}{*}{2014} & 1 & -10784 & 21716 & 20 & 1620 & 0.00 \\
\hline & 2 & -10377 & 21118 & 49 & 1591 & 0.00 \\
\hline & 3 & -10206 & 20989 & 78 & 1562 & 0.00 \\
\hline & $\underline{4}$ & $\underline{-10092}$ & $\underline{20976}$ & $\underline{107}$ & $\underline{1533}$ & $\underline{0.00}$ \\
\hline & $\overline{5}$ & -10016 & 21038 & $\overline{136}$ & $\overline{1504}$ & $\overline{0.00}$ \\
\hline & 6 & -9962 & 21145 & 165 & 1475 & 0.00 \\
\hline & 7 & -9919 & 21275 & 194 & 1446 & 0.00 \\
\hline & 8 & -9877 & 21405 & 223 & 1417 & 0.00 \\
\hline \multirow[t]{8}{*}{2016} & 1 & -10640 & 21427 & 20 & 1620 & 0.00 \\
\hline & 2 & -10288 & 20940 & 49 & 1591 & 0.00 \\
\hline & 3 & -10110 & 20798 & 78 & 1562 & 0.00 \\
\hline & $\underline{4}$ & -10002 & 20795 & 107 & 1533 & $\underline{0.00}$ \\
\hline & $\overline{5}$ & $\overline{-9932}$ & $\overline{20871}$ & $\overline{136}$ & $\overline{1504}$ & $\overline{0.00}$ \\
\hline & 6 & -9866 & 20953 & 165 & 1475 & 0.00 \\
\hline & 7 & -9808 & 21051 & 194 & 1446 & 0.00 \\
\hline & 8 & -9781 & 21212 & 223 & 1417 & 0.00 \\
\hline
\end{tabular}

Note. $\mathrm{LL}=$ Log Likelihood; BIC(LL) = Bayesian Information Criterion (based on log-likelihood); $\mathrm{df}=$ degrees of freedom

Testing for measurement invariance across the LC model parameters is a necessary stage in latent transitions analysis to aid the interpretation of trend data over time (Chung et al., 2011). Measurement invariance means the number and definitions of classes remain the same over time (Lanza et al., 2010). Two models were estimated to test measurement invariance across time. The first model constrained the item-response probabilities (used to assign each participant to the most likely latent class) to be equal across time (measurement invariance model), and the second model had no restrictions (measurement variance model). We used the BIC value to compare the two models (Nylund, 2007). Our results show that relying on this criterion, the fit of the constrained model is better, which indicates that the structure of the latent class patterns did not change between 2014 and 2016, i.e., the latent classes for both years show the same patterns. Section 3.5.1 details the sample characteristics of the four latent classes.

\section{Step 2: Specification of the latent transition model}

The second step involved the specification of the latent transition model. This model resulted in a matrix of transition probabilities between the four identified latent classes over the period 2014 to 2016 . We used different covariates as predictors for both initial state membership and transitions between 2014 and 2016. From previous research, we knew which variables were most likely to differ between segments based on attitudes; see, for example, the work by Anable $(2005,2013)$. Based on the literature, we used socio-demographic characteristics (gender, age, employment status, educational level, household composition, personal income), variables related to the built environment (urbanisation of the residential location) and mobility-related factors (driving license, PT season ticket holder). Also, time-varying covariates, such as life events, were incorporated in the model to interact with the transitions between the latent classes. Section 3.5.2 contains the model results. 
Step 3. Relating latent classification scores to mode use

In the final step, mode use for different transport modes (i.e., car, train, BTM and bicycle) were regressed on the latent transition probabilities. This final step is necessary to answer our research question to what extent changes between attitude-based segments affect travel behaviour. Section 3.5.3 presents the results for this step.

\subsection{Results}

\subsubsection{Latent class characteristics (results of step 1)}

In step 1, the optimal number of latent classes was assessed, which resulted in four latent classes. After that, the highest mean score of the five latent factor scores served as the primary basis for labelling the four identified latent classes: cost-sensitive, car-minded, environmentally aware and social-conscious. For ease of interpretation, in our analysis, the scores of the first two statements that belonged to the 'environmental awareness' factor (see table 3.1) were reversed, so a higher score implied a higher sense of environmental awareness. The mean score for each factor for each latent class remained stable over time. A brief description of the latent classes is set out below, based on the mean factor scores, as expressed in Figure 3.2, the latent class characteristics (Table 3.5) and mode use (Table 3.6).

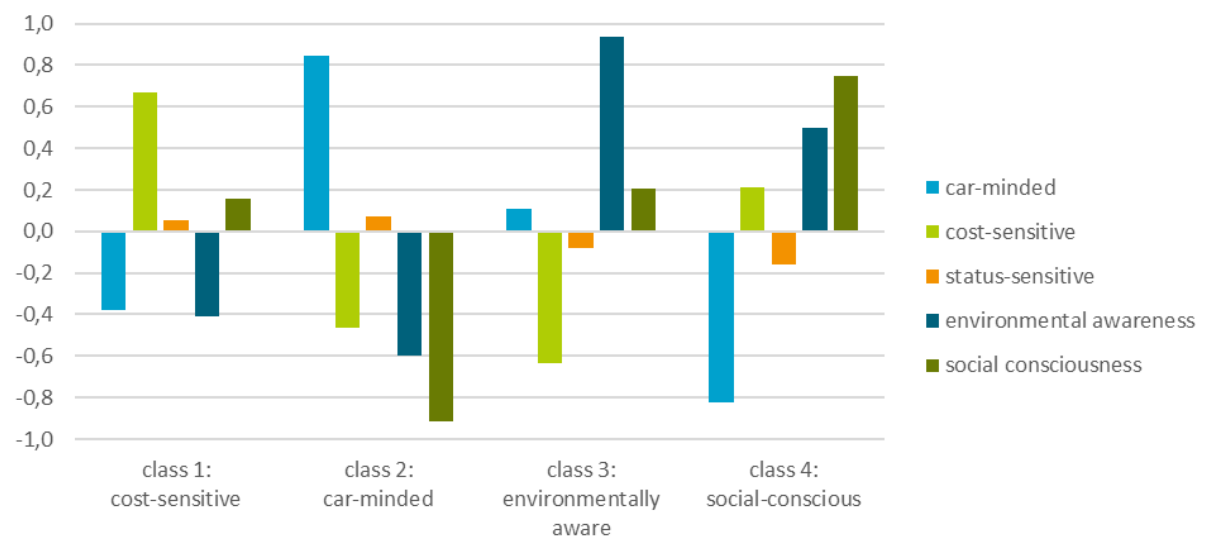

Figure 3.2 Mean score of the latent factors reflecting traveller's attitudes towards car use and ownership for each latent class in $2014(\mathrm{~N}=1,640)$

Latent Class 1 - Cost-sensitive. Cost-sensitive travellers, 33\% of the sample in 2014, had a negative attitude towards the car. Their mode choice depended largely on travel costs and owning a car was not common among them. For members of this class, their financial situation was an important consideration in using or owning a car. Contrary to class 3 , this class was more cost-sensitive and less aware of the environmental consequences of car use. Although class 1 and class 3 are different latent classes based on their attitudes towards car use and ownership, mode use hardly differed between these two classes. This class had a high share of participants under 29 years of age and females. Almost half of the cost-sensitive travellers had no paid job, partly because of a relatively high percentage of students. 
Latent Class 2 - Car-minded. Car-minded travellers, 26\% of the sample in 2014, scored very high on the car-minded factor. This means they liked travelling by car, appreciated the flexibility of driving and preferred the car in favour of other transport modes. Conversely, they tended to have lower scores on the other factors. As expected, car-minded travellers had the highest number of car trips per person per day. They rarely used public transport or cycled. The low number of trips by bicycle is very different from the behaviour of the average population in the Netherlands. Car-minded travellers were remarkably different from the other three classes in many characteristics. Car-minded travellers tended to be more often male, between 30 and 49 years old, were mostly employed, were not often PT season ticket holders and more often lived in rural areas.

Latent Class 3 - Environmentally aware. This class, 23\% of the sample in 2014, scored high on the environmental awareness factor, relative to class 4. However, this class reported relatively low scores on the cost statements. They were most aware of the harmful impact car use has on the environment. Travels costs seemed to play a minor role in their willingness and opportunities to drive. This class was not car-dependent or addicted to the car, liked to cycle and had a positive attitude toward PT accessibility (64\%). Although this class rarely used PT on a weekly base, data from the MPN household questionnaire showed that more than $65 \%$ used PT at least a few times a year. This suggests they were not frequently PT users, however, they used PT for non-daily and weekly trips. This class had a high share of participants aged over 50 years. Only a small percentage of this class $(11 \%)$ consisted of younger participants. Travellers who were most environmentally aware were more often higher educated and part of couples without children. Also, this class had the highest share of higher incomes.

Latent Class 4 - Social-conscious. This class, $18 \%$ of the sample in 2014, was characterised by the lowest score on the car-minded factor and the highest score on the social-consciousness factor. Also, members of this class tended to have higher scores on the cost-sensitive and environmental awareness factors. Social-conscious travellers tended to make well-considered choices in determining the best transport mode, being aware of the negative consequences of car use for society and partly affected by financial constraints. Social-conscious travellers used public transport more frequently and cycled most often of all classes. This class had a relatively high share of young adults and elderly, women, singles and participants without a driving licence. Also, social-conscious travellers more often lived in urban areas than people in the other classes, which means that other opportunities of (public or non-motorized) transport might be available. 
Table 3.5 Characteristics latent classes in $2014(\mathrm{~N}=1,640)$

\begin{tabular}{|c|c|c|c|c|c|c|}
\hline & & $\begin{array}{l}\text { class 1: } \\
\text { cost- } \\
\text { sensitive }\end{array}$ & $\begin{array}{l}\text { class 2: } \\
\text { car- } \\
\text { minded }\end{array}$ & $\begin{array}{l}\text { class 3: } \\
\text { environ- } \\
\text { mentally } \\
\text { aware }\end{array}$ & $\begin{array}{l}\text { class 4: } \\
\text { social- } \\
\text { conscious }\end{array}$ & $\begin{array}{l}\text { Total } \\
\text { sample }\end{array}$ \\
\hline & Class size & $33 \%$ & $26 \%$ & $23 \%$ & $18 \%$ & $100 \%$ \\
\hline \multicolumn{7}{|l|}{ Indicators (factor scores) } \\
\hline Car-minded & Mean & -0.24 & 0.84 & 0.13 & -0.91 & 0.00 \\
\hline Cost-sensitive & Mean & 0.64 & -0.49 & -0.63 & 0.35 & 0.00 \\
\hline Status-sensitive & Mean & 0.13 & 0.09 & -0.07 & -0.28 & 0.00 \\
\hline Environmental awareness & Mean & -0.41 & -0.60 & 0.94 & 0.50 & 0.00 \\
\hline Social consciousness & Mean & 0.16 & -0.91 & 0.21 & 0.75 & 0.00 \\
\hline \multicolumn{7}{|l|}{ Exogenous covariates $(\%)$} \\
\hline \multirow[t]{2}{*}{ Gender } & Male & 42 & 51 & 49 & 37 & 45 \\
\hline & Female & 58 & 49 & 51 & 63 & 55 \\
\hline \multirow[t]{5}{*}{ Age group } & $18-29$ yrs & 31 & 17 & 11 & 22 & 21 \\
\hline & $30-39$ yrs & 13 & 24 & 18 & 12 & 17 \\
\hline & $40-49$ yrs & 19 & 27 & 22 & 19 & 22 \\
\hline & $50-64$ yrs & 24 & 25 & 34 & 30 & 28 \\
\hline & $>64$ yrs & 13 & 7 & 16 & 17 & 13 \\
\hline \multirow[t]{3}{*}{ Education } & No or low & 16 & 11 & 5 & 7 & 10 \\
\hline & Medium & 55 & 50 & 39 & 43 & 48 \\
\hline & High & 29 & 39 & 56 & 50 & 42 \\
\hline \multirow[t]{4}{*}{ Employment } & $>12 \mathrm{hr}$ paid work & 48 & 75 & 68 & 50 & 60 \\
\hline & Self-employed & 4 & 4 & 5 & 5 & 4 \\
\hline & Student & 16 & 3 & 2 & 10 & 8 \\
\hline & No paid work & 32 & 18 & 25 & 36 & 28 \\
\hline \multirow[t]{4}{*}{ Household composition } & Single & 24 & 17 & 18 & 38 & 24 \\
\hline & Couple without children & 23 & 30 & 35 & 28 & 29 \\
\hline & Couple with children & 44 & 48 & 44 & 30 & 42 \\
\hline & Other & 9 & 5 & 3 & 4 & 6 \\
\hline \multirow[t]{3}{*}{ Residential location } & Urban & 46 & 45 & 46 & 64 & 49 \\
\hline & Suburban & 27 & 25 & 26 & 18 & 25 \\
\hline & Rural & 27 & 30 & 28 & 18 & 26 \\
\hline \multirow[t]{2}{*}{ PT season ticket holder } & Yes & 43 & 17 & 28 & 56 & 35 \\
\hline & No & 57 & 83 & 72 & 44 & 65 \\
\hline \multirow[t]{2}{*}{ Driving licence } & Yes & 83 & 99 & 97 & 85 & 91 \\
\hline & No & 17 & 1 & 3 & 15 & 9 \\
\hline \multirow[t]{6}{*}{ Personal income } & No personal income & 11 & 4 & 5 & 8 & 7 \\
\hline & $<€ 1,000$ & 27 & 11 & 12 & 25 & 19 \\
\hline & $€ 1,000-€ 2,000$ & 36 & 40 & 32 & 35 & 36 \\
\hline & $€ 2,000-€ 3,000$ & 12 & 25 & 31 & 20 & 21 \\
\hline & $\geq € 3,000$ & 3 & 6 & 9 & 5 & 6 \\
\hline & missing & 12 & 14 & 11 & 7 & 11 \\
\hline \multirow[t]{3}{*}{ Attitude PT accessibility } & Negative & 19 & 27 & 18 & 12 & 19 \\
\hline & Neutral & 16 & 19 & 19 & 13 & 17 \\
\hline & Positive & 66 & 54 & 64 & 75 & 64 \\
\hline
\end{tabular}

Note. Bold numbers indicate the highest share (\%) of each category across the latent profiles 
Table 3.6 Mode use (number of trips per person per day) of the four latent classes in $2014(\mathrm{~N}=1,640)$

\begin{tabular}{lllllll}
\hline & & $\begin{array}{l}\text { class 1: cost- } \\
\text { sensitive }\end{array}$ & $\begin{array}{l}\text { class 2: car- } \\
\text { minded }\end{array}$ & $\begin{array}{l}\text { class 3: } \\
\text { environmentally } \\
\text { aware }\end{array}$ & $\begin{array}{l}\text { class 4: } \\
\text { social- } \\
\text { conscious }\end{array}$ & $\begin{array}{l}\text { Total } \\
\text { sample }\end{array}$ \\
\hline Mode use & Car & 1.1 & 2.3 & 1.7 & 0.9 & 1.5 \\
(\# trips per & Train & 0.1 & 0.0 & 0.1 & 0.2 & 0.1 \\
person per day) & BTM & 0.1 & 0.1 & 0.0 & 0.1 & 0.1 \\
& Bicycle & 1.2 & 0.2 & 1.0 & 1.7 & 1.0 \\
\hline
\end{tabular}

\subsubsection{Examining transition behaviour between latent classes (results of step 2)}

Table 3.7 shows the estimated transition probabilities between the latent classes. The higher values on the diagonal indicate that most of the participants were in the same class in 2014 and 2016. The share of participants that stayed in the same class was higher than what other studies found in which latent classes were based on the frequency of mode use instead of attitudes (de Haas et al., 2016; Kroesen, 2014; Kroesen and Cranenburgh, 2016; Molin et al., 2016). This might suggest that travellers' attitudes towards car use and ownership are more stable over time than the frequency of mode use, prompting us to take a closer look at the relationship with mode use (see section 5.6.3).

The first class, the cost-sensitive travellers, had a high share of participants who remained in the same class between 2014 and 2016 (85\%) and was also the most stable class over time. Participants who changed their attitudes towards car use and ownership switched to either the environmentally aware class $(4 \%)$, the car-minded class $(8 \%)$ or the social-conscious class (3\%). Most participants who moved from the car-minded class transitioned to the costsensitive class $(10 \%)$. Among the travellers who were most environmentally aware, $76 \%$ maintained the same attitudes towards car use and ownership between the two waves. Most of the participants who belonged to this class in 2014 and changed their attitudes, changed into the car-minded class $(9 \%)$ or cost-sensitive class (11\%). A small group (4\%) switched to the social-conscious class. Table 8 indicates approximately $72 \%$ stability in the social-conscious class, which means that $28 \%$ transitioned to a different class. This mostly concerned a transfer to the environmentally aware class $(16 \%)$ or the cost-sensitive class $(9 \%)$. Only a small percentage transitioned to the car-minded class (3\%). Conversely, all classes showed a low probability of transitioning to the social-conscious class.

Table 3.7 Estimated latent transition probabilities between 2014 and $2016(\mathrm{~N}=1,640)$

\begin{tabular}{lllll}
\hline & $\mathbf{2 0 1 6}$ & & & \\
\hline 2014 & $\begin{array}{l}\text { Class 1: } \\
\text { cost-sensitive }\end{array}$ & $\begin{array}{l}\text { Class 2: } \\
\text { car-minded }\end{array}$ & $\begin{array}{l}\text { Class 3: } \\
\text { environmentally } \\
\text { aware }\end{array}$ & $\begin{array}{l}\text { Class 4: } \\
\text { social- } \\
\text { conscious }\end{array}$ \\
\hline Class 1: cost-sensitive & $\mathbf{8 5 \%}$ & $8 \%$ & $4 \%$ & $3 \%$ \\
Class 2: car-minded & $10 \%$ & $\mathbf{7 9 \%}$ & $5 \%$ & $6 \%$ \\
Class 3: environmentally aware & $11 \%$ & $9 \%$ & $\mathbf{7 6 \%}$ & $4 \%$ \\
Class 4: social-conscious & $9 \%$ & $3 \%$ & $16 \%$ & $\mathbf{7 2 \%}$ \\
\hline
\end{tabular}

Note. In bold the probability of staying in the same class 
Regarding the factors that made people switch to a different class, Table 3.8 presents the parameter estimates of the four-class transition model. All covariates that were significant in estimating initial latent class membership were retained in the analysis, and time-varying covariates were added. Also, Table 3.8 includes standardised coefficients and corresponding p-values for all variables. For every variable in Table 3.8, we found significant results for transitioning from one class to another.

Among the cost-sensitive travellers, employed and higher educated people had a higher chance of switching to a different class, especially to the environmentally aware and socialconscious class, possibly related to having a higher income and a lower travel cost-sensitivity. Cost-sensitive travellers with a PT season ticket did not switch to the car-minded class; however, they were more likely to transfer to the environmentally aware or social-conscious class. Conversely, females and people with a drivers' license are less likely to switch to another class. Finally, a new job or moving home significantly influenced the attitudes of cost-sensitive travellers.

As we have seen, car-minded travellers had a probability of $79 \%$ of staying in the same class in our study. After an increase in the number of children in the household or a new job, car-minded travellers were more likely to switch to the environmentally aware class. Also, car-minded travellers aged over 50 years had a higher chance of changing to the environmentally aware class. Apparently, for car-minded travellers, these life-changing moments and ageing form a trigger for reconsideration their attitudes towards car use and ownership. None of the variables showed a significant effect on transitioning from the carminded to the social-conscious class.

Of the travellers who were most environmentally aware, higher-educated people had a higher probability of remaining in this class. This corresponds to the results of other studies. For example, (Anable, 2005) found that within the travel segment 'aspiring environmentalists' (i.e., people who feel the highest responsibility concerning environmental problems), the share of higher-educated people is very high. Class members living in urban areas were less likely to become car-minded. In general, the level of public transport services and the availability of bicycle facilities in Dutch cities are excellent, so there is no need to change car attitude, especially if people care about the environment. As expected, an increase in the number of children younger than 17 had a higher probability of switching to class 1 (parents become more cost-sensitive) and class 2 (parents experience travelling by car as more convenient). Moving to class 1 and 2 also implies less environmentally awareness. This contrasts with the so-called 'legacy hypothesis', which states that parents become more concerned about the environment. However, (Thomas et al., 2018a) did not found evidence in support of this theory. In line with Thomas et al. (2018a), we found mixed results, suggesting changes in environmental concern after having a child depends on other factors such as individual attitudes in relation to practical considerations such as comfort. When children reach adulthood, members from this class were more likely to transition to the cost-sensitive class. This seems counter-intuitive; however, when children leave home, parents become less car-oriented as they don't have to bring and collect their children anymore. Job changes make them more likely to switch to the car-minded or social-conscious class. Turning to the socialconscious profile might be the result of a new work location with excellent PT facilities, while the opposite might be right for changing to the car-minded profile. 
Finally, for social-conscious travellers, increasing age had a negative association with transitioning to other classes. This might suggest that car use and ownership are indeed less widespread among young adults Kuhnimhof et al. (2011); Kuhnimhof et al. (2012), reflected by the higher share of young people in this class. Increasing age does not seem to affect this; however, members of this class showed the highest transition probabilities. From this point of view, it is arguable that other factors are responsible for developing a more positive attitude towards the car, such as being employed, starting or changing jobs, moving and changes in household composition. These characteristics all show significant effects for switching to the environmentally aware profile. Furthermore, PT season ticket holders and higher educated people are less likely to switch to other classes.

Although attitude-based segments appear very stable over time, we draw some interesting conclusions from the observed switching behaviour. We found the highest transition probabilities for less frequent car users (i.e. social-conscious travellers). This suggests that once people use the car more frequently, changes in attitudes become less likely. Furthermore, we found that car use and ownership were less prevalent among younger adults, as both the cost-sensitive and the social-conscious profile have a higher share of younger people. Less car dependency among younger adults is in line with what was found in previous studies (Delbosc, 2016; Klein and Smart, 2017; Kuhnimhof et al., 2013). Even so, for cost-sensitive and social-conscious travellers, increasing age is not positively associated with transitioning to more car-oriented profiles. One explanation might be that in the Netherlands, younger people stay longer at home, extend their study, and postpone buying a car (CBS, 2018). Because of this changing social position of young adults, their attitudes remain the same for a longer period. Only when younger adults face life events, such as moving, starting a job or become parents, transitioning to more car-oriented profiles appears more likely. This suggests that there is no fundamental difference in the popularity of the car among young adults. However, people become more car-dependent at a later stage.

Table 3.8 Parameter estimates of latent class membership in 2016

\begin{tabular}{|c|c|c|c|c|c|}
\hline & & 2016 & & & \\
\hline 2014 & Parameter & $\begin{array}{l}\text { Class 1: } \\
\text { cost-sensitive }\end{array}$ & $\begin{array}{l}\text { Class 2: } \\
\text { car-minded }\end{array}$ & $\begin{array}{l}\text { Class 3: } \\
\text { environmentally } \\
\text { aware }\end{array}$ & $\begin{array}{l}\text { Class 4: } \\
\text { social-conscious }\end{array}$ \\
\hline \multirow{17}{*}{$\begin{array}{l}\text { Class 1: } \\
\text { cost- } \\
\text { sensitive }\end{array}$} & Constant & 0.00 & $-13.30(.24)$ & $-49.85(.06)$ & $-24.01(.07)$ \\
\hline & Gender $($ male $=$ ref $)$ & 0.00 & $-1.62(.12)$ & $-9.69(.05)^{* *}$ & $-14.61(.01)^{* *}$ \\
\hline & Age $30-39$ yrs $(18-29$ yrs $=$ ref $)$ & 0.00 & $-1.68(.23)$ & $1.21(.66)$ & $-45.31(.02)^{* *}$ \\
\hline & Age $40-49$ yrs $(18-29$ yrs $=$ ref $)$ & 0.00 & $1.16(.22)$ & $-14.12(.05)^{* *}$ & $-11.63(.12)$ \\
\hline & Age $50-64$ yrs $(18-29$ yrs $=$ ref $)$ & 0.00 & $-6.22(.44)$ & $-2.86(.78)$ & $10.12(.12)$ \\
\hline & Age $>64$ yrs $(18-29$ yrs $=$ ref $)$ & 0.00 & $-6.24(.57)$ & $10.92(.08)$ & $-28.99(.06)$ \\
\hline & Moderately educated (low=ref) & 0.00 & $0.70(.70)$ & $-13.82(.39)$ & $-6.35(.25)$ \\
\hline & Highly educated $($ low $=$ ref $)$ & 0.00 & $-0.10(.95)$ & $9.84(.48)$ & $17.09(.02)^{* *}$ \\
\hline & Employment $($ no $=$ ref $)$ & 0.00 & $1.24(.19)$ & $10.12(.05)^{* *}$ & $9.88(.09)$ \\
\hline & Driver license $(n p=r e f)$ & 0.00 & $5.74(.60)$ & $-2.08(.76)$ & $-30.40(.01)^{* * *}$ \\
\hline & PT season ticket $($ no $=$ ref) & 0.00 & $-0.91(.29)$ & $15.17(.03)^{* *}$ & $19.70(.01)^{* *}$ \\
\hline & Urban environment $($ no $=$ ref) & 0.00 & $0.89(.21)$ & $3.29(.27)$ & $11.44(.07)$ \\
\hline & Attitude accessibility PT (negative $=$ ref) & 0.00 & $1.38(.22)$ & $-25.13(.02)^{* *}$ & $-5.78(.17)$ \\
\hline & Incr $\#$ children $<17$ yrs (no change $=$ ref) & 0.00 & $0.79(.54)$ & $9.66(.10)$ & $16.31(.35)$ \\
\hline & Decr $\#$ children $<17$ yrs $($ no change $=$ ref) & 0.00 & $-1.25(.27)$ & $-2.48(.80)$ & $25.59(0.02)^{* * *}$ \\
\hline & New job / started working $($ no $=$ ref $)$ & 0.00 & $1.99(.01)^{* * * *}$ & $24.24(.02)^{* *}$ & $-7.01(.21)$ \\
\hline & Moved home $($ no $=$ ref $)$ & 0.00 & $0.96(.03)^{* *}$ & $-5.35(.27)$ & $14.86(.07)$ \\
\hline
\end{tabular}




\begin{tabular}{|c|c|c|c|c|c|}
\hline \multirow{17}{*}{$\begin{array}{l}\text { Class 2: } \\
\text { car-minded }\end{array}$} & Constant & $-3.62(.69)$ & 0.00 & $1.07(.96)$ & $-14.56(.63)$ \\
\hline & Gender $($ male $=$ ref $)$ & $-0.43(.56)$ & 0.00 & $-3.81(.23)$ & $2.03(.78)$ \\
\hline & Age $30-39$ yrs $(18-29$ yrs $=$ ref $)$ & $-2.56(.06)$ & 0.00 & $-44.78(.04)^{* *}$ & $0.06(.99)$ \\
\hline & Age $40-49$ yrs $(18-29$ yrs $=$ ref $)$ & $-2.51(.04)^{* *}$ & 0.00 & $-10.62(.29)$ & $-2.77(.86)$ \\
\hline & Age $50-64$ yrs $(18-29$ yrs $=$ ref $)$ & $-2.02(.08)$ & 0.00 & $20.14(.05)^{* *}$ & $7.99(.61)$ \\
\hline & Age $>64$ yrs $(18-29$ yrs $=$ ref $)$ & $-9.40(.40)$ & 0.00 & $29.36(.05)^{* *}$ & $-0.29(.99)$ \\
\hline & Moderately educated (low=ref) & $-0.74(.44)$ & 0.00 & $-12.76(.08)$ & $1.71(.93)$ \\
\hline & Highly educated $($ low $=$ ref $)$ & $-2.49(.05)^{* *}$ & 0.00 & $-10.55(.07)$ & $6.44(.75)$ \\
\hline & Employment $($ no $=$ ref $)$ & $-0.58(.51)$ & 0.00 & $5.50(.21)$ & $1.17(.93)$ \\
\hline & Driver license $(n p=r e f)$ & $-0.65(.74)$ & 0.00 & $-20.56(.15)$ & $-10.97(.44)$ \\
\hline & PT season ticket $($ no $=$ ref) & $1.45(.08)$ & 0.00 & $-23.13(.04)^{* *}$ & $-1.02(.90)$ \\
\hline & Urban environment $($ no $=$ ref $)$ & $-1.64(.03)^{* *}$ & 0.00 & $16.52(.05)^{* *}$ & $7.72(.44)$ \\
\hline & Attitude accessibility PT (negative $=$ ref) & $7.95(.35)$ & 0.00 & $-6.38(.09)$ & $5.97(.50)$ \\
\hline & Incr $\#$ children $<17$ yrs (no change $=$ ref) & $-8.13(.55)$ & 0.00 & $34.19(.04)^{* *}$ & $9.87(.32)$ \\
\hline & Decr $\#$ children $<17$ yrs $($ no change $=$ ref) & $-2.10(.22)$ & 0.00 & $-14.85(.27)$ & $1.82(.91)$ \\
\hline & New job / started working $($ no $=$ ref $)$ & $-2.31(.09)$ & 0.00 & $27.94(.05)^{* *}$ & $9.76(.39)$ \\
\hline & Moved home $($ no $=$ ref $)$ & $-0.18(.88)$ & 0.00 & $-38.27(.05)^{* *}$ & $-5.21(.67)$ \\
\hline \multirow{17}{*}{$\begin{array}{l}\text { Class 3: } \\
\text { environ- } \\
\text { mentally } \\
\text { aware }\end{array}$} & Constant & $-17.36(.22)$ & $-10.13(.76)$ & 0.00 & $-15.96(.48)$ \\
\hline & Gender $($ male $=$ ref $)$ & $-4.47(.09)$ & $6.94(.07)$ & 0.00 & $-9.46(.15)$ \\
\hline & Age $30-39$ yrs $(18-29$ yrs $=$ ref $)$ & $8.36(.33)$ & $-12.72(.06)$ & 0.00 & $6.17(.52)$ \\
\hline & Age $40-49$ yrs $(18-29$ yrs $=$ ref $)$ & $-45.21(.00)^{* * *}$ & $-24.66(.02)^{* *}$ & 0.00 & $2.92(.77)$ \\
\hline & Age $50-64$ yrs $(18-29$ yrs $=$ ref $)$ & $-15.68(.07)$ & $-13.76(.05)^{* *}$ & 0.00 & $2.05(.85)$ \\
\hline & Age $>64$ yrs $(18-29$ yrs $=$ ref $)$ & $23.53(.03)^{* *}$ & $-28.77(.29)$ & 0.00 & $2.11(.82)$ \\
\hline & Moderately educated (low=ref) & $-3.92(.20)$ & $15.52(.45)$ & 0.00 & $3.86(.65)$ \\
\hline & Highly educated $($ low $=$ ref $)$ & $-29.71(.00)^{* * * *}$ & $-15.22(.47)$ & 0.00 & $-11.96(.28)$ \\
\hline & Employment $($ no $=$ ref $)$ & $9.78(.05)^{* *}$ & $15.56(.05) * *$ & 0.00 & $-11.77(.13)$ \\
\hline & Driver license ( $\mathrm{np}=\mathrm{ref})$ & $-15.95(.16)$ & $3.06(.80)$ & 0.00 & $-13.49(.09)$ \\
\hline & PT season ticket $($ no $=$ ref) & $-4.31(.30)$ & $-30.38(.02)^{* *}$ & 0.00 & $12.81(.14)$ \\
\hline & Urban environment $($ no $=$ ref $)$ & $9.76(.02)^{* *}$ & $2.07(.46)$ & 0.00 & $-11.84(.09)$ \\
\hline & Attitude accessibility PT (negative=ref) & $3.43(.65)$ & $-7.32(.09)$ & 0.00 & $-3.10(.36)$ \\
\hline & Incr $\#$ children $<17$ yrs $($ no change $=$ ref) & $23.58(.00)^{* * *}$ & $19.37(.01)^{* * *}$ & 0.00 & $-3.26(.76)$ \\
\hline & Decr $\#$ children $<17$ yrs $($ no change $=$ ref) & $26.18(.00)^{* * *}$ & $-1.48(.94)$ & 0.00 & $-0.66(.98)$ \\
\hline & New job $/$ started working $($ no $=$ ref $)$ & $-7.60(.16)$ & $20.90(.00)^{* * *}$ & 0.00 & $20.46(.04)^{* *}$ \\
\hline & Moved home $($ no $=$ ref $)$ & $-19.90(.03)^{* *}$ & $-18.30(.11)$ & 0.00 & $22.07(.09)$ \\
\hline \multirow{17}{*}{$\begin{array}{l}\text { Class 4: } \\
\text { social- } \\
\text { conscious }\end{array}$} & Constant & $3.30(.72)$ & $-8.02(.68)$ & $-8.03(.56)$ & 0.00 \\
\hline & Gender $($ male $=$ ref $)$ & $-2.72(.45)$ & $4.19(.50)$ & $-12.32(.03)^{* *}$ & 0.00 \\
\hline & Age $30-39$ yrs $(18-29$ yrs $=$ ref $)$ & $-19.33(.36)$ & $-6.65(.68)$ & $-6.55(.17)$ & 0.00 \\
\hline & Age $40-49$ yrs $(18-29$ yrs $=$ ref $)$ & $-39.89(.05)^{* *}$ & $-1.20(.93)$ & $-45.52(.02)^{* *}$ & 0.00 \\
\hline & Age $50-64$ yrs $(18-29$ yrs $=$ ref $)$ & $-25.84(.07)^{* *}$ & $-13.02(.41)$ & $-15.76(.05)^{* *}$ & 0.00 \\
\hline & Age $>64$ yrs $(18-29$ yrs $=$ ref $)$ & $10.12(.12)$ & $-2.90(.84)$ & $16.06(.09)$ & 0.00 \\
\hline & Moderately educated (low=ref) & $-19.07(.05)^{* *}$ & $-7.26(.32)$ & $-51.07(.01)^{* *}$ & 0.00 \\
\hline & Highly educated $($ low $=$ ref $)$ & $-39.28(.04)^{* *}$ & $-13.73(.21)$ & $-10.97(.07)$ & 0.00 \\
\hline & Employment $($ no $=$ ref $)$ & $9.98(.11)$ & $-10.60(.30)$ & $4.02(.23)$ & 0.00 \\
\hline & Driver license $(n p=r e f)$ & $-8.68(.18)$ & $6.69(.72)$ & $5.19(.67)$ & 0.00 \\
\hline & PT season ticket $($ no $=$ ref) & $1.56(.58)$ & $-3.49(.67)$ & $-20.72(.01)^{* *}$ & 0.00 \\
\hline & Urban environment (no $=$ ref) & $-15.36(.03)^{* *}$ & $4.79(.33)$ & $-8.25(.03)^{* *}$ & 0.00 \\
\hline & Attitude accessibility PT (negative $=$ ref) & $-4.19(.34)$ & $-17.89(.09)^{*}$ & $-3.90(.32)$ & 0.00 \\
\hline & Incr $\#$ children $<17$ yrs (no change $=$ ref) & $8,73(.72)$ & $2.24(.88)$ & $59.45(.01)^{* *}$ & 0.00 \\
\hline & Decr $\#$ children $<17$ yrs (no change $=$ ref) & $35.86(.04)^{* *}$ & $-8.38(.58)$ & $15.29(.05)^{* *}$ & 0.00 \\
\hline & New job / started working $($ no $=$ ref $)$ & $-30.19(.09)$ & $7.31(.60)$ & $35.54(.01)^{* *}$ & 0.00 \\
\hline & Moved home $($ no $=$ ref $)$ & $9.14(.56)$ & $-11.58(.46)$ & $9.33(.05)^{* *}$ & 0.00 \\
\hline
\end{tabular}

Note: $P$-values are presented in parentheses; significant $p$-values are in bold $(* * p<0.05 * * * p<0.01)$ 
The results set out above show that life events were significantly associated with transitioning between the four latent classes. To explore the impact of life events on changes in the membership of the latent classes further, we compared the share of participants who switched to a different class and had a life event with the share of participants who stayed in the same class and experienced a life event (Table 3.9). In general, transitioning to a different class was associated with a higher share of participants who had a life event. In particular, the non-car minded' profiles showed significantly more movers after the occurrence of a life event. Also, an increase in the number of children resulted in a substantially higher share of travellers who were environmentally aware and social-conscious transitioning to another class. Because life events often coincide, we also compared the percentage of stayers and movers for people facing more than one life event. As can be seen from Table 4.9, all profiles showed significantly more movers when different life events occur in the same year. These results are in line with other studies, which found a positive relationship between life events and, for example, car preferences (Olde Kalter et al., 2021).

Table 3.9 Share of respondents with a life event between 2014 and 2016.

\begin{tabular}{lllllllll}
\hline & New job & & Moving & & \multicolumn{2}{l}{ Increase children } & $\begin{array}{l}\text { New job, moving } \\
\text { or increase } \\
\text { children }\end{array}$ \\
\hline Classes & Stayers & Movers & Stayers & Movers & Stayers & Movers & Stayers & Movers \\
\hline Cost-sensitive & $17 \%$ & $\mathbf{5 9 \%}$ & $7 \%$ & $\mathbf{2 0} \%$ & $5 \%$ & $5 \%$ & $26 \%$ & $\mathbf{6 7 \%}$ \\
Car-minded & $17 \%$ & $\mathbf{3 0 \%}$ & $7 \%$ & $6 \%$ & $9 \%$ & $5 \%$ & $29 \%$ & $\mathbf{3 6 \%}$ \\
Enviromentally aware & $11 \%$ & $\mathbf{2 4 \%}$ & $8 \%$ & $10 \%$ & $6 \%$ & $\mathbf{1 6 \%}$ & $20 \%$ & $\mathbf{3 5 \%}$ \\
Social-conscious & $19 \%$ & $23 \%$ & $9 \%$ & $\mathbf{1 3 \%}$ & $2 \%$ & $\mathbf{1 1 \%}$ & $25 \%$ & $\mathbf{4 0 \%}$ \\
\hline
\end{tabular}

Note: Significant differences between stayers and movers are in bold

\subsubsection{Impact of changing between latent classes on mode use (results step 3)}

Besides the dynamics of change in attitudes towards car use and ownership, we were also interested in the effects of this switching behaviour on changes in mode use. In our descriptive analysis, we found a meaningful and significant difference in mode use between the four estimated latent classes (see Section 3.5.1). The results of the latent transition model made us interested in whether stability or change in attitudes towards car use and ownership might explain stability or change in mode use. Following the three-step approach developed by Vermunt (2010) and extended by Bakk et al. (2013), we used the posterior latent transition probabilities to predict changes in the number of trips by car, public transport and bicycle (Table 3.10).

A change in the number of trips by car was significantly $(\mathrm{p}<0.05)$ and positively affected by changing from both the environmentally aware profile and social-conscious profile to the carminded profile. Other transitions to the car-minded profile did not increase car use. Also, changing from the car-minded profile to a less car-oriented profile had only a significant and negative effect on the number of trips by car of changers to the social-conscious profile. This suggests that in most cases, different attitudes towards car use and ownership did not directly affect the frequency of car use. 
Table 3.10 Parameter estimates 3-step model approach: Predicting the number of trips by car, train, BTM and bicycle with latent transition probabilities

\begin{tabular}{lllll}
\hline & & \multicolumn{3}{l}{ Change in the number of trips by: } \\
& & Car & PT & Bicycle \\
\hline From & To & $\boldsymbol{\beta}$ & $\boldsymbol{\beta}$ & $\boldsymbol{\beta}$ \\
\hline Cost-sensitive & Cost-sensitive & $-0,35$ & -0.12 & $-0,23$ \\
& Car-minded & 0.08 & $\mathbf{- 0 . 2 3}$ & -0.02 \\
& Environmentally aware & 0.36 & 0.26 & 0.01 \\
& Social-conscious & -0.09 & 0.09 & 0.23 \\
\hline Car-minded & Cost-sensitive & -0.30 & 0.09 & -0.14 \\
& Car-minded & 0.24 & 0.04 & -0.00 \\
& Environmentally aware & -0.10 & $\mathbf{- 0 . 2 6}$ & 0.55 \\
& Social-conscious & $\mathbf{- 0 . 6 5}$ & 0.13 & -0.40 \\
\hline Environmentally aware & Cost-sensitive & -0.41 & 0.07 & 0.38 \\
& Car-minded & $\mathbf{0 . 9 4}$ & $\mathbf{- 0 . 1 8}$ & -0.14 \\
& Environmentally aware & -0.04 & 0.05 & -0.05 \\
Social-conscious & Social-conscious & -0.49 & 0.06 & -0.19 \\
& Cost-sensitive & -0.00 & -0.02 & 0.16 \\
& Car-minded & $\mathbf{0 . 6 8}$ & $\mathbf{- 0 . 2 4}$ & -0.09 \\
& Environmentally aware & 0.40 & -0.01 & -0.09 \\
& Social-conscious & -0.19 & $\mathbf{0 . 1 2}$ & 0.03 \\
\hline
\end{tabular}

Note. In bold: significant estimates ( $p$-value $<0.05$ )

\subsection{Discussion}

In the past decade, several studies explored the attitude-behaviour relationship in transportation research. In the current study, we developed a latent transition model to examine the impact of temporal dynamics in attitudes on transport mode choice. Latent classes were based on traveller's attitudes towards car use and ownership. This study shows that traveller's profiles based on attitudes are very stable over time. Kroesen and Cranenburgh (2016) and de Haas et al. (2018) found lower probabilities for staying in the same class. However, these classes were based on the frequency of mode use and not, as in this study, attitudes. This suggests that attitudes are more stable over time than the frequency of mode use. One possible explanation for fewer observed changes in attitudes is that we used only two waves of data and these changes are difficult to measure in a relatively short period. When conditions change, there might be a possible delayed response of changes in travellers' attitudes.

Based on the literature, we expected transitioning to more car-oriented profiles to be positively associated with car use and transitioning to less car-oriented profiles negatively related to car use. For example, Kroesen (2014) found that switching from a 'multimodal' profile to a 'strictly car users' profile is significantly and positively related to the frequency of car use. However, in that study, latent classes were based on the frequency of mode use, which means that transitioning from one class to another has a direct relationship with the frequency of mode use. The results of the present study show that in most cases, there is no significant relationship between changes in attitudes and the frequency of car use. Although the outcome of several studies in other countries found indications of the opposite effect (Delbosc and Currie, 2013; Dutzik and Baxandall, 2013), the empirical results of our study are in line with earlier findings by Jorritsma and Berveling (2014) in the Netherlands, based on a one time survey among young adults. The fact that different attitudes towards car use and ownership did not directly affect the frequency of car use might reflect that people do not 
directly change their mode choice behaviour when they become more or less car-oriented, and travellers might postpone changes in the frequency of car use. A more logical explanation is that individuals who switch to a different class already show behaviours that fit in the class that they are moving to. This is confirmed by Kroesen et al. (2017), who found people are more likely to adjust their attitudes in such a way that it matches their behaviour. Also, Thøgersen (2006) found that travel mode choices are strongly influenced by habits, despite changes in personal beliefs and attitudes.

We identified different attitude-based segments, each segment existing of individuals with unique characteristics and behaviours. The identification of differences in attitudes towards car use and ownership between sub-groups, and stability in these attitudes, can help policymakers to develop specific policy strategies for these sub-groups. For example, to stimulate more sustainable modes of transport, policymakers could develop policy measures targeting "car minded" or "non-car minded" people after a life event (e.g. moving house, childbirth) when they are more likely to switch to less or more car-oriented profiles. However, this study also confirms that changing attitudes of car-minded travellers is very hard, considering their low chance of transitioning to less car-oriented profiles. Although we focus in the present study on the impact of changes in personal conditions, we know changing the attitude of die-hard drivers is also found to be difficult in practice with 'soft' measures or improvements of the quality of alternative modes. For example, stated preference and early adopter studies on mobility innovations, such as bike and car-sharing and mobility-as-aservice, typically find infrequent car users and multi-modal travellers as the most likely adopters (Burghard and Dütschke, 2019; Ho et al., 2018) and car-sharing to mainly replace a second or third car (Nijland et al., 2015). This means policymakers should make a wellinformed decision about the target group and suitable measures. However, as we found attitudes are very stable over time, it is still the question if policymakers should target on attitudes, behaviour or both? Testing interventions that focus on attitudes or behaviour can help to improve our understanding of temporal dynamics in attitudes and behaviour.

\subsection{Limitations and future research}

One of the limitations of this study is that we examined the attitude-behaviour relationship in one direction. Examining the reciprocal relationship between attitudes and behaviour requires the use of panel data. With panel data, attitudes and behaviour at time point 1 , can be explained by attitudes and behaviour at time point 0 and vice versa. There are a few examples of studies that examined this reciprocal relationship. Thøgersen (2006) developed a crosslagged panel model to explore the causal relationship between attitudes and public transport use and found several significant effects in both directions. (Kroesen et al., 2017) investigated the mutual relationship between attitudes and travel behaviour and concluded that travellers with a difference between their behaviour and attitude are more inclined to change their attitudes. Because our primary goal of interest was to identify travellers' profiles based on their attitudes towards car use and ownership, to examine switching behaviour between these latent profiles and the relationship with mode use, we focussed on the attitude-behaviour relationship. However, including the reciprocal relationship between attitudes and behaviour in this approach will enhance our understanding of the direction of causation, and therefore is an interesting topic for further research. 
Another limitation is that only two waves of data exist with the measurement of attitudes towards car use and ownership. An important direction for future research is to repeat the measurement of attitudes using the dedicated surveys analysis in future waves of the panel survey, for example, every two years. A longer period could provide more variation in changes in attitudes and mode use for different population segments over time, and both firstorder and second-order effects could be included. Similarly, a latent transition model can be implemented to analyse the impact of transport measures in the attitudes before and after the implementation. Bamberg et al. (2003) showed that interventions affect travel behaviour through changes in attitudes.

One of our research questions was to examine the impact of life events on changes between attitude-based segments. We did find that life events were significantly associated with transitioning between the four identified latent classes and that all profiles showed significantly more movers when life events coincide in the same year. However, we did not examine the impact of two specific related life events. For example, increased car ownership is more likely after a new job, except when household income reduces, and someone moves to an urban area at the same time. In future research, it will be interesting to examine such relationships and the impact of these interactions on attitudes and travel behaviour.

Furthermore, in our analysis, we used one type of attitudes (i.e. attitudes towards car use and ownership). Changes in other mode attitudes might also affect changes in travel behaviour, which can be explored as well. Also, a relative analysis of observable versus unobserved (latent) elements could be conducted. Finally, additional models can be developed that not only look at the impacts of changes in attitudes on mode choice but also on trip distance and kilometres driven. Overall, it can be said that there are some exciting topics for further research.

\subsection{Conclusions}

In this study, we examined the impact of changes in traveller's attitudes over time, and the effect of these changes on mode use, using panel data of 1,640 Dutch respondents from 2014 and 2016. Firstly, based on 16 different statements, we identified five factors reflecting travellers' attitudes towards car use and ownership. Secondly, we developed a latent transition model to investigate transitions between different population segments and used the five factors reflecting attitudes towards car use and ownership to identify these segments. Shifts to more and less car-oriented profiles were investigated, including the influence of life events on these changes. Thirdly, we examined the relationship between transitioning behaviour between the latent classes and changes in mode use.

One of the main conclusions of this study is that latent classes can be distinguished based on attitudes towards car use and ownership. And, these classes, which are related to socioeconomic profiles, influence the stability over time of both attitudes and behaviour. Furthermore, three specific conclusions can be derived from the results of this study.

Firstly, in our sample, we have identified four latent profiles: cost-sensitive, car-minded, environmentally aware and social-conscious. The four latent profiles represent clusters of travellers with different personal values about car use and ownership, while at the same time travel behaviour can be the same. Particularly, cost-sensitive and social-conscious travellers score differently on the five car attitude factors; however, they show a similar frequency of car use. 
Secondly, we examined changes in the latent profiles reflecting travellers' attitudes towards car use and ownership over time, which is not often done in the literature. The latent transition analysis revealed that most of the participants remained in the same class between 2014 and 2016. The probability of staying in the same class lies between $72 \%$ (social-conscious travellers) and $85 \%$ (cost-sensitive travellers).

Thirdly, we predicted observed changes in mode use by the estimated latent transition probabilities. The frequency of car use was not significantly affected by changes in travellers' attitudes towards car use and ownership, except for social-conscious travellers who transitioned to the car-minded class. 


\title{
4. Impact of life events on mode preference and mode use of young adults
}

This chapter is based on: Olde Kalter, M.J.T., La Paix Puello, L. \& Geurs, K.T. (2021). Exploring the relationship between life events, mode preferences and mode use of young adults: a 3-year cross-lagged panel analysis in the Netherlands. Travel Behaviour and Society, 24, 195-204.

\begin{abstract}
This study examines the impact of life events on transport mode preferences and the frequency of mode use of young adults in the Netherlands, using data from three waves (2014, 2015 and 2016) of the Netherlands Mobility Panel. The database used for this study contains 1,180 young adults (18-39 years) who participated in all three waves. Cross-lagged structural equation panel models were estimated to examine the longitudinal relationship between life events (childbirth, moving home or a new job) and travel behaviour. We investigated the relationship between frequency of mode use and mode preference over time, and the impact of life events on mode preference and frequency of mode use. Young adults showed very stable behaviour over time: frequency of mode use and mode preference are good predictors of frequency of mode use and mode preference in the future. The results show that changes in the frequency of mode use have a stronger effect on changes in mode preferences than vice versa. In addition, young adults subjected to life events are more likely to change travel behaviour. Car use and car preference are found to increase significantly after childbirth. Bicycle use and preference for the bicycle were more likely to increase for young adults who moved home. Changing jobs showed a negative association with bicycle use. These lifechanging moments could offer a window of opportunity for policymakers and other parties to create more awareness of alternative, more sustainable, modes of transport.
\end{abstract}




\subsection{Introduction}

Many governments across the globe try to achieve mode shifts from car use to public transport, cycling, and walking to reduce congestion and the environmental impacts of transport. In the development and implementation of policies and measures to facilitate these mode shifts, it is essential to understand when people consider changes in travel behaviour. People may change their daily routines, including their mode use, as they move through different stages of life (Bamberg and Schmidt, 2003). Major life events, such as moving home or getting a new job, may force changes in daily routines, also called the habit-discontinuity hypothesis (Verplanken et al., 1998). Several studies show that people are more often aware of possible changes in their behaviour when faced with these life events (e.g., Bamberg, 2006; Herde, 2007; Klockner, 2005). There is a clear link between the stress and tension caused by life events and changes in travel behaviour, either in the short- or long-term (Clark et al., 2016). Therefore, life events provide new opportunities for policymakers (Schäfer et al., 2012), for example providing alternative means of transport, and offering different mobility services on an individual level. These windows of opportunity provided by life events have also become the subject of many studies by travel behaviour researchers. Among them are several studies using the mobility biographies (or life course) approach (Müggenburg et al., 2015).

This study examines the influence of life events on mode preference and mode use of people aged between 18-39 years in the Netherlands. According to Erikson's stages of human development this group are referred to as "young adults" (Erikson, 1998). Data was used from the Netherlands Mobility Panel, the most extensive ongoing mobility panel in the world, to explore the causal directions between life events, sociodemographic factors, mode preference and mode use, and to examine whether life events are indeed triggers for changes in mode choice behaviour. (Kroesen et al., 2017) found there is a bi-directional relationship between mode use and the attitude towards using that mode between two time-points. In line with this study, we examine the relationship between mode use and attitude. However, the main objective of our research is to analyse the impact of life events on mode preference and frequency of mode use of young adults. Our focus was on young adults as they experience life events more frequently than other age groups. Furthermore, several studies have indicated that young adults in industrialised countries develop less car-oriented travel preferences (Delbosc and Currie, 2013; Kuhnimhof et al., 2012). However, these studies are mostly based on crosssectional data and do not take life events into account. In this study, we applied three-wave cross-lagged panel models to estimate the impact of life events and other travel behaviour related changes on mode preference and mode use of young adults simultaneously.

Although previous studies examined the impact of life events and an individual's preference of transport modes on travel behaviour (e.g., Chatterjee and Scheiner, 2015; Clark et al., 2016; Susilo et al., 2019; Zhang et al., 2014), most of these studies assume that mode preferences have not simultaneously changed during the life event. However, mode preferences may also change over time, and these changes may affect travel behaviour as well (Susilo et al., 2019). Furthermore, based on cognitive theory, we might expect that life events affect travel behaviour through influencing preferences (Andersen and Chen, 2002). Therefore, in this study, we aim to examine the bi-directional feedback effects between mode use and mode preferences over time, as well as the mediating effects of mode preference between life events and mode use, and mode use between life events and mode preference. 
We address the following two research questions:

1. How do life events affect mode preferences and mode use of young adults over time?

2. How do mode preferences of young adults mediate the effects of life events on mode use and vice versa?

The rest of this chapter is structured as follows. Section 4.2 reviews research on the relationship between life events, mode preference, and mode use and describes the contribution of this study. Section 4.3 comprises the methodology and theoretical framework used for modelling the relationship between life events, mode preference, and mode us. Section 4.4 describes the data and variables used, followed by the results of the analysis in section 4.5. Finally, section 4.6 discusses the results, describes policy implications, and makes recommendations for further research.

\subsection{Literature review}

In previous years, several studies have been undertaken to examine the impact of life events on travel behaviour and to improve our understanding of travel behaviour changes (Müggenburg et al., 2015). In this study, we focus on the relationship between life events, mode preference, and mode use.

\subsubsection{Life events, mode preferences and mode use}

In recent years, the impact of life events on travel behaviour has received increasing attention. Various studies reveal that important events in someone's life course can provide the trigger for changes in travel behaviour (e.g., Beige and Axhausen, 2006; de Haas et al., 2016; Lanzendorf, 2010). Previous research shows that life events such as the birth of a child, entering the labour market, moving home or changing jobs increase the chance of changing mode choice behaviour (e.g., Clark et al., 2016; Rau and Manton, 2015; Scheiner, 2016). Also, to understand the relationship between life events and mode choice behaviour, it is essential to have insight into the personal values and experiences regarding different transport modes. 'Personal values, feelings, preference and social norms mainly predict individual mode choices', as argued by Steg and Kalfs (2000). Mode preferences may also change over time, and these changes may also affect travel behaviour (Susilo et al., 2019). As mentioned before, cognitive theory might lead us to expect mode preferences to play a mediating role between life events and mode choice behaviour.

Janke and Handy (2019) found that having children, meeting a new partner, and residential relocation (to a bicycle-friendly community) changed bicycling behaviour and attitudes through a causal mechanism of social norms, latent demand and alteration of interests. Also, from previous research, we know there is a strong correlation between mode preference and frequency of mode choice (Harms et al., 2007). In general, people who use the car, public transport or bicycle are more likely to prefer these transport modes relative to less frequent users. Social and spatial differences, such as age and residential location, do not seem to impact their preferences (Olde Kalter et al., 2015). In a recent study, (Olde Kalter et al., 2020) showed that changes in attitudes towards the car did not significantly affect the frequency of mode use. However, younger adults turned out to show a more positive attitude towards the car after facing life events, such as moving home, starting a new job or the birth of a child. These results suggest that personal values and mode preferences play a mediating role between life events and mode choice behaviour. 


\subsubsection{Research gaps and the contribution made by our study}

Although the relationship between life events and changes in travel behaviour has been the subject of many studies, we need a better understanding of these changes because policy interventions may be more effective during times of transition (Thompson et al., 2011). Previous research showed that various life events increase the likelihood of behavioural changes, such as frequency of mode use, car ownership and commuting mode choice (e.g., Clark et al., 2014, 2016; Oakil et al., 2016b). However, there is little evidence on how changes in mode preferences affect travel behaviour at the time of life events. Moreover, there is also a lack of longitudinal studies examining these relationships in the Netherlands. Most longitudinal studies are conducted in Germany and Great Britain. Research from the Netherlands mostly used retrospective surveys (Oakil, 2014; Oakil et al., 2016b), longitudinal data from the eighties (Kroesen, 2014) or qualitative studies (Schwanen, 2011). The Netherlands is an interesting case study area to examine changes in mode preferences given the quality and role of alternatives to the car. In particular, the Netherlands is well known for good quality cycling and public transport infrastructure, and a significant portion of the Dutch population prefers cycling and/or public transport over the car as commuting mode (Olde Kalter et al., 2015).

This study aimed to contribute to filling this research gap. The start of the Netherlands Mobility Panel in 2013 has made longitudinal data available for the present Dutch situation, offering new opportunities to examine the relationship between life events and travel behaviour. Longitudinal modelling allows mode choice behaviour to be examined over time as well as testing the impact life events have on changes in mode preference and mode use, which is not possible with cross-sectional data (Burkholder and Harlow, 2003). Also, the availability of more than two time points allows us to model patterns of change over time (Liu, 2016) and to investigate the impact of life events on travel behaviour both at time $t+1$ and time t-1. Previous studies indicate the relevance of life events in understanding changes in travel behaviour. However, the direction of the relationship between life events and changes in mode preference and the frequency of mode use is not always clear and needs further investigation. Furthermore, it is obvious that life events may affect both mode preference and mode use simultaneously, whereas most studies consider only one of these measures. In our research, we assume that life events are exogenous. We do not examine the reciprocal relationship between life events and mode preference or mode use. Moreover, in this study, the relationship between life events, mode preference and mode use is explored separately for each transport mode (i.e. car, public transport and bicycle).

\subsection{Method}

We expected to find that mode preference in the past is a strong predictor for mode preference in the present situation. The same accounts for the frequency of mode use. However, we also expected people to adjust their mode preference as well as their frequency of mode use in response to life events. To examine whether these expectations were right, we developed a three-wave random-intercept cross-lagged panel model (RI-CLPM) for each transport mode separately, based on structural equation modelling (SEM). An important advantage of SEM above multivariate regressions is that within the SEM framework simultaneous equations are allowed. In panel analysis, it is essential to consider the correlation between repeated observations of the same individual (Zeger and Liang, 1992). For example, it is likely that variations in the frequency of mode use for the same individual will be less than the variation in the frequency of mode use for different individuals. Parameters' standard errors may be biased if this correlation is not included (Ghisletta and Spini, 2004). The traditional cross- 
lagged panel model (CLPM) does not consider this intrapersonal correlation. Within the RICLPM the scores of the variables of interest are split into two components: an interpersonal and an intrapersonal part (Hamaker et al., 2015).

Figure 4.1 shows our conceptual framework, and this model can be expressed as follows:

$x_{i t}=\mu_{t}+\kappa_{i}+\xi_{i t}$

$y_{i t}=\pi_{t}+\omega_{i}+\eta_{i t}$

with

$\xi_{i t}=\alpha_{t} \xi_{i, t-1}+\beta_{t} \eta_{i, t-1}+u_{i t}$

$\eta_{i t}=\delta_{t} \eta_{i, t-1}+\gamma_{t} \xi_{i, t-1}+v_{i t}$

where

$\mathrm{Xit}_{\mathrm{it}}=$ mode preference of individual $i$ at time $t$

$\mathrm{y}_{\mathrm{it}}=$ mode use of individual $i$ at time $t$

$\mu_{\mathrm{t}}$ and $\pi_{\mathrm{t}}$ are the temporal group means for mode preference and mode use $\kappa_{i}$ and $\omega_{i}$ are the individual's trait-like deviations from these means $\xi_{\text {it }}$ and $\eta_{\text {it }}$ are the individual temporal deviation terms

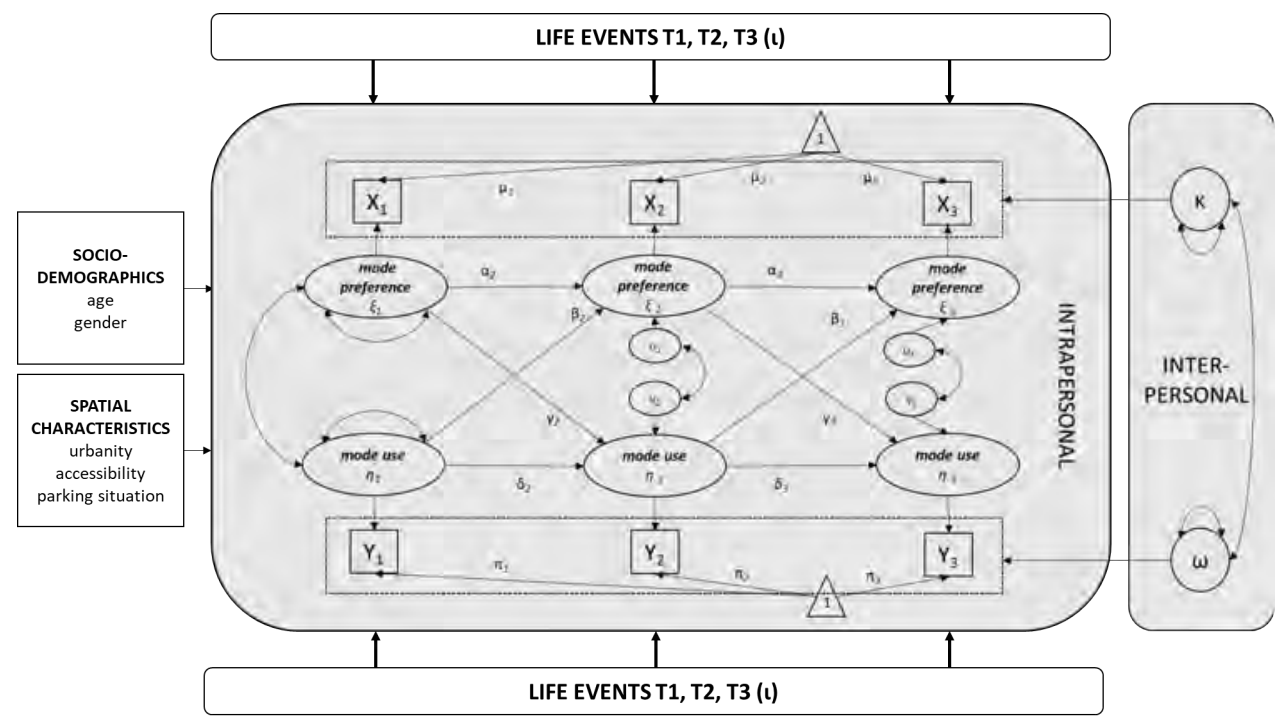

Figure 4.1 Random-intercept cross-lagged panel model. Triangles represent constants (which define the mean structure), rectangles represent observed variables, and circles represent latent constructs.

Within the model, a distinction is made between autoregressive ( $\alpha$ and $\delta$ ) and regression coefficients $(\beta$ and $\gamma)$. Autoregressive effects, also stability or inertia effects, represent the association between the values of the same variable at time t- 1 and time $t$ (e.g., Cherchi et al., 2013; Selig and Little, 2012; Yáñez et al., 2009). 
The autoregressive parameters in a RI-CLPM reveal the amount of intrapersonal carry-over (Hamaker, 2012; Kuppens et al., 2010). A positive autoregressive parameter means that people who use the car more frequently than their expected frequency of car use, are also likely in following years to use the car more frequently than expected. The regression coefficients represent cross-lagged effects or the effect of a variable at time t- 1 on another variable at time $t$. We assumed two directions of cross-lagged effects: the impact of mode preference on mode use over time and the impact of mode use on mode preference over time. An important feature of the model is that cross-lagged effects are controlled for previous levels of the dependent variable (Selig and Little, 2012). For example, mode preference at time $t+1$ can be predicted by the frequency of mode use at time $t$ while controlling for previous levels of mode preference at time $t$ (i.e., the stable portion). Life events (i.e. new job, moving home and birth of a child) affect mode use and mode preference both within and between waves (1). Furthermore, all relationships are controlled for possible confounding effects of sociodemographic and spatial characteristics at the baseline situation. The included variables were age, gender, urbanity, residential accessibility, and parking situation at home (see also section 4.4).

Within the RI-CLPM framework, it is possible to examine both the causal relation between several variables and the magnitude of change in behaviour under various conditions, distinguishing between- and within-person effects. The autoregressive effects and crosslagged relationships represent processes at the intrapersonal level over time. The correlation between the random-intercept factor for mode preference and mode use shows how young adults differ from each other, i.e. the interpersonal level.

\subsection{Data}

\subsubsection{Netherlands Mobility Panel}

To answer our research questions, we used data from the 2014, 2015 and 2016 waves of the Netherlands Mobility Panel (in Dutch: Mobiliteitspanel Nederland, MPN). The MPN is an annual online household panel, in which all household members aged 12 and over are asked to participate. The MPN consists of approximately 2,000 complete households and 6,000 individuals every year. For an elaborate description of the set-up of the MPN, see Hoogendoorn-Lanser et al. (2015). Respondents were randomly selected and recruited from an online access panel. The attrition rate between the waves lies between the 18 and $28 \%$ (La Paix Puello et al., 2017). Each wave, the sample is refreshed to retain a representative sample of the Dutch population.

The main objective of the MPN is to examine the short- and long-term dynamics in the travel behaviour of households and individuals. Another goal of the MPN is to gain more insight into the relationship between sociodemographic characteristics and individual changes in travel behaviour (Hoogendoorn-Lanser et al., 2015). Mobility-related and background information is collected through household and individual questionnaires. In addition, respondents are asked about changes in their work situation (e.g., changing job, changes in working hours, change of work location) and changes in their household situation (e.g., the birth of a child, start living together, moving home). This unique combination of information on life-changing moments and (changes in) travel behaviour enabled us to study the relationship between life events and mode choice behaviour. 


\subsubsection{Sample selection}

In our analysis, we examined whether young adults were more likely to change their mode preference and frequency of mode use when faced with a life event such as becoming a parent, moving home or changing jobs. According to existing research, these are the life events that appear to have the greatest impact on travel behaviour (e.g., Clark et al., 2014; Rau and Manton, 2016). The total MPN sample for 2014, 2015 and 2016 consists of 12,348 individuals, of which 3,900 participated in all three waves. From this group, we selected respondents aged between 18 and 39 in 2014 (i.e. young adults), because this age-group experiences the highest frequency of life events and it has been suggested that young adults are easier to influence than older people (Beige and Axhausen, 2012). Our final sample consisted of 1,180 respondents, who participated in 2014, 2015 as well as in 2016. To measure the variation in mode preference and mode use over time, while controlling for individual characteristics that do not change over time, only respondents who participated in 2014, 2015 and 2016 were included in the sample. Including only participants who responded to all three waves, might lead to attrition biases. However, for our main variables of interest, mode preference and frequency of mode use, we did not find any significant differences between participants who dropped out and those who participated in 2014, 2015 and 2016. This suggests there are no major attrition biases in our sample regarding mode preference and mode use. In La Paix Puello et al. (2017) more information can be found about the impact of non-random attrition in the MPN data on travel behaviour,

\subsubsection{Variable specification}

Mode preference and mode use

Every year participants of the MPN are asked about their preferred transport mode for eight different purposes (i.e. work, business, education, daily groceries, shopping, visiting family or friends, going out, recreational trips and sports activities). First, we calculated the number of times each mode was mentioned as the preferred mode. Mode preference for the car, public transport (PT), and the bicycle was derived as the ratio between this frequency and the total number of purposes that were scored, resulting in scores from 0 to 1 for each transport mode. Respondents could choose more than one preferred mode for each purpose. Young adults were more likely to select multiple modes compared to respondents aged 40 years and older. This might suggest that young adults are more flexible in terms of mode choice.

In the MPN survey, the frequency of mode use is measured in two ways. Firstly, respondents were asked to report their mode use on a seven-point ordinal scale ranging from "never" to "four or more days a week". Secondly, respondents reported the modes of trips made in a three-day trip diary. In this study, the self-reported frequency of mode was used in the analysis as less frequently used travel modes were underreported in the trip diary, for example, the use of public transport.

\section{Explanatory variables}

To control for time-invariant confounders, explanatory variables with meaningful differences in mode choice behaviour were included in the model. We will briefly discuss which explanatory variables we included in our analysis. Socio-economic characteristics at both individual and household level affect mode choice behaviour (e.g., Commins and Nolan, 2011; Feng et al., 2014; Vij et al., 2013). In our analysis, we included gender and age, based on the evidence that women are less likely to use the car and that increasing age is associated with increased car use and less public transport use (e.g., Paulssen et al., 2014). Built environment variables describing the characteristics of the spatial and transport infrastructure have a significant effect on mode choice decisions (e.g., Dieleman et al., 2002; Limtanakool 
et al., 2006; Rubin et al., 2014; Van Acker and Witlox, 2010). We enriched the MPN dataset with spatial characteristics of the residential location. Based on the zip code we included for every respondent the distance from home to public transport services, and the nearest highway exit. Following Hilbers et al. (2005), we derived a dichotomous variable describing whether an individual's residential neighbourhood is easily accessible by high-frequent public transport (1) or not (0) (i.e. A-location). An A-location means that the distance to a large (intercity) railway station is less than 3 kilometres. In the Netherlands, intercity stations are located in central urban areas where land use is dominated by offices and shops. This explains the relatively low share of people that live here. Also, we controlled for urban density (reference $=$ urban, i.e. $>1500$ inhabitants $/ \mathrm{km} 2)$ and paid parking or not (reference $=$ no costs or permit necessary).

\section{Life events}

For each life event, we created a binary variable according to whether the life event occurred in 2014, 2015, 2016 (1) or not (0). It is possible that life events coincide, for instance moving home often coincides with a change in household structure. Although the sample size is very small for these inter-relationships, there are some significant associations between life events for young adults (Table 4.1). Young adults are more likely to move home either before or after starting a new job. However, the effect sizes, which measures how strongly two life events are associated, are very small (Cramer's $\mathrm{V}<0,10^{6}$ ), implying that there is a low association (Cohen, 1988). Therefore, we only included the impact of a single life event on mode choice behaviour ${ }^{7}$.

Table 4.1 Significance test for coinciding life events, Pearson Chi Square values $\left(\chi^{2}\right)$ and Cramer's V

\begin{tabular}{|c|c|c|c|c|c|c|c|}
\hline \multirow[t]{2}{*}{ life event } & \multirow[t]{2}{*}{ Time } & \multicolumn{2}{|c|}{ t1 } & \multicolumn{2}{|c|}{ t2 } & \multicolumn{2}{|c|}{ t3 } \\
\hline & & $\chi^{2}$ & $\mathbf{V}$ & $\chi^{2}$ & $\mathbf{V}$ & $\chi^{2}$ & $\mathbf{V}$ \\
\hline & & \multicolumn{6}{|c|}{ Birth of a child } \\
\hline New job & $\mathrm{t} 1$ & 0.525 & 0.021 & 0.393 & 0.018 & 0.459 & 0.020 \\
\hline New job & $\mathrm{t} 2$ & 0.540 & 0.021 & 2.516 & 0.046 & 0.042 & 0.006 \\
\hline \multirow[t]{2}{*}{ New job } & $\mathrm{t} 3$ & 0.252 & 0.015 & 2.584 & 0.047 & 2.794 & 0.053 \\
\hline & & \multicolumn{6}{|c|}{ Moving home } \\
\hline Birth of a child & $\mathrm{t} 1$ & 3.043 & 0.051 & 1.035 & 0.030 & 1.316 & 0.033 \\
\hline Birth of a child & $\mathrm{t} 2$ & 0.000 & 0.000 & 3.488 & 0.054 & 0.076 & 0.008 \\
\hline \multirow[t]{2}{*}{ Birth of a child } & $\mathrm{t} 3$ & 0.184 & 0.013 & 1.906 & 0.040 & 0.158 & 0.012 \\
\hline & & \multicolumn{6}{|c|}{ New job } \\
\hline Moving home & $\mathrm{t} 1$ & 2.897 & 0.050 & $6.518^{*}$ & 0.074 & 1.408 & 0.035 \\
\hline Moving home & $\mathrm{t} 2$ & 1.925 & 0.040 & $12.847^{*}$ & 0.098 & 2.934 & 0.050 \\
\hline Moving home & $\mathrm{t} 3$ & $4.881 *$ & 0.064 & $10.099 *$ & 0.093 & 3.106 & 0.051 \\
\hline
\end{tabular}

Note: * association is significant at the 0.05 level

\subsubsection{Sample description}

Table 4.2 presents descriptive statistics for mode preference and mode use regarding the included variables for young adults at the baseline situation in 2014. Young adults who had a high car preference and who were frequent car users were more likely to be male, live in rural

\footnotetext{
${ }^{6}$ Cramers V is an effect size measurement for the chi-square test of independence

${ }^{7}$ Other life-events, such as marriage / start living together might be important life changing moments for young adults. The main reason for not including marriage is that it is not measured directly with the MPN and cannot be derived from other variables.
} 
areas, and to be 30 to 39 years old (in comparison to the 18 to 29 age group). Young adults who were frequent public transport users had a greater tendency to be 18 to 29 years old, live in single families, urban areas and at A-locations (i.e. nearby public transport). Young adults who preferred cycling and were frequent bicycle users appeared more likely to be women with a high level of education and to live in urban areas. Compared to the Dutch population of young adults in $2014^{8}$, female and people living in rural areas are somewhat underrepresented. Overall, our sample is a good representation of the Dutch young adult population.

Table 4.2 Sample characteristics of young adults in $2014(\mathrm{~N}=1,180)$

\begin{tabular}{|c|c|c|c|c|c|c|c|c|c|}
\hline & & \multirow{2}{*}{$\begin{array}{c}\text { Sample } \\
2014 \\
\end{array}$} & \multirow{2}{*}{\begin{tabular}{|l|} 
Pop. \\
2014 \\
\end{tabular}} & \multicolumn{3}{|c|}{$\begin{array}{l}\text { Mode preference } \\
\text { (mean score) }\end{array}$} & \multicolumn{3}{|c|}{$\begin{array}{c}\text { Mode use } \\
\text { (\% weekly users) }\end{array}$} \\
\hline & & & & car & PT & bicycle & car & PT & bicycle \\
\hline \multirow[t]{2}{*}{ Gender } & Male & $42 \%$ & $47 \%$ & 0.56 & 0.13 & 0.37 & 79 & 32 & 67 \\
\hline & Female & $58 \%$ & $53 \%$ & 0.49 & 0.17 & 0.43 & 72 & 35 & 75 \\
\hline \multirow[t]{2}{*}{ Age group } & $18-29$ yrs. & $59 \%$ & $57 \%$ & 0.45 & 0.18 & 0.45 & 69 & 46 & 78 \\
\hline & 30-39 yrs. & $41 \%$ & $43 \%$ & 0.62 & 0.10 & 0.34 & 83 & 16 & 63 \\
\hline \multirow{2}{*}{$\begin{array}{l}\text { Urban density home } \\
\text { location (inhab } / \mathrm{km}^{2} \text { ) }\end{array}$} & Urban $(>1,500)$ & $51 \%$ & $57 \%$ & 0.41 & 0.19 & 0.46 & 64 & 40 & 77 \\
\hline & Rural $(\leq 1,500)$ & $49 \%$ & $43 \%$ & 0.63 & 0.11 & 0.34 & 86 & 28 & 67 \\
\hline \multirow{2}{*}{$\begin{array}{l}\text { Paid parking or not at } \\
\text { home location }\end{array}$} & Costs or pern & $86 \%$ & $87 \%$ & 0.56 & 0.15 & 0.39 & 79 & 31 & 71 \\
\hline & No costs or permit & $14 \%$ & $13 \%$ & 0.28 & 0.17 & 0.51 & 50 & 50 & 78 \\
\hline \multirow{2}{*}{$\begin{array}{l}\text { Accessibility home } \\
\text { location }\end{array}$} & No A-location & $95 \%$ & $95 \%$ & 0.53 & 0.15 & 0.39 & 76 & 33 & 71 \\
\hline & A-location & $5 \%$ & $5 \%$ & 0.26 & 0.18 & 0.50 & 57 & 46 & 79 \\
\hline
\end{tabular}

Table 4.3 shows the frequency of life events in our sample and Figure 4.2 the frequency of the three selected life-events by age. Each year, about 12 to $13 \%$ of the young adults moved home and 7 to $9 \%$ became parents. In 2014, 14\% of the respondents found a new job, in 2015 and 2016 this was $19 \%$. Previous research showed that changes in travel behaviour are more likely when people move from urban to non-urban areas or vice versa (e.g., Scheiner and Holz-Rau, 2013). However, in our sample only a small number (i.e. 15-17 in the years 2014 to 2016) moved home to a neighbourhood with a very different urban density. Therefore, we did not make this distinction in our analysis.

New jobs were most prevalent at the age of 25-29 years, after finishing school. Childbirth peaks in the early $30 \mathrm{~s}$, while moving home seems to have a double peak. The first one at 2529 years, also after finishing school, and the second one at 40-44 years, possibly linked to increasing family size and needing a bigger home some years later.

Table 4.3 Frequency of life events of young adults $(\mathrm{N}=1,180)$

\begin{tabular}{llll}
\hline & $\mathbf{2 0 1 4}$ & $\mathbf{2 0 1 5}$ & $\mathbf{2 0 1 6}$ \\
\hline Moving home & $13 \%$ & $12 \%$ & $12 \%$ \\
birth of child & $9 \%$ & $9 \%$ & $7 \%$ \\
New job & $14 \%$ & $19 \%$ & $19 \%$ \\
\hline
\end{tabular}

\footnotetext{
${ }^{8}$ Data from Statistics Netherlands for 2014 (CBS, 2014)
} 


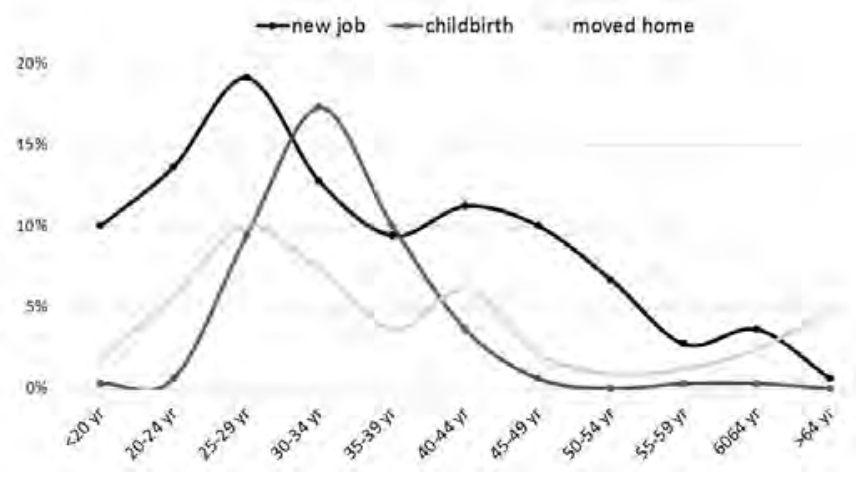

Figure 4.2 Frequency of life events by age (Source: MPN)

Table 4.4 shows the level of change of frequency of mode use and mode preference for all purposes between the waves. The share of respondents that did not change frequency of mode use varies between 50 and $70 \%$. Car users were the most stable group in terms of the frequency of mode use. Furthermore, almost half of the respondents did not change their preference for public transport, while car and bicycle preference show more dynamics. There are no significant differences in the level of change of frequency of mode use and mode preference between the waves.

Table 4.4 Level of change in frequency of mode use and mode preference between waves of young adults $(\mathrm{N}=1,180)$

\begin{tabular}{lllllll}
\hline & car use & \multicolumn{3}{c}{ PT use } & bicycle use \\
\hline Frequency of mode use & $\mathbf{2 0 1 4 - 2 0 1 5}$ & $\mathbf{2 0 1 5 - 2 0 1 6}$ & $\mathbf{2 0 1 4 - 2 0 1 5}$ & $\mathbf{2 0 1 5 - 2 0 1 6}$ & $\mathbf{2 0 1 4 - 2 0 1 5}$ & $\mathbf{2 0 1 5 - 2 0 1 6}$ \\
\hline Decrease & $14 \%$ & $14 \%$ & $22 \%$ & $19 \%$ & $24 \%$ & $22 \%$ \\
No change & $69 \%$ & $70 \%$ & $51 \%$ & $53 \%$ & $60 \%$ & $59 \%$ \\
Increase & $17 \%$ & $16 \%$ & $27 \%$ & $28 \%$ & $16 \%$ & $19 \%$ \\
\hline \multicolumn{2}{l}{ car preference } & \multicolumn{2}{c}{ PT preference } & \multicolumn{2}{c}{ bicycle preference } \\
\hline$<50 \%$ decrease & $2 \%$ & $2 \%$ & $1 \%$ & $2 \%$ & $4 \%$ & $2 \%$ \\
1 to 50\% decrease & $27 \%$ & $28 \%$ & $26 \%$ & $24 \%$ & $36 \%$ & $36 \%$ \\
no change & $33 \%$ & $35 \%$ & $50 \%$ & $53 \%$ & $28 \%$ & $28 \%$ \\
1 to 50\% increase & $36 \%$ & $33 \%$ & $22 \%$ & $21 \%$ & $31 \%$ & $32 \%$ \\
$>50 \%$ increase & $3 \%$ & $3 \%$ & $1 \%$ & $0 \%$ & $1 \%$ & $2 \%$ \\
\hline
\end{tabular}




\subsection{Results}

A separate SEM is estimated to explain frequency of mode use and mode preference for each of the three modes considered: car, public transport and bicycle. Final models were constructed by model trimming: we removed non-significant structural paths to find the most parsimonious model. For evaluation of model fit, we used the following three model fit indices, mostly used in structural equation modelling: Comparative Fit Index (CFI), Root Mean Square Error of Approximation (RMSEA), and (Standardized) Root Mean squared Residual ((S)RMR). For each goodness of fit indicator, we applied the cut-off criteria from $\mathrm{Hu}$ and Bentler (1999), which is shown in Table 4.5. To perform the analyses, we used the software program R and the package LAVAAN (Rosseel, 2012). As we can observe, the three models satisfy the minimum fit to be considered a valid model.

Table 4.5 Summary of fit indices

\begin{tabular}{lcrr}
\hline & CFI1 & RMSEA & (S)RMR \\
\hline RI-CLPM - CAR & 0.958 & 0.054 & 0.035 \\
RI-CLPM - PT & 0.971 & 0.046 & 0.044 \\
RI-CLPM - BICYCLE & 0.978 & 0.037 & 0.034 \\
Criteria for good model fit & $>0.95$ & $<0.06$ & $<0.08$ \\
\hline
\end{tabular}

In this section, we firstly present and discuss the model results of the interpersonal correlations $\left(\kappa^{*} \omega\right)$ and intrapersonal correlations $\left(\xi^{*} \eta\right)$ (section 4.5.1), the autoregressive $(\alpha$ and $\delta$ ) and cross-lagged effects $(\beta$ and $\gamma$ ) between mode preference and mode use (section 4.5.2). Secondly, we describe the impact of life events on mode use and mode preference ( 1 ) for each transport mode (section 4.5.3). The coefficients i provide evidence of the relationship between life events and mode preference and mode use (research question 1), while the interpersonal correlations, autoregressive and cross-lagged effects provide evidence of the mediating effects of mode preference and mode use (research question 2). To examine the difference between the inter- and intrapersonal dynamics and the impact of life events on the frequency of mode use and mode preference, the results were split across the tables 4.6 and 4.7. This prevents different effects are mixed up. Table 4.6 and 4.7 presents the standardized effects (ß), which are indicators of effect size. In a RI-CLPM parameters reflect how intrapersonal variations relative to their own scores are correlated or can be predicted. The significance of the estimated parameters is based on the t-statistic.

\subsubsection{Inter- and intrapersonal correlations}

The interpersonal correlation between the random-intercept factors shows how stable between-person differences in mode preference are associated with between-person differences in frequency of mode use (Table 4.6). The interpersonal correlation between car preference and car use was very high $(\beta=0.731, \mathrm{p}<.001)$. This indicates that young adults who reported a higher preference for the car over time are more likely to use the car more frequently over time than other young adults. Also, young adults who have a higher preference for the bicycle across the three waves tend to be more frequent bicycle users over time ( $\beta=0.727, p<.001)$. No significant interpersonal correlation between mode use and mode preference was found for public transport. This means that more frequent public transport users do not necessarily have a higher preference for public transport than other young adults across the three waves, or vice versa. The positive intrapersonal correlations for all transport modes reflect that at the personal level, an above-average score of the frequency of mode use at time $t$ goes hand-in-hand with an above-average score of mode preference at time $t$, in addition to the interpersonal correlation. 


\subsubsection{Autoregressive and cross-lagged effects}

The estimated standardized parameters for the autoregressive and cross-lagged effects represent intrapersonal dynamics. The autoregressive effects $(\alpha$ and $\delta)$ for mode preference and frequency of mode use were all significant and positive $(\mathrm{p}<0.05)$. For example, the estimated parameter for the effect of car preference in 2014 on car preference in 2015 was 0.528 and for bicycle use in 2015 on bicycle use in 20160.369 (see table 4.6). Positive estimates reflect that at the individual level above average scores at time $t$ imply aboveaverage scores at time $t+1$. Generally, the autoregressive effects were also the largest in the model. This means that mode use at time $t$ is the best predictor for mode use at time $t+1$, and mode preference at time $t$ is the best predictor for mode preference at time $t+1$. Regarding mode preference, the strongest autoregressive effects were found for public transport $(\beta=0.811$ and $\beta=0.768$, both $\mathrm{p}<0.00)$. For the car, the stability effects were stronger for mode preference $(\beta=0.528$ and $\beta=0.569$, both $p<0.00)$ compared to the frequency of mode use $(\beta=0.251$ and $\beta=0.230$, both $p<0.00)$. For public transport and the bicycle, the opposite effect was found: the stability effects were stronger for frequency of mode use compared to mode preference. This suggests that for both public transport and the bicycle, frequency of mode use is more likely to stay more stable than mode preference.

Also, the results show that cross-lagged effects ( $($ and $\gamma$ ) between frequency of mode use and mode preference in a prior period (and vice versa) were weaker compared to stability effects, and not significant for all relationships. For instance, the effect of car preference in 2015 on car preference in $2016(\beta=0.569)$ was 4.2 times higher than the effect of car use in 2015 on car preference in $2016(\beta=0.136)$. This means that habit and inertia effects have a stronger influence on mode preference than changes in mode use or vice versa. Frequency of mode use shows a significant and positive regression on all later measures of mode preference, except for the prediction of the preference for cycling in $2016(\beta=0.033, p>0.10)$. The frequency of public transport use had the largest positive effect on mode preference for that mode in the next year $(\beta=0.412$ in 2014 and $\beta=0.463$ in 2015 , both $p<0.00)$. This indicates that when the frequency of public transport use of young adults was higher than expected at time $t$ (based on his or her average score over time), these young adults also have a higher preference for public transport at time $\mathrm{t}+1$. However, there were no significant cross-lagged effects between mode preference and mode use for public transport across the waves. This means that, after an increase in mode use, young adults develop a stronger preference for public transport over time, whereas an increase in mode preference does not necessarily lead to an increase in the frequency of public transport use. The baseline socio-demographics and spatial characteristics significantly affected the frequency of car use and preference for the car. Young adults aged 30-39 years and those living in rural areas were more likely to use the car more frequently, whereas female respondents and those having no free parking space at home or good access to public transport services were more likely to use the car infrequently. For public transport and the bicycle, a negative association was found between increasing age and those living in rural areas and mode preference. 


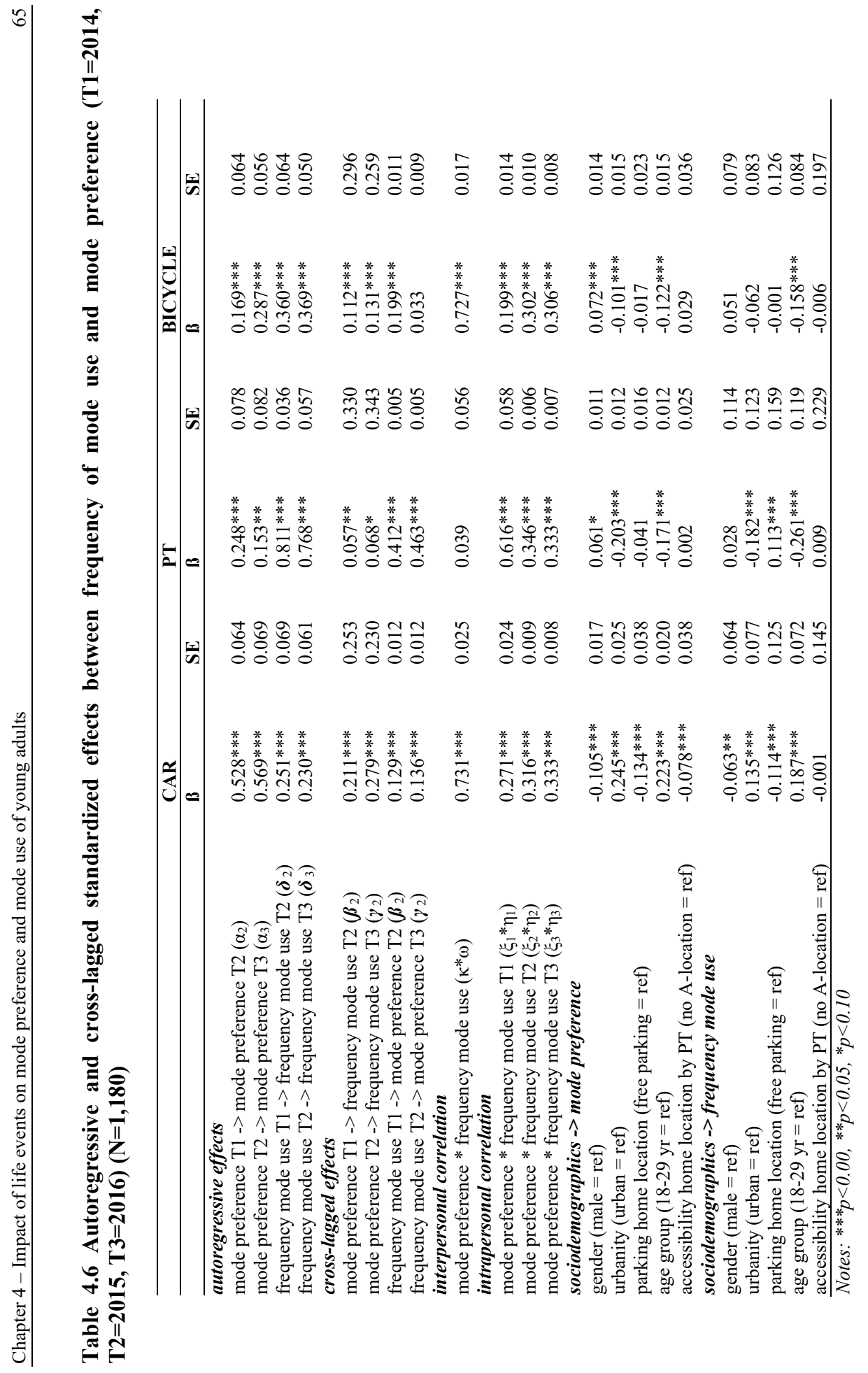




\subsubsection{Impact of life events on mode preference and frequency of mode use}

We now discuss the impact of life events, both within and between waves, on mode use and mode preference for each transport mode (1). We found a positive and significant association between childbirth and car preference and the frequency of car use (table 4.7). Parents became more car-minded, both after the birth of a child and in anticipation of this life-changing moment. Between moving home and car preference we found a negative association, although there was no significant relationship between moving home and the frequency of car use. Young adults with a new job showed less preference for public transport across all waves, although this did not result in a significant change in the frequency of mode use. Young adults with a new job show a lower frequency of bicycle use in all three waves, although not all coefficients were significant at the 0.05 -level. Movers developed a more positive attitude towards cycling over time and were more likely to use the bicycle more often. In general, the birth of a child seemed to have the greatest effect on mode preference and the frequency of mode use. Young parents use the car more frequently and develop a less positive attitude towards public transport and cycling. Furthermore, movers intend to cycle more often, while young adults with a new job were less likely to prefer public transport.

\subsection{Discussion and implications}

\subsubsection{Discussion}

Based on the literature, we expected past behaviour to be a good predictor of current behaviour. For example, Thøgersen (2006) addressed the question of stability in travel behaviour and found that past behaviour is the main predictor of ongoing behaviour. The results of the present study confirm these findings. Young adults showed very stable behaviour regarding mode preference and frequency of mode use. For the car, stability in car preference is more than two times higher than stability in the frequency of mode use. This corresponds with the finding of Olde Kalter et al. (2020), who found that traveller's profiles based on attitudes towards the car were remarkably stable over time. However, based on existing research, it can be argued that this is not solely a stable attitude towards the car, but might also be the case for multimodal preferences (de Haas et al., 2018; Kroesen and Cranenburgh, 2016). The stability effects of frequency of mode use found in this study are two (for bicycle) or three (for public transport) times higher compared to stability effects of mode preference. This suggests that young adults are more likely to change their preference towards public transport and cycling then their frequency of public transport or bicycle use. Besides stability effects, previous research on mode choice behaviour showed that there is a strong relationship between mode preference and mode use (e.g., Bjerkan and Nordtømme, 2014; Buehler, 2011; Olde Kalter et al., 2015). In our three-wave panel study, we found that after an increase in mode use over time, young adults develop a stronger preference for that mode. In contrast, an increase in mode preference does not necessarily lead to an increase in the frequency of mode use. This implies changes in travel behaviour are more likely to precede changes in preferences rather than the other way around, e.g. young adults who start using the car more frequently are more likely to show stronger car preferences later on. This process can be explained by the cognitive dissonance reduction theory, as discussed by Kroesen et al. (2017) who found similar effects in a two-wave panel study for the Netherlands and indicates that a dynamic Theory of Planned Behaviour should include a feedback loop from behaviour to preference. 


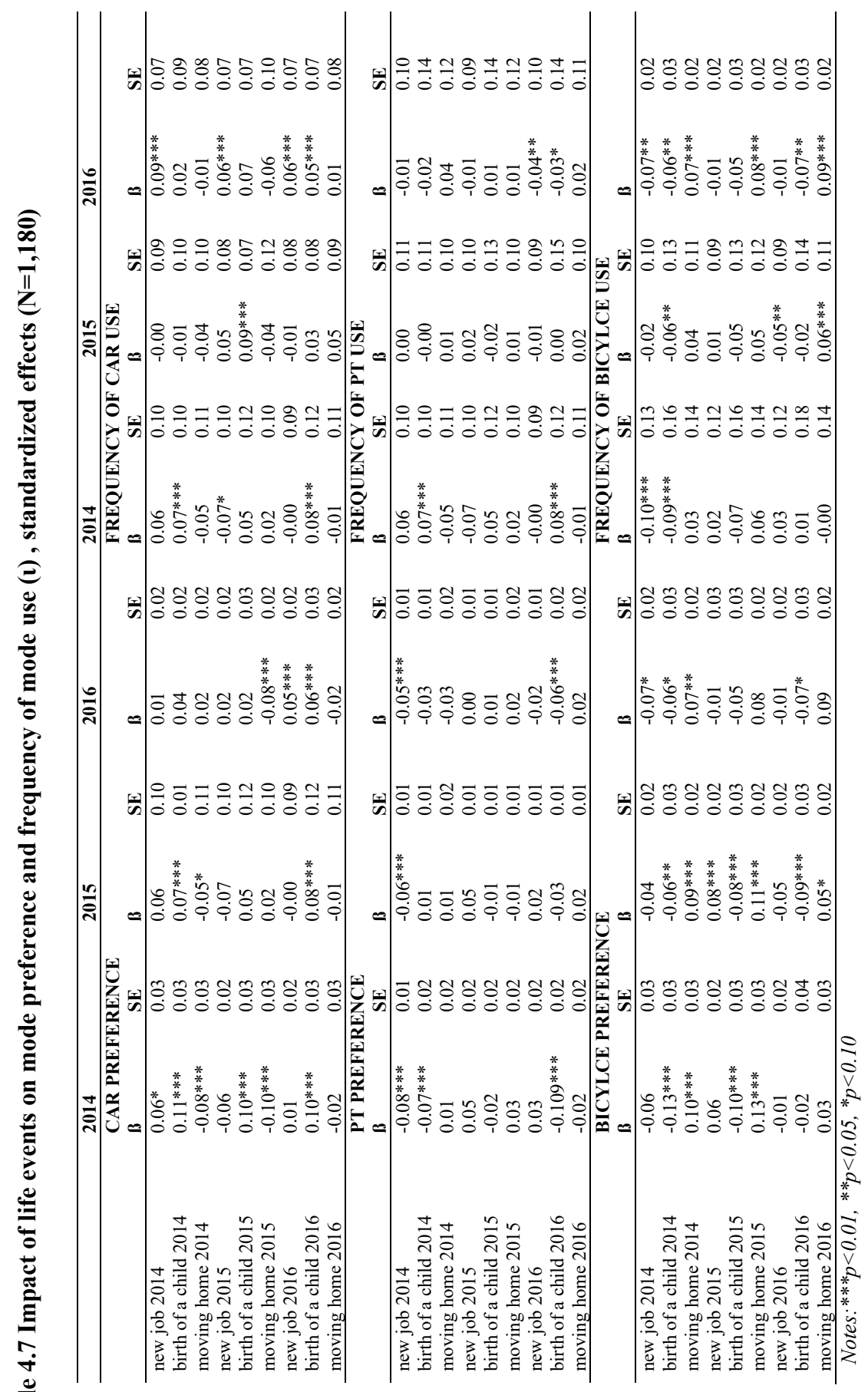


The results of this study highlight the importance of considering the impact of life events when examining changes in the travel behaviour of young adults. Young adults showed fixed habits regarding mode use and mode preference. However, life events act as a trigger for changes and affect both the travel behaviour and attitudes of young adults. This finding implies that a change in frequency of mode use is not only because of a change in attitude towards the car, public transport or bicycle or vice versa but also directly related to life events. The impact of life events on changes in the frequency of mode use and mode preference depends on the type of life event. In particular, car use among Dutch young adults increased significantly after the birth of a child. In addition, there is a significant positive relationship with a higher car preference. This means that young adults with above average scores for car preference at time t, are more likely to have an above average score for car preference a year later, after the birth of a child. At the same time, we found a negative association between the birth of a child and the use of public transport and the bicycle. This result is consistent with other studies about the inertia effects of car use that show car users as the most inert travellers (González et al., 2017). Moving home increased both the frequency of cycling and preference for the bicycle. This is in line with Janke and Handy (2019). Young adults with a new job showed less preference for public transport across all waves, although this did not result in a significant change in the frequency of the use of this transport mode.

\subsubsection{Policy implications}

Overall, this study provides more insight into the impact of life events on travel behaviour and indicates that policymakers can make use of life events as windows of opportunity. However, we know that developing interventions and implementation are not simple. Considering life events and lifestyle changes might help to establish more accurate policy scenarios. A contextual change in someone's life is an essential pre-condition for increasing the effectiveness of policy measures. Policy interventions can be more effective when centred around the three life events we studied in this study (i.e. a new job, moving home and the birth of a child). Policymakers who want to utilise these life events to influence behaviour should primarily focus on three points: the target group, timing, and the parties that, in addition to the government, can make relevant contributions.

As a result, this study identifies three main policy recommendations. Firstly, policymakers need a clear understanding of the target group. An intervention should be designed in such a way that the highest possible effect will be achieved in the selected target group. This means that interventions should match people's motives and specific interests. For example, young parents are probably more interested in safety and comfort whilst travelling. In contrast, the accessibility of residential and work locations may be more critical mobility-related issues for those who are looking for a new home. In this respect, it is worth mentioning that life events are strongly associated with social and cultural aspects. In cultures in which companies offer new employees a lease car by default, public transport is not an equal alternative. When applying policy interventions, it is essential to keep such social and cultural preferences in mind (Schwanen et al., 2012). Secondly, policymakers should take note of and, if possible, involve relevant stakeholders, such as employers, land register and midwives or consultancy agencies. In-depth interviews with young adults in the Netherlands reveal that young adults hardly receive any information about transport-related issues when they are about to relocate, change jobs or become a parent (Berveling et al., 2017). These life-changing moments could offer an excellent opportunity for policymakers and other parties to create more awareness of alternative, more sustainable, modes of transport. Thirdly, the timing and duration of policy measures are crucial aspects of implementation in order to achieve structural changes in travel behaviour. Policymakers should focus on the actions that cope with the new deliberation 
process brought by the life-event changes. This deliberation process can be anticipated by the individual and household characteristics of the target groups, such as income level, the urbanity of the residential location, gender, composition of the household. or first job age. A common mobility strategy in the Netherlands is stimulating cycling among employees. National fiscal regulations are available which allow employees to purchase new bicycles at reduced costs, and pilots are conducted to give employees the opportunity to test e-bikes. These measures could be targeted towards new employees.

\subsubsection{Research implications}

There are several possible directions for further research. Some life events coincide, which results in compounded effects. For illustration, increased car ownership is more likely after a new job or when someone moves from an urban to a rural area. It would be interesting to examine in which way these interactions affect travel behaviour. Also, it would be interesting to disentangle the effects of moving between urban and rural areas and moving within the same area. Based on existing research, we might expect that, for example, car use or car preference would decrease after moving from rural areas to more urban areas. Moving to a more urban area could explain the increase in cycling after moving home we found. However, in our sample, only a relatively small portion (i.e. less than 3\%) moved to a different area, and consequently, it was not possible to estimate these effects. Another potential avenue for further research concerns the relationship between life events at the level of the individual and travel behaviour on the household level, as well as the difference between short-term and long-term effects. Generally, the short-term effects of life events on travel behaviour are higher than long-term outcomes. In particular, gender differences and (short- and long-term) effects of childbirth are interesting to explore. Shortly after becoming parents, young adults spend more time at home and at activities in their neighbourhood, resulting in less trips and car use. After a certain period, for example, when parents return to work, preference for the car might increase. Also, the difference between first-time parents and other parents is an exciting direction of future research. As a result of limitations in our dataset, we were not able to make these distinctions. When more waves of the MPN become available, both first-order and second-order effects could be included. Part of the stability effects we found for mode preference, might be a result of the direct way of measuring mode preference. However, mode preference might be a function of different underlying attitudes. Including other attitudinal variables would be interesting to explore the variation in mode preferences over time more thoroughly. Finally, one of the limitations of this study is that we examined the causal relationship between mode preference and the frequency of mode use over time. We examined the impact of one variable at time $t$ on the other variable at time $t+1$. The lead effects between mode preferences and mode choice behaviour (i.e. the impact of one variable at time $t$ on the other variable at time $t-1)$ should be further analysed.

\subsection{Conclusions}

In this study, we examined the relationship between life events, mode preference and frequency of mode use over time for young adults in the Netherlands. We found that young adults show very stable behaviour over time: those who use the car, public transport or bicycle at an above average level, are more likely to use these transport modes at an above average level across the waves. Frequent car users are the most stable in their behaviour, compared to public transport and bicycle users. Concerning the relationship between mode preference and mode use, one of the main conclusions of this study is that young adults who increase the use of the car, public transport or the bicycle are more likely to develop a more positive attitude towards this mode. Changes in mode preference seem to have less influence 
on the frequency of mode use, in particular for public transport users. Furthermore, the results of this study show the impact of three different life events (the birth of a child, getting a new job and moving home) on changes in travel behaviour and mode preference. Young adults who become parents show an increase in car use and develop a higher preference for the car over time. Public transport and the bicycle are less popular after the birth of a child. Moving home and changing jobs mainly affects cycling, both the frequency of use and preference, although these effects are not significant at all temporal scopes (i.e. first year or second year of event). This can be associated with the substantial role played by the urban characteristics and accessibility of public transport. 


\title{
5. Impact of COVID-19 on commuting behaviour
}

This chapter is based on: Olde Kalter, M.J.T., Geurs, K.T. \& Wismans, L.W.J. (2021). Post COVID-19 teleworking and car use intentions. Evidence from large scale GPS-tracking and survey data in the Netherlands. Submitted for publication in Transportation Interdisciplinary Perspectives $\left(2^{\text {nd }}\right.$ review round)

\begin{abstract}
This study examines the changes in teleworking during the lockdown in April 2020 and the intention to change commuting behaviour after COVID-19 in the Netherlands. Survey data of 1,515 Dutch employees and large-scale smartphone-based GPS-data of the same participants before and during COVID-19 is used. The probability of increasing teleworking during COVID-19 is estimated using an ordinal logistic regression model, considering sociodemographic characteristics, the initial travel behaviour and the initial work situation as determining factors. Two binary logistic regression models are developed to analyse whether employees expect to continue teleworking after the COVID-19 pandemic and whether they will decrease car use for commuting. Both models consider teleworking and car use intentions in the context of behavioural changes during COVID-19. The main factors that influenced teleworking during the lockdown are job characteristics. Office workers and teaching staff were more likely to increase the amount of time spent working from home and showed a higher chance of changes in daily commuting routines. After COVID-19, office workers expect to increase teleworking. The results suggest that employees with a relatively large change in teleworking during the early lockdown expect to work from home more frequently after COVID-19. This effect is strengthened further by positive experiences with teleworking (i.e. more pleasure and higher productivity) and supporting policy measures by the employer, such as sufficient ICT facilities. The main conclusion related to intended changes in mode choice is that car use for commuting is expected to decrease after COVID-19, mostly because of an increase in teleworking.
\end{abstract}




\subsection{Introduction}

The COVID-19 virus outbreak at the beginning of 2020 had massive impacts on societies in Europe and elsewhere across the globe. In the Netherlands, the Dutch government announced in the early stage of the pandemic a lockdown. All schools, universities, libraries, pubs, barbershops and hairdressers, museums, cinemas, and restaurants had to be closed, and the government cancelled sports competitions, festivals, and major events. Everyone was advised to keep 1,5-meter distance from each other and not to travel to other countries unless strictly necessary. People were asked to stay at home as much as possible and, whenever possible, to work from home or to telework9. Teleworking was seen as an essential measure to reduce daily travel and, consequently, to reduce the further spread of the virus. There was also a request to minimise the use of public transport. These measures strongly reduced travel options. The impact of COVID-19 on travel behaviour has been the subject of much research recently and mainly consists of analyses of observed changes during the pandemic (e.g., Abdullah et al., 2020; de Haas et al., 2020; Irawan et al., 2021; Molloy et al., 2021; Rauws and Lierop, 2020; Shakibaei et al., 2021; Shamshiripour et al., 2020). In the Netherlands, the number of trips, distance travelled, and mode choice changed considerably (e.g., van der Drift et al., 2021). Teleworking contributed substantially to strongly reduced commuting flows by car and public transport in the first few weeks of the lockdown, reducing traffic congestion by more than $90 \%$ and resulting in empty trains during peak hours (e.g., van der Drift et al, 2021; Taale and Turpijn, 2020).

In recent years, the impact of teleworking on travel behaviour or the factors that influence teleworking have received increasing attention. Teleworking is considered as an effective policy measure to reduce commuting trips and hence a positive contribution to reducing congestion and the negative externalities of transportation (Helminen and Ristimäki, 2007; O'Keefe et al., 2016; Shabanpour et al., 2018). In most industrialised countries, including the Netherlands, teleworking strongly increased during the COVID-19 pandemic, also among employees which did not or hardly worked remotely before (de Haas et al., 2020). This inspired us to examine the impact of teleworking on commuting behaviour during and after the pandemic. This study aims to provide insight into the determinants that influenced teleworking during the pandemic and the impact of behavioural changes during the COVID19 lockdown on stated intentions about teleworking and mode choice for commuting. The availability of tracking data at the individual level (i.e. travel and location data) for a more extended period, before and during the lockdown, and an online survey among the same individuals provided us with a unique dataset, with both changes in commuting behaviour during the pandemic and the intention to change behaviour afterwards. Some recent studies examined teleworking in the context of COVID-19. For example, Riggs (2020) examined the relationship between teleworking and changes in daily travel during the COVID-19 pandemic, while Nguyen (2021) investigated the determinants that affect working from home during the lockdown and employees' attitudes towards teleworking in the post-COVID-19 era. Other studies focus on the safety of employees in relation to teleworking (e.g., Belzunegui-Eraso and Erro-Garcés, 2020). No studies were found that examine simultaneously travel behaviour and teleworking before, during and after the lockdown.

\footnotetext{
9 Working from home and teleworking are used interchangeably in this study and mean that employees work from home for at least one day a week to avoid commuting trips. Working from home for one or two hours, before travelling to work is not included.
} 
The contribution to the literature of this study is twofold. Firstly, this is the first study, to the authors' knowledge, that investigates the relationship between observed changes in commuting behaviour during the lockdown and intended changes afterwards. Secondly, the paper contributes to the literature $b$ examining the impact of moderating factors such as experiences with teleworking and the effect of policy measures, both by employers and the government, on teleworking intentions.

The rest of this chapter is organised as follows. In section 5.2, an overview is provided of the literature on the determinants that influence teleworking, the impacts of teleworking on commuting behaviour, and the contribution of this study to existing literature. Section 5.3 explains the conceptual model and methods we used for the analysis, and section 5.4 presents the data and variables used in the analysis. Section 5.5 describes the model results. Section 5.6 ends with a discussion and summary of the main conclusions.

\subsection{Teleworking and commuting behaviour}

\subsubsection{Factors explaining teleworking}

Most of the literature on teleworking describes research conducted before the COVID-19 virus outbreak in 2020. The literature distinguishes three groups of determinants that affect teleworking: the work situation, sociodemographic characteristics and travel behaviour.

First, the individual work situation impacts the opportunities to telework, such as job function and job sector (e.g., He and $\mathrm{Hu}, 2015$; Hjorthol and Nossum, 2007; Singh et al., 2013). In general, employees with office jobs were more likely to work from home. However, also in other job functions a growing trend in teleworking was observed (e.g., Thulin et al., 2019; Vilhelmson and Thulin, 2016), partly motivated by technological innovations (e.g., Frey and Osborne, 2017). Commuting distance might also be an influencing factor in the choice to telework or not. For instance, Helminen and Ristimäki (2007) found that larger commuting distances were positively associated with teleworking. Moreover, employees' preferences towards teleworking (e.g., Haddad et al., 2009; İşcan and Naktiyok, 2005; Peters et al., 2004) and experiences with working from home (e.g., Mokhtarian and Salomon, 1994) may influence teleworking choices.

Several studies examined the influence of sociodemographic characteristics on teleworking. People with higher income (e.g., He and Hu, 2015; Loo and Wang, 2018; Sener and Reeder, 2012) and higher education levels (e.g., de Graaff and Rietveld, 2004; Hjorthol and Nossum, 2007; Singh et al., 2013) were found to be more likely to work from home. Peters et al. (2004) showed that the chance of teleworking was higher for people from households without children, while others concluded that young children might encourage individuals to work from home (e.g., İşcan and Naktiyok, 2005; Mokhtarian and Salomon, 1994). Singh et al. (2013) concluded that living in urbanised areas was positively associated with teleworking, because employers who allow teleworking are mostly concentrated in urban areas and the ICT network is of a higher quality in urbanised areas. Other sociodemographic characteristics that may affect the choice to telework are gender and age, although the results in this area were mixed. Some studies found a positive relationship between men and teleworking (Hjorthol and Nossum, 2007; Popuri and Bhat, 2003), while others found that women were more likely to work from home, mostly because of the combination of work and care tasks (e.g., Mokhtarian et al., 1998). 
Finally, the teleworking choice may also be affected by people's initial travel behaviour. For instance, previous research showed that car users were less likely to adopt teleworking than frequent public transport users (e.g., Nurul Habib et al., 2012; Yen, 2000). Yen (2000) also found that increased car ownership reduces teleworking adoption, controlling for other sociodemographic characteristics.

\subsubsection{Impact of teleworking on commuting behaviour}

The impact of teleworking on travel behaviour has been the subject of many studies. Most of these studies found a reduction in the number of trips by teleworkers (e.g., Choo et al., 2005; Elldér, 2020; Helminen and Ristimäki, 2007; Lachapelle et al., 2017; Pendyala et al., 1991; Shabanpour et al., 2018). Andreev et al. (2010) reviewed about 30 papers about the impact of telecommuting on travel behaviour and concluded that in the short-term teleworking reduces commuting trips. However, in the long term, the positive impact on congestion levels and transport-related emissions might disappear because of so-called rebound effects, such as induced travel demand for other purposes. For example, de Abreu e Silva and Melo (2018) found a positive relationship between higher teleworking frequencies and non-commuting car trips among single-worker households. Kim (2017) showed that telecommuting reduces commuting trips, but that at the household level there was an increase in non-commuting trips.

\subsubsection{The rationale of the study}

Existing research provides insight into teleworking adaption and the relationship with mode choice for commuting before the COVID-19 virus outbreak. However, these studies do not provide enough information about changes in teleworking during and after the pandemic. Therefore, this research was conducted. The context of the COVID-19 pandemic allowed to examine how employees changed teleworking due to a forced intervention aimed at this behaviour. Employees were strongly advised to stay and work from home for an extended period resulting in changes in the number of teleworking days. How these changes in behaviour influenced intended behaviour when the restrictions no longer apply was explored. Before the COVID-19 pandemic, stimulating teleworking had been considered a potential factor to reduce commuting traffic. However, it is difficult and complex to change behaviour: "habitual processes strongly determine the daily routine of commuting in particular" (e.g., Guell et al., 2012). It is assumed that people facing life events or interventions are more likely to start the process of re-evaluating daily routines and, therefore, are more likely to change behaviour (e.g., Verplanken et al., 2008). However, during the first lockdown in the Netherlands, there was no time for re-evaluating daily routines. The COVID-19 pandemic can be considered as a large-scale 'live-experiment', offering empirical data about changes in and experiences with teleworking, and as a result, providing more insight into the potential impact of an increase in teleworking on commuting behaviour through changing behaviour. Moreover, a survey among employees in the Netherlands, whose travel behaviour was recorded before and during the lockdown by a smartphone app, allowed us to study the relationship between observed travel behaviour, revealed experiences and stated intentions. To the authors' knowledge, there is no research on the effects of changing behaviour on intentions when people had no choice but to change behaviour, as is the case in this study. 


\subsection{Methods}

In this study, insight is provided into the factors that influence teleworking during the lockdown and the impact of behavioural changes on intended commuting behaviour afterwards. This research is unique in that the behavioural changes resulting from 'imposed' changes to behaviour rather than reconsidering daily routines is investigated. The COVID-19 pandemic forced a large group of employees to work from and stay at home as much as possible. Daily routines were broken, such as cycling to work every morning. Ouellette and Wood (1998) found that when people face unstable conditions, they are more willing to reconsider their behavioural intentions. Moreover, experiences with new behaviour during the lockdown may increase the chance of structural changes in behaviour. Therefore, the question is whether these forced changes in teleworking and travel behaviour affect the intention to change behaviour after the COVID-19 pandemic.

The following two research questions were addressed:

1. Which factors determined changes in teleworking during the April 2020 lockdown?

2. Do changes in teleworking and travel behaviour during the lockdown influence the intention to increase teleworking or reduce car use for commuting after COVID-19, and how do experiences with teleworking and policy measures affect the stated intentions?

The conceptual model to answer the research questions is presented in Figure 5.1. The framework shows the different factors that affect changes in teleworking during the lockdown and the intended changes in teleworking and car use after COVID-19. To answer the research questions, two analyses were performed. First, the factors that influenced the changes in the number of days working from home during the lockdown using sociodemographic characteristics, the initial work situation and the initial travel behaviour before the virus outbreak as explanatory variables were determined (RQ1). Second, the intended changes in teleworking and car use for commuting after COVID-19, considering different elements were examined (RQ2). It is suggested that changes in teleworking and travel behaviour during COVID-19 impact the intention to change behaviour after COVID-19. This process might be influenced by experiences with teleworking (i.e. change in pleasure or productivity) or by policy measures stimulating teleworking, both from the government and employer.

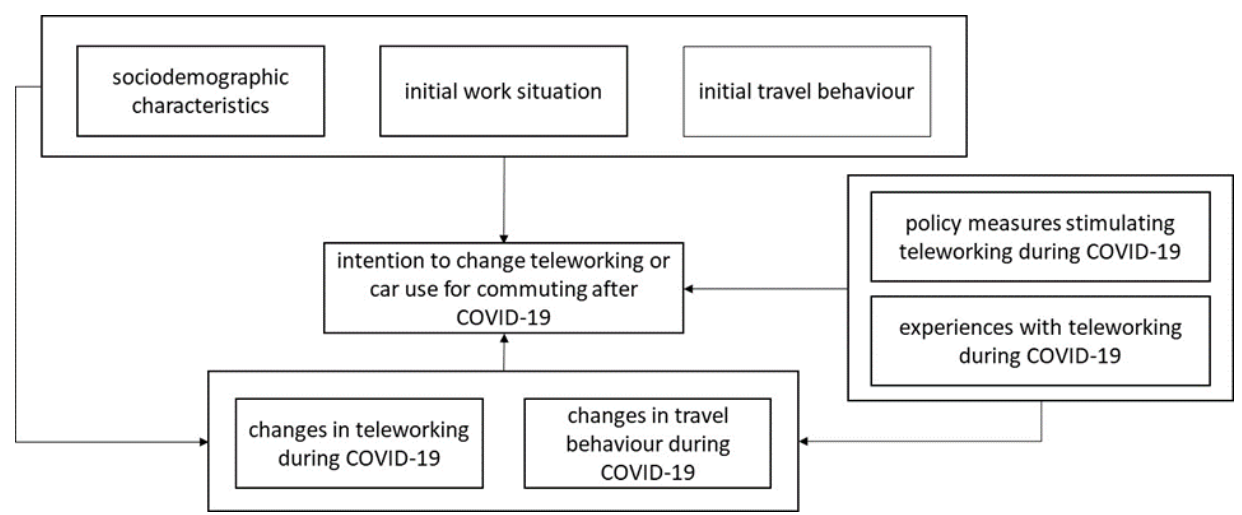

Figure 5.1 Conceptual model of the factors that determine changes in teleworking during the lockdown and intended changes in teleworking and car use for commuting after COVID-19 
To answer the research questions, the following three models were estimated:

- Model 1, an ordinal logistic regression (OLR) model, was estimated to determine the degree to which sociodemographic characteristics, the initial work situation, and the initial travel behaviour (i.e. explanatory variables) predict the odds of the relative increase in teleworking during the lockdown (i.e. dependent variable). To distinguish the different degrees of increases in teleworking, an ordinal variable was created with the following four categories: $0-25 \%, 25-50 \%$ and $50-75 \%$ and $75-100 \%$ increase in teleworking. The response variable consists of three or more categories with a natural ordering to the levels. To make full use of all information in the ordinal response data and to predict multi-class ordered variables, an ordinal logistic regression technique was used. The ordinal logistic regression model is expressed as follows:

$\ln \left(\frac{P(Y \leq i)}{1-P(Y \leq i)}\right)=\alpha_{i}+\beta_{i 1} X_{1}+\cdots+\beta_{i m} X_{m} \quad, \quad i=1, \ldots, k$

in which:

$\mathrm{Y}=$ dependent variable wit $\mathrm{k}+1$ ordered categories

$\mathrm{P}(\mathrm{Y})=$ the probability of $\mathrm{Y}$ occurring

$\mathrm{X}_{\mathrm{i} 1} \ldots \mathrm{X}_{\mathrm{im}}=$ set of predictors

$\beta_{\mathrm{i}}=$ parameter of the predictor variables

$\alpha_{i}=$ intercepts

- Two binary logistic regression (BLR) models were estimated to examine the factors that influence the intention to increase teleworking (model 2a) and the intention to decrease car use for commuting (model 2b) after COVID-19 compared to initial travel behaviour before the lockdown. This stud explores the intention to change or not after COVID-19. Therefore, for both models, a dichotomous variable was created as dependent variable $(0=$ no intention to change, $1=$ intention to change). Variables that measure changes in travel behaviour, changes in the number of days working from home, changes in experiences with teleworking and policy measures from both the government and employers to stimulate working from home during and after COVID-19 were added as explanatory variables, while controlling for the features of the situation before COVID- 19 . When the dependent variable is dichotomous or binary, simple linear regression cannot be used. Logistic regression is the statistical technique to predict the relationship between the predictors and binary dependent variable. The binary logistic regression model is expressed as follows:

$\ln \left(\frac{P(Y)}{1-P Y)}\right)=\alpha+\beta_{1} X_{1}+\beta_{2} X_{2}+\beta_{3} X_{3}+\cdots$

in which,

$\mathrm{Y}=$ dependent variable

$\mathrm{P}(\mathrm{Y})=$ the probability of $\mathrm{Y}$ occurring

$\mathrm{X} 1 \ldots \mathrm{Xn}=$ set of predictors

$\beta \mathrm{i}=$ parameter of the predictor variables

$\alpha=$ intercept 


\subsection{Data collection and description}

\subsubsection{Data collection}

In the analysis, data was used from the Dutch Travel Panel (in Dutch: Nederlands Verplaatsingspanel, NVP). The NVP, an initiative of DAT.Mobility, Kantar and Mobidot, started in 2019 and is a large-scale source of information to examine the dynamics in the travel behaviour of individuals (e.g., van der Drift et al, 2021). GPS and survey data are collected with user consent and data collection procedures comply with EU's privacy rules (GDPR). Travel information (for example, number of trips, distance, travel mode, origin and destination) was collected continuously through the smartphones of about 6,000 participants, along with their socio-demographic information. Modes are deduced from the enhanced trip data using probabilistic Bayesian mode use models. Thomas et al. (2018b) provide more information about the automatic trip detection and registration process, as well as the mode deduction process. The members of the NVP are recruited from the online Kantar panel (TNS NIPObase), comprising over 200,000 respondents and form a representative selection of the Dutch population. In April 2020, during the first lockdown, the Ministry of Infrastructure and Water Management invited employed panel member of the NVP, whose GPS data were collected to fill in an online survey. The respondents had to answer questions about the number of days they worked from home before and during the lockdown, their experiences with teleworking during the lockdown and their expectations about future behaviour. Experiences with teleworking during the lockdown included pleasure and productivity in work compared to the situation before COVID-19. Expectations about future behaviour comprised the number of days working from home and mode choice for travel days to work. This unique combination of information about observed changes in travel behaviour from the smartphone application of the NVP and revealed experiences and stated intentions from the online survey provided by the same participants enabled us to study the potential impact of behavioural changes on commuting behaviour.

In this research, before COVID-19 covers the period from January to (mid) March 2020, when there were no travel restrictions. During COVID-19 is the first period of the lockdown, from 16 March till the end of April 2020. After COVID-19 considers the period without any restrictions and when people can behave like 'normal'. A total of 3,562 individuals aged 20 years and older completed the online survey between 20-26 $6^{\text {th }}$ April 2020. Respondents who participated in the NVP for at least one entire week before and during the lockdown in the Netherlands were selected $(\mathrm{N}=1,675)$. For each respondent, one week before and during the lockdown was picked. The focus of this study is on employees who did not work fulltime from home before COVID-19 and to highlight the differences between employees who did not change and employees who started or increased teleworking with at least one day teleworking. Respondents were classified as "not teleworking", "started teleworking" or "increased teleworking". Consequently, respondents who during the lockdown worked fewer hours from home than before $(n=36)$ were excluded. Also, employees who already worked full-time from home before the lockdown and did not change their behaviour $(n=124)$ were excluded from further analyses.

The final sample contained 1,515 individuals with observed data about their travel behaviour before and during the lockdown from the NVP. From the online survey, the number of days they worked from home and their mode choice for commuting before and during the lockdown, and their expectations about teleworking and mode choice for commuting after COVID-19 is known. Based on changes in the number of teleworking days of respondents who were not fulltime teleworking before COVID-19, the following three subgroups were distinguished: 
1. Not teleworking (no change): Respondents who were not teleworking before the COVID19 outbreak and did not change their working pattern during the first lockdown $(n=496)$

2. Started teleworking (change): Respondents who were not teleworking before the COVID19 outbreak and worked at least one day from home during the first lockdown $(n=675)$

3. Increased teleworking (change): Respondents who were teleworking at least one day before the COVID-19 outbreak and increased the number of days teleworking during the first lockdown $(\mathrm{n}=344)$

\subsubsection{Data description}

To analyse the relationships in our conceptual model, the following variables were used:

\begin{tabular}{|c|c|c|c|}
\hline Period & Category & Variables & Source \\
\hline \multirow[t]{4}{*}{$\begin{array}{l}\text { Before } \\
\text { COVID-19 }\end{array}$} & $\begin{array}{l}\text { Sociodemographic } \\
\text { characteristics }\end{array}$ & $\begin{array}{l}\text { Age, gender, educational level, urbanisation of the } \\
\text { residential location, household composition }\end{array}$ & Survey data \\
\hline & Initial work situation & Job function, job sector & Survey data \\
\hline & & $\begin{array}{l}\text { Commuting distance and accessibility work } \\
\text { environment }\end{array}$ & NVP data \\
\hline & Initial travel behaviour & $\begin{array}{l}\text { Frequency of mode use for all trips, intrapersonal mode } \\
\text { use variation }\end{array}$ & NVP data \\
\hline \multirow{4}{*}{$\begin{array}{l}\text { During } \\
\text { COVID-19 }\end{array}$} & Changes in teleworking & Change in number of days working from home & Survey data \\
\hline & $\begin{array}{l}\text { Changes in travel } \\
\text { behaviour }\end{array}$ & $\begin{array}{l}\text { Frequency of mode use for all trips, intrapersonal mode } \\
\text { use variation }\end{array}$ & NVP data \\
\hline & $\begin{array}{l}\text { Changes in experiences } \\
\text { with teleworking }\end{array}$ & Pleasure, productivity & Survey data \\
\hline & $\begin{array}{l}\text { Policy measures } \\
\text { stimulating teleworking }\end{array}$ & $\begin{array}{l}\text { Policy measures to facilitate teleworking such as } \\
\text { offering sufficient teleconferencing tools }\end{array}$ & Survey data \\
\hline \multirow[t]{2}{*}{$\begin{array}{l}\text { After } \\
\text { COVID-19 }\end{array}$} & $\begin{array}{l}\text { Intention to change } \\
\text { teleworking }\end{array}$ & $\begin{array}{l}\text { Intention to increase the number of days working from } \\
\text { home }\end{array}$ & Survey data \\
\hline & $\begin{array}{l}\text { Intention to change car } \\
\text { use for commuting }\end{array}$ & Intention to decrease car use for commuting & Survey data \\
\hline
\end{tabular}

\section{Variables describing the situation before COVID-19}

$\underline{\text { Sociodemographic characteristics and initial work situation }}$

In the analyses, the following sociodemographic characteristics of the respondents were included: age, gender, educational level, urbanisation of the residential location and household composition. As it is known from previous research, these factors might influence teleworking and commuting behaviour (see section 2.1). Dichotomous variables were created for gender $($ male $=0,1=$ female $)$, educational level $(0=\text { no or low educated, } 1=\text { high educated })^{10}$, urbanisation $(0=\text { rural, } 1=\text { urban })^{11}$ and household composition $(0=$ without children $<12 \mathrm{yr}$, $1=$ with children $<12 \mathrm{yr})$.

To describe the initial work situation, the job function and job sector of each employee from the survey data were used. Job functions were categorised as follows: office worker, working in health care, teaching staff, and production or sales personnel. For the job sector, three main categories were distinguished, conforming to the standard business classification in the Netherlands: building and construction, professional services, and non-commercial services ${ }^{12}$.

${ }^{10}$ High education includes graduates from universities of applied sciences (HBO) and research universities (WO)

${ }^{11}$ Urban comprises residential locations with more than 1500 addresses per $\mathrm{km}^{2}$

${ }^{12}$ Standard Business Classification 2008 - update 2019 (CBS, 2019) 
Also, the commuting distance based on the zip code of the residential and job location from the NVP data was calculated. Previous research has shown that the accessibility of the work environment affects mode choice for commuting (.g., Maat and Timmermans, 2009). Therefore, the dataset was enriched with the distance from the job location to the nearest highway exit and public transport facilities. Following Hilbers et al., (2005), a variable representing the job location's accessibility was derived. A-locations represent good access by both public transport and car (i.e. areas in the immediate area around intercity stations and close to the highway), while R-locations represent poor access (i.e. not easily accessible by public transport and not close to the highway).

Table 5.1 gives an overview of the sociodemographic and initial work situation of the selected sample and the Dutch employed population ${ }^{13}$. Higher educated people and teaching staff are underrepresented in the sample, and production/sales employees and families without children are overrepresented. Other sociodemographic characteristics are comparable with the total employed population in the Netherlands, such as age, gender and urbanity level of the residential location. Overall, the selected sample fairly represents the composition of the Dutch employed population.

Respondents who did not work from home before and during the lockdown were more likely to be women, to live in rural areas, to be lower educated, and to live in households without children. Also, members of this group had a greater tendency to work in the building/construction sector or to have a care or production/sales function. Respondents who started to telework during the lockdown were more likely to live in urban areas and to be higher educated. Also, they had a higher chance of being employed in the non-commercial service sector, and to be an office worker or teacher. Because universities and schools were closed, teachers and students were forced to distance learning. Finally, respondents who already worked from home and increased the number of teleworking days during the lockdown were more likely to be male, to be higher educated and to live in households with children under 12 years old. These findings were confirmed by earlier research (see section 5.2). Also, these employees had a higher chance of being an office worker and having a longer commuting distance.

\section{Initial travel behaviour}

The NVP-data was used to describe the initial travel behaviour. First, the share of mode use for all trips was calculated. From previous research it is known that in particular frequent public transport users are more likely to telework (see section 5.2). Also, significant differences in public transport use were found between employees who do not telework and employees who started or increased teleworking. Therefore, public transport was used as an explanatory variable in the models. Also, the intrapersonal mode use variation was calculated, conform the method used by Thomas et al. (2019), based on the most frequently used mode for all trips. It is hypothesised that respondents with higher levels of intrapersonal mode use variation are more likely to change behaviour because they are more used to accessing different alternatives.

${ }^{13}$ Population statistics of employed people from CBS at 2019 (CBS, 2019) 
Table 5.1 Sociodemographic characteristics and initial work situation of the selected sample (Source: Survey data)

\begin{tabular}{|c|c|c|c|c|c|}
\hline & $\begin{array}{r}\text { before and } \\
\text { during not } \\
\text { teleworking } \\
(\mathrm{n}=496)\end{array}$ & $\begin{array}{r}\text { before not } \\
\text { teleworking, } \\
\text { during started } \\
\text { teleworking } \\
(\mathrm{n}=675)\end{array}$ & $\begin{array}{r}\text { before } \\
\text { teleworking, } \\
\text { during increased } \\
\text { teleworking } \\
(\mathrm{n}=344) \\
\end{array}$ & $\begin{array}{r}\text { total sample } \\
(\mathrm{n}=1,515)\end{array}$ & $\begin{array}{r}\text { Dutch } \\
\text { employed } \\
\text { population }\end{array}$ \\
\hline \multicolumn{6}{|l|}{ Gender } \\
\hline$\%$ male & 47.0 & 48.0 & 54.9 & 49.2 & 53.3 \\
\hline \multicolumn{6}{|l|}{ Age } \\
\hline mean & 46.6 & 44.4 & 44.7 & 45.2 & 43.0 \\
\hline \multicolumn{6}{|l|}{ Residential location (\%) } \\
\hline urban & 48.4 & 59.0 & 58.4 & 55.4 & 55.5 \\
\hline non-urban & 51.6 & 41.0 & 41.6 & 44.6 & 44.5 \\
\hline \multicolumn{6}{|l|}{ Education level } \\
\hline$\%$ high educated & 29.4 & 67.3 & 80.5 & 57.9 & 48.5 \\
\hline \multicolumn{6}{|l|}{ Household composition (\%) } \\
\hline single & 20.0 & 18.2 & 18.3 & 18.8 & 18.0 \\
\hline without children & 46.6 & 37.6 & 36.0 & 40.2 & 44.3 \\
\hline with children $<12$ years & 24.8 & 34.7 & 34.3 & 31.4 & 26.2 \\
\hline with children $12-17$ years & 8.7 & 9.5 & 11.3 & 9.6 & 11.4 \\
\hline \multicolumn{6}{|l|}{ Job sector $(\%)$} \\
\hline building and construction & 18.5 & 12.6 & 8.4 & 13.6 & 12.2 \\
\hline professional services & 34.1 & 34.1 & 54.4 & 38.7 & 54.1 \\
\hline non-commercial services & 47.4 & 53.3 & 37.2 & 47.7 & 33.8 \\
\hline \multicolumn{6}{|l|}{ Job function type $(\%)$} \\
\hline office worker & 34.7 & 70.2 & 77.9 & 60.3 & 63.0 \\
\hline health care & 29.4 & 8.7 & 5.2 & 14.7 & 11.5 \\
\hline education & 2.6 & 15.3 & 8.4 & 9.6 & 3.8 \\
\hline production/sales & 33.3 & 5.8 & 8.4 & 15.4 & 21.6 \\
\hline \multicolumn{6}{|l|}{ Distance to job location } \\
\hline average distance $(\mathrm{km})$ & 14.7 & 17.9 & 26.9 & 18.9 & 19.8 \\
\hline \multicolumn{6}{|l|}{ Accessibility of job location } \\
\hline A-location & 8.1 & 13.2 & 11.7 & 11.0 & $\mathrm{n} / \mathrm{a}$ \\
\hline R-location & 29.6 & 19.6 & 15.9 & 21.8 & $\mathrm{n} / \mathrm{a}$ \\
\hline
\end{tabular}

Table 5.2 gives an overview of the travel behaviour before COVID-19 of the selected sample. Respondents who did not telework before and during COVID-19 were more likely to use the car for all trips, although this does not provide direct evidence for causality in this relationship. Respondents who did telework before and increased their working hours at home during COVID-19 were more frequent walkers and users of public transport and consequently showed higher levels of intrapersonal mode use variation based on the number of trips. Respondents who did not telework before COVID-19 and increased working from home during the lockdown were more frequent cyclists.

Table 5.2 Travel behaviour before COVID-19 of the selected sample (Source: NVP data)

\begin{tabular}{lrrrr}
\hline & $\begin{array}{r}\text { before and } \\
\text { during not } \\
\text { teleworking } \\
(\mathrm{n}=496)\end{array}$ & $\begin{array}{r}\text { before not } \\
\text { teleworking, during } \\
\text { started teleworking } \\
(\mathrm{n}=675)\end{array}$ & $\begin{array}{r}\text { before teleworking, } \\
\text { during increased } \\
\text { teleworking }(\mathrm{n}=344)\end{array}$ & $\begin{array}{r}\text { total sample } \\
(\mathrm{n}=1,515)\end{array}$ \\
\hline Mode choice, all trips (\%) & & & & \\
$\quad$ Car & $\mathbf{6 2 . 1}$ & 56.1 & 57.9 & 58.4 \\
Public transport & 2.9 & $\mathbf{5 . 8}$ & 19.0 & 2.3 \\
$\quad$ Bicycle & 20.6 & 16.8 & $\mathbf{1 7 . 4}$ & 16.1 \\
$\quad$ Walk & 14.4 & 33.4 & $\mathbf{3 5 . 1}$ & 32.2 \\
Intrapersonal mode use variation (\%) & & & & \\
$\quad$ Trips & 28.6 & & & \\
\hline
\end{tabular}




\section{Variables describing changes in behaviour during COVID-19}

\section{Changes in teleworking}

For each employee, the difference between the share of the number of teleworking days before and during the lockdown was calculated. This variable was used as the dependent variable in model 1 and an explanatory variable in model 2. Before the lockdown, most employees did not work from home $(77 \%)$ or worked one day a week from home $(16 \%)$. More than half of the employees (58\%) who did not work from home before the lockdown, started teleworking during the lockdown.

\section{Changes in travel behaviour}

Changes in travel behaviour were derived from the NVP data. The shift in mode use for all trips, and the change in intrapersonal mode use variation based on the number of trips during the lockdown were calculated. Changes in the frequency of public transport use were used as an explanatory variable for intended changes after COVID-19. For all trips, the car and public transport were used less frequently during the lockdown and the use of active modes increased (Figure 5.2). Increased cycling and walking trips reflect the increase in shorter trips nearby home. During the lockdown, the intrapersonal mode use variation for all trips decreased, most likely because of the considerable reduction in public transport use. On the contrary, employees who increased teleworking showed a higher intrapersonal mode use variation, caused by an increase in the number of trips travelled by active modes for noncommuting trips.

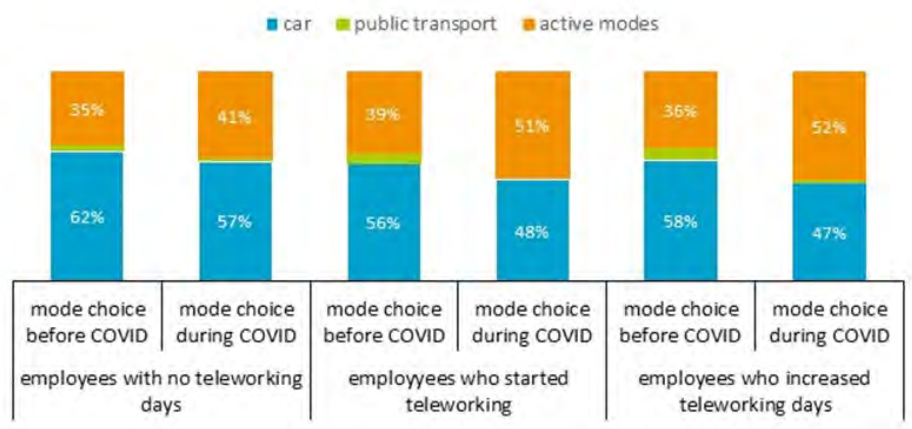

Figure 5.2 Changes in mode choice of all trips (Source: NVP data)

\section{Experiences with teleworking}

The survey data provided information about changes in experiences with teleworking. These changing experiences were measured on a five-point Likert scale by asking each respondent if pleasure and productivity during the lockdown changed. These two categorical variables were used to explain intended changes in behaviour. Only employees who worked from home one or more days before and during the lockdown were asked about their experiences. Different views exist regarding changes in productivity and pleasure during the lockdown (Figure 5.3). Half of the respondents reveal they are less productive while working from home, and $16 \%$ thinks they are more productive. Teleworking brings $37 \%$ of the respondents more pleasure, and almost one third (31\%) less pleasure. 


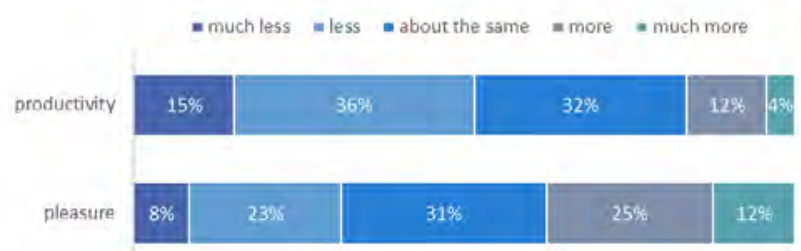

\section{Figure 5.3 Experiences with working from home during the lockdown (Source: Survey data)}

Policy measures to stimulate teleworking

For each employee who worked from home during the lockdown, in the survey questions were asked if their employer took additional measures to facilitate teleworking, for example, offering a headset or office chair and providing fast and sufficient tools for teleconferencing. Also, from the survey it is known whether teleworking was affected because it was obligated by the national government and employer. Concerning future policy regarding teleworking after COVID-19, questions were asked about what measures employers could take to promote teleworking in the future. A set of dichotomous variables was created to describe whether measures were present (1) or not (0) and used them as explanatory variables in model 2.

\section{Variables describing intended changes in behaviour after COVID-19}

Stated intentions about teleworking were derived from the survey data. Respondents were asked to imagine a post-COVID19 situation without any travel restrictions and to assume their personal situation was the same as the situation before COVID-19 (e.g., no income or job loss).

\section{Intention to change teleworking}

Each respondent was asked how many days they were expecting to work from home. As expected, employees who did not telework before or during the lockdown do not have the intention to start teleworking after COVID-19. Almost two-thirds of the employees who started or increased teleworking during the lockdown expect to return to the situation as it was before COVID-19. Nearly a third of the employees who did not telework before COVID-19, and started teleworking during the lockdown, expect to continue working from home one day a week $(23 \%)$ or two or more $(14 \%)$. About $36 \%$ of the employees who already worked from home before the lockdown expect to increase teleworking after COVID-19. Most of them intend to switch from one to two days teleworking (24\%). Most employees (68\%) expect to increase teleworking by one day. A dichotomous variable based on the difference between the number of teleworking days before and after COVID-19 ( $0=$ no increase, $1=$ increase) was derived, which represents the intention to change teleworking after COVID-19 and was used as a dependent variable in model $2 \mathrm{a}$ and an explanatory variable in model $2 \mathrm{~b}$.

\section{Intention to change mode choice for commuting}

Similarly to intended changes in teleworking, intended changes in mode choice for commuting at the individual level were derived from the survey. At the aggregated level, there are hardly any differences between the share in mode choice for commuting before and after COVID-19. Overall, there is a slight reduction in public transport use and a modest increase in the use of active modes. However, in absolute numbers, there is a significant decrease in the distance travelled for commuting, because of the intended increase in teleworking. To disentangle the impact of expected changes in teleworking on mode choice 
for commuting, a distinction was made between employees with the same travel days to work as before the lockdown and employed respondents who expect to make fewer commuting trips, mostly because of an increase in teleworking. For both groups, the commuting distance travelled by mode was calculated and the difference relative to the period before the lockdown (Figure 5.4). Employees with the same travel days expect an increase in car use $(+1 \%)$ and active modes $(+6 \%)$, while public transport will be used less frequently $(-10 \%)$. For employees who expect to commute less, the total commuting distance and the distance travelled by car, public transport, and bicycle decreases by 30 to $40 \%$ compared to the situation before the lockdown. The total commuting distance reduces by $13 \%$, while the total reduction in car kilometres is $12 \%$. The intended decrease in car use $(0=$ no, $1=$ yes $)$ was used as a dependent variable in model $2 b$.

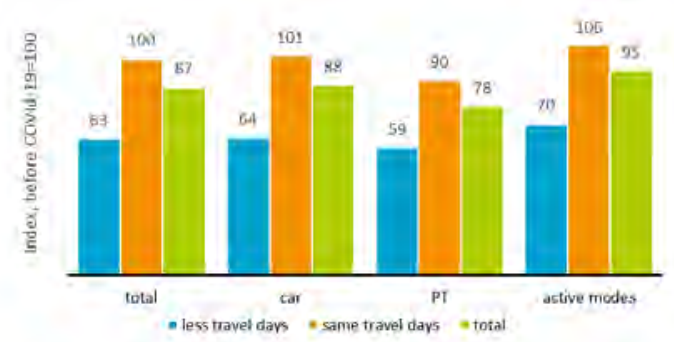

Figure 5.4 Intended changes in commuting distance travelled (Source: Survey data)

\subsection{Model results}

\subsubsection{Changes in teleworking during the lockdown}

The model results for Model 1 are reported in Table 5.3. The proposed model presents a good model fit regarding the final loglikelihood statistic $\left(\chi^{2}=566.243, \mathrm{p}<0.000\right)$. Ordinal logistic regression models are performed under the assumption of proportional odds (i.e. the effects of the explanatory variables are the same across the different thresholds). The 'test of parallel lines' showed that this assumption was upheld in our model $(\mathrm{p}=0.192)$.

Job function seems to have the strongest influence on changes in teleworking, given the large and significant coefficients for office workers and teaching staff. Office workers were 4.9 and teachers 6.6 times more likely to have higher values for the relative change in the number of days working from home. This suggests that office workers and teachers had a considerable chance of changing daily routines regarding commuting behaviour during the lockdown. This is not surprising considering that all schools and universities were closed during the lockdown. Being an employee in the non-commercial or professional sector increases the probability of being in the second $(25-50 \%$ change), third (50-75\% change) or fourth (75$100 \%$ change) category compared to employees in the building and construction sector. However, office workers in the building and construction sector were more likely to have a larger change in teleworking. Considering sociodemographic characteristics, higher educated people were more likely to increase working from home during the lockdown, while increasing age showed a negative association with changes in teleworking. For employees with a commuting distance of more than $50 \mathrm{~km}$, the probability of being more likely to change is multiplied by 1.4. Intrapersonal mode use variation showed a small but positive effect on changes in teleworking. Employees who use more different modes, were more likely to increase the number of days working from home. 
Table 5.3 Ordinal logistic regression model estimates for change in teleworking during the lockdown

\begin{tabular}{|c|c|c|}
\hline & Model 1 & \\
\hline Threshold dependent variable & $\mathbf{B}$ & \\
\hline \begin{tabular}{l|l|l}
$0-25 \%$ & $25-50 \%$ change in teleworking \\
\end{tabular} & $0.877 * *$ & \\
\hline \begin{tabular}{l|l}
$25-50 \%$ & $50-75 \%$ change in teleworking \\
\end{tabular} & $1.346^{* * *}$ & \\
\hline \begin{tabular}{l|l}
$50-75 \%$ & $75-100 \%$ change in teleworking \\
\end{tabular} & $2.051 * * *$ & \\
\hline Explanatory variables & $\mathbf{B}$ & $\operatorname{Exp}(\boldsymbol{B})$ \\
\hline \multicolumn{3}{|l|}{ Sociodemographic characteristics } \\
\hline gender $($ ref $=$ female $)$ & 0.070 & 1.073 \\
\hline age & $-0.009 *$ & 0.991 \\
\hline residential location $($ ref $=$ rural $)$ & 0.113 & 1.119 \\
\hline education (ref $=$ no or low education) & $1.066 * * *$ & 1.902 \\
\hline household with children < 12 yr $(\mathrm{ref}=$ no $)$ & $0.206^{*}$ & 1.228 \\
\hline \multicolumn{3}{|l|}{ Initial work situation } \\
\hline distance to the job location $(\mathrm{ref}=<50 \mathrm{~km})$ & $0.325^{*}$ & 1.384 \\
\hline A-location $(\mathrm{ref}=\mathrm{no})$ & 0.184 & 1.202 \\
\hline R-location $(\mathrm{ref}=\mathrm{no})$ & $-0.359 * *$ & 0.698 \\
\hline job function: office worker $(\mathrm{ref}=\mathrm{no})$ & $1.585 * * *$ & 4.881 \\
\hline job function: health care $(\mathrm{ref}=\mathrm{no})$ & $-0.449 * *$ & 0.638 \\
\hline job function: teaching staff $(\mathrm{ref}=$ no $)$ & $1.885 * * *$ & 6.585 \\
\hline sector: building and construction $(\mathrm{ref}=\mathrm{no})$ & $-1.608 * * *$ & 0.200 \\
\hline office worker $*$ building and construction $(\mathrm{ref}=$ no $)$ & $1.321 * *$ & 3.745 \\
\hline \multicolumn{3}{|l|}{ Initial travel behaviour } \\
\hline intrapersonal mode use variation (\%) & $0.009 * *$ & 1.009 \\
\hline share of PT use $(\%)$ & 0.781 & 2.184 \\
\hline Number of observations & 1,515 & \\
\hline Pseudo $\mathrm{R}^{2}$ of Nagelkerke & 0.344 & \\
\hline Loglikelihood with zero coefficients & 3607.246 & \\
\hline Final Loglikelihood & 3041.002 & \\
\hline$\chi^{2}$ & $566.243^{* * *}$ & \\
\hline
\end{tabular}

\subsubsection{Intention to change teleworking and car use for commuting after COVID-19}

The model results of model 2 are reported in table 5.4. For this analysis, respondents who increased teleworking during the lockdown were selected $(\mathrm{N}=1,019)$ because changes in teleworking are only known for these respondents. The proposed models present a good model fit regarding the final loglikelihood statistic $\left(\chi^{2}=160.813\right.$ and $\left.439.415, p<0.000\right)$.

Model 1 showed that higher educated employees were almost two times more likely to switch from not working from home to (almost) full-time working from home during the first lockdown. In addition, the results of model $2 \mathrm{a}$ reveal that higher educated employees are also more likely to increase teleworking after COVID-19. No significant relationships were found between other sociodemographic characteristics and the intended increase in teleworking. The initial work situation seems to have a greater influence. A positive and significant association was found with the intention to increase teleworking and to reduce car use for employees with longer commuting distances and office workers. This is not surprising, as reducing travel time is considered as one of the main advantages of teleworking. Teaching and health care personnel showed a positive association with the intention to reduce car use for commuting after COVID-19. This indicates that teaching staff and health care personnel are more likely to switch from the car to other modes of transport. However, they do not show a higher chance of increasing the amount of teleworking. Although teachers were forced to work from home and provide online education, most of them prefer teaching in the classroom.

In model 2, the relationship between the observed changes during the lockdown and intended behaviour after COVID-19 was examined. No significant associations between changes in 
travel behaviour (i.e. change in use of public transport or intrapersonal mode use variation) and the intention to increase teleworking were found. However, changes in travel behaviour show some small but significant associations with the intention to reduce car use after COVID-19. Frequent public transport users are less likely to reduce car use for commuting after COVID-19. This is not surprising, as they did not use the car frequently before the pandemic. Also, a higher share of mode use variation during the lockdown increases the chance of reducing car use. This suggests that experiences with other transport modes might cause a re-consideration of mode choice behaviour.

Regarding changes in teleworking during the lockdown, employees with relatively high changes in teleworking are more likely to increase the amount of time working from home and reduce car use after COVID-19. Also, there is a very strong association between the intention to increase teleworking and reducing car use. This is in line with prior expectations that experiences with new behaviour weakens daily routines and increases the likelihood of behavioural changes. This is further emphasised by the positive impact of positive experiences with teleworking during the lockdown. Employees who experienced more pleasure and a higher level of productivity during the lockdown have a higher chance of increasing the extent to which they work from home after COVID-19. However, additional policy measures are required to sustain a higher share of teleworking after the pandemic. Employees expressed the need to make agreements about teleworking at the individual level. Continued encouragement to work from home and offering a helpdesk for teleworking-related questions both positively impact the intention to increase the amount of time spent working from home. This suggests that if policy measures regarding teleworking match these expectations, intended changes might result in structural behavioural changes.

\subsection{Discussion and conclusions}

In this study, the factors that influence changes in teleworking and explored the impact of behavioural changes during the COVID-19 lockdown on stated intentions about teleworking and mode choice for commuting were examined. Large-scale smartphone-based GPS-data and survey data from 1,515 Dutch employees were used. First, the changes in teleworking and travel behaviour during the lockdown and the intention to change commuting behaviour after COVID-19 were described. Secondly, logit models were developed to investigate the odds to increase teleworking and reduce car use. Our research findings contribute to the literature about teleworking and travel behaviour before the pandemic. The main factors that influenced teleworking during the lockdown were job characteristics. Office workers and teaching staff were more likely to increase working from home and showed a higher chance of changes in daily commuting routines. Also, office workers were more likely to increase working from home after COVID-19, although this does not apply to teaching staff. In particular, employees with relatively large changes in teleworking during the lockdown expect to work from home more often after COVID-19. This effect is strengthened further by positive experiences with teleworking (i.e. more pleasure and higher productivity) and supporting policy measures by the employer, such as sufficient ICT facilities. Furthermore, evidence is provided that an increase in teleworking leads to a substantial reduction in car use for commuting. In this way, there is an excellent potential for the contribution of teleworking in meeting climate targets, such as the reduction of transport-related emissions and congestion. It must be noted, however, that most employees in the Netherlands have access to high internet quality. Therefore, the results of this study are not necessarily applicable to countries where internet is of much lower quality. 
Table 5.4 Binary logit model estimates for intention to increase teleworking and reduce car use for commuting after COVID-19

\begin{tabular}{|c|c|c|c|c|}
\hline \multirow{3}{*}{$\begin{array}{l}\text { Dependent variable } \\
\text { Explanatory variables }\end{array}$} & \multirow{2}{*}{\multicolumn{2}{|c|}{$\begin{array}{c}\text { Model 2a } \\
\begin{array}{c}\text { Intended increase in } \\
\text { teleworking }\end{array}\end{array}$}} & \multirow{2}{*}{\multicolumn{2}{|c|}{$\begin{array}{c}\text { Model 2b } \\
\text { Intended reduce } \\
\text { in car use for } \\
\text { commuting }\end{array}$}} \\
\hline & & & & \\
\hline & B & $\operatorname{Exp}(\boldsymbol{B})$ & B & $\operatorname{Exp}(\boldsymbol{B})$ \\
\hline \multicolumn{5}{|l|}{ Sociodemographic characteristics } \\
\hline gender $($ ref $=$ female $)$ & -0.221 & 0.802 & -0.285 & 0.752 \\
\hline Age & -0.005 & 0.995 & -0.006 & 0.994 \\
\hline residential location $($ ref $=$ rural $)$ & 0.050 & 1.052 & -0.273 & 0.761 \\
\hline education $($ ref $=$ no or low education $)$ & $0.410 * *$ & $1 . .507$ & -0.242 & 0.785 \\
\hline household with children $<12$ yr $($ ref $=$ no $)$ & -0.217 & 0.805 & -0.132 & 0.876 \\
\hline \multicolumn{5}{|l|}{ Initial work situation } \\
\hline distance to the job location $(\mathrm{ref}=<50 \mathrm{~km})$ & $0.455 * *$ & 1.577 & $0.622 * *$ & 1.862 \\
\hline A-location $(\mathrm{ref}=$ no $)$ & -0.114 & 0.892 & -0.086 & 0.918 \\
\hline R-location $(\mathrm{ref}=$ no $)$ & 0.135 & 1.144 & 0.133 & 1.143 \\
\hline job function: office worker $(\mathrm{ref}=\mathrm{no})$ & $0.664 * *$ & 1.942 & $0.943 * *$ & 2.567 \\
\hline job function: health care $(\mathrm{ref}=\mathrm{no})$ & 0.441 & 1.555 & $1.383 * *$ & 3.987 \\
\hline job function: teaching staff $(\mathrm{ref}=$ no $)$ & -0.268 & 0.765 & $0.968^{*}$ & 2.633 \\
\hline sector: building and construction $(\mathrm{ref}=\mathrm{no})$ & 0.432 & 1.540 & 0.642 & 1.901 \\
\hline office worker $*$ building and construction $(\mathrm{ref}=\mathrm{no})$ & -0.361 & 0.697 & -0.614 & 0.541 \\
\hline \multicolumn{5}{|l|}{ Initial travel behaviour } \\
\hline intrapersonal mode use variation $(\%)$ & 0.000 & 1.000 & -0.008 & 0.992 \\
\hline share of PT trips $(\%)$ & -0.773 & 0.462 & $-5.878 * *$ & 0.003 \\
\hline \multicolumn{5}{|l|}{ Changes in teleworking } \\
\hline change in teleworking (\%) & $0.727 * *$ & 2.068 & -0.640 & 0.527 \\
\hline \multicolumn{5}{|l|}{ Changes in travel behaviour } \\
\hline change in mode use variation $(\%)$ & -0.002 & 0.998 & $0.014 * * *$ & 1.014 \\
\hline change in use of public transport (\%) & -0.747 & 0.474 & 1.337 & 3.809 \\
\hline \multicolumn{5}{|l|}{ Changes in attitudes towards teleworking } \\
\hline pleasure: less $($ ref $=$ much less $)$ & 0.116 & 1.123 & 0.273 & 1.314 \\
\hline pleasure: about the same (ref = much less) & $0.504 *$ & 1.655 & 0.566 & 1.761 \\
\hline pleasure: more $(\mathrm{ref}=$ much less $)$ & $0.558^{*}$ & 1.748 & $0.731^{*}$ & 2.076 \\
\hline pleasure: much more $(\mathrm{ref}=$ much less $)$ & $0.837 * *$ & 2.308 & 0.313 & 1.367 \\
\hline productivity: less (ref $=$ much less) & 0.296 & 1.345 & $-1.268^{* * *}$ & 0.281 \\
\hline productivity: about the same (ref = much less) & 0.089 & 1.093 & $-0.786^{*}$ & 0.456 \\
\hline productivity: more $($ ref $=$ much less $)$ & $0.683 *$ & 1.979 & $-1.074 * *$ & 0.342 \\
\hline productivity: much more (ref = much less) & $0.748^{*}$ & 2.112 & -0.770 & 0.463 \\
\hline \multicolumn{5}{|l|}{ Measures during lockdown } \\
\hline flexible working hours $($ ref $=$ no $)$ & $0.330 * *$ & 1.392 & 0.189 & 1.208 \\
\hline facilitating tools for teleconferencing $(\mathrm{ref}=\mathrm{no})$ & 0.261 & 1.298 & 0.314 & 1.369 \\
\hline facilitating computer supplies $(\mathrm{ref}=\mathrm{no})$ & -0.101 & 0.904 & 0.076 & 1.078 \\
\hline obligated by government $($ ref $=$ no $)$ & 0.123 & 1.131 & 0.136 & 1.145 \\
\hline obligated by employer $(\mathrm{ref}=\mathrm{no})$ & 0.078 & 1.081 & 0.140 & 1.150 \\
\hline \multicolumn{5}{|l|}{ Future measures employer after COVID-19 } \\
\hline making agreements about teleworking at individual level $(\mathrm{ref}=$ no $)$ & $0.493 * * *$ & 1.638 & -0.342 & 0.710 \\
\hline active stimulating teleworking by employer $(\mathrm{ref}=\mathrm{no})$ & $0.359 * *$ & 1.432 & 0.189 & 1.209 \\
\hline appointing a contact person for questions about teleworking $(\mathrm{ref}=\mathrm{no})$ & $0.509 * *$ & 1.664 & 0.044 & 1.045 \\
\hline \multicolumn{5}{|l|}{ Intention to increase teleworking after COVID-19 } \\
\hline intention to increase teleworking $(\mathrm{ref}=\mathrm{no})$ & - & - & $3.336 * * *$ & 28.119 \\
\hline Constant & $-3.297 * * *$ & 0.037 & $-2.026^{* *}$ & 0.132 \\
\hline Number of observations & 1,019 & & 1,019 & \\
\hline $\mathrm{R}^{2}$ of Nagelkerke & 0.201 & & 0.517 & \\
\hline$\chi^{2}$ & $160.813^{* * *}$ & & $439.415^{* * *}$ & \\
\hline
\end{tabular}

Notes: ${ }^{*} \mathrm{p}<0.10,{ }^{* *} \mathrm{p}<0.05,{ }^{* * *} \mathrm{p}<0.00$ 
Habits strongly influence our daily behaviour (e.g., Lally et al., 2010; Verplanken and Wood, 2006). Most of our travel behaviour, including commuting, is habitual behaviour. Research outside the transport domain has shown that it takes about two months to adopt new habits (e.g., Lally et al., 2010). In this respect, the first lockdown in the Netherlands, a period of two and a half months, was a perfect chance to build new habits. There was no time for reconsidering existing habits, and people were directly 'forced' into new behaviour. The model results show that these experiences with behaviour changes for a more extended period contribute to an expected increase in teleworking and changes in mode choice for commuting after COVID-19. However, intentions do not always lead to actual changes in behaviour. Intention to change travel behaviour is, to a large extent, determined by preferences and attitudes (e.g., Clark et al., 2016; Klöckner and Friedrichsmeier, 2011; Paulssen et al., 2014). The findings of this study confirm this relationship: employees who experienced more pleasure and higher productivity during the lockdown, mostly white-collar jobs, are more likely to increase working from home after COVID-19. However, as the pandemic continued, the question is whether this group of employees remained this positive and what possible effect there might be on the intention to change behaviour. The survey was carried out six weeks after the start of the COVID pandemic, and at that time respondents might have anticipated that the situation would soon return to normal. The longer duration of the pandemic might have influenced the intention to work from home after COVID-19 (e.g., MarketResponse, 2020). Meanwhile, some large employers in the Netherlands, for instance, KPMG and ABN Amro, have already changed their policy to retain teleworking ${ }^{14}$. The future will show whether and to what extent the intention to change commuting behaviour remains and whether it eventually lead to changes in actual behaviour.

This study clearly shows the added value of using GPS tracking data in combination with an online survey to examine changes in travel and activity patterns. GPS tracking data with detailed information about the travel behaviour of the same persons over time allowed us to analyse differences in weekly travel patterns at the individual level. This is not possible with traditional cross-sectional surveys and 1- or 3-day travel diaries. With information about expected behaviour after COVID-19 of the same respondents from the online survey it was, in this study, possible to examine the relationship between changes in actual behaviour and stated intentions. This possibility of submitting a survey with in-depth questions to the panel members offers many opportunities for future research. For example, conducting the same survey will reveal if and to what extent intentions to change behaviour have changed over time, or an online survey among employees who do not intend to increase teleworking might provide more insight into the barriers.

The results of this study are in line with previous research on the impact of teleworking on commuting behaviour on the short term (e.g., Choo et al., 2005; Clark et al., 2016; Elldér, 2020). A reduction in car use and an increase in cycling and walking were found. However, re-bound effects on teleworking are debatable. It would be an interesting topic to examine the relationship between the impact of teleworking on, for example, travel behaviour for noncommuting activities. Another direction for future research is to investigate whether changes in travel behaviour and teleworking during the lockdown affect gender differences in mobility. Furthermore, the impact of an increase in teleworking on residential relocation could also be explored. Employees with longer commuting distances are more likely to expect

14 https://www.rtlnieuws.nl/economie/business/artikel/5170360/niet-meer-naar-kantoor-bij-abnamro-na-corona 
an increase in teleworking after COVID-19. In the long term, an increase in working from home could, therefore, result in residential relocations (e.g., Toger et al., 2021).

This study provides policymakers with new insights when it comes to achieving structural changes in commuting behaviour. A contextual change in someone's life is an essential precondition for increasing the effectiveness of policy measures. The government's appeal to work from home as much as possible caused a major change in the work situation, although there is still a large group of employees for whom working from home is not possible. Our results show that the changes in teleworking have had a large impact on the intention to telework after COVID-19 and reduces in particular car use for commuting. The impact of changes in travel behaviour during the lockdown on mode choice for commuting after COVID-19 is much less. This is because factors determining mode choice, for example, commuting distance, do not change in the short term. To that end, the COVID-19 pandemic is a 'best' practice of how interventions can stimulate future changes in behaviour. Therefore, policymakers who want to utilize this situation in order to influence behaviour after COVID19 should primarily focus on stimulating teleworking, possibly in combination with stimulating the use of more sustainable modes of transport.

This study shows that the first signs of intended changes in teleworking are positive, however, there are also some remarks. First, there is still a substantial part of the workforce in the Netherlands that have no or low digital skills, which makes teleworking more complicated (Non et al., 2021). Investments in skills development are key to responding to these challenges. Second, the most reported disadvantages of teleworking are the absence of social contacts, a disturbed balance between work and free time, and the lack of a good and quiet workplace at home. Clear agreements between employer and employees in which there is room for individual needs may help remove these barriers and achieve structural changes in teleworking. 


\section{Conclusions, implications and further research}

In this thesis, the different factors that influence the dynamics in mode choice, the causal relationships between these factors and the directions of these relationships over time are examined. Several research gaps related to changes in mode choice behaviour over time were identified, concerning the impact of household interactions on car use, the relationship between life events and mode preferences, temporal dynamics in mode attitudes, and teleworking and commuting behaviour. Panel analyses were conducted for each of the four topics mentioned to improve our knowledge about changes in mode choice behaviour over time. This final chapter presents the main conclusions based on the research questions (section 6.1), discusses the implications for the research field and policy-making practice (section 6.2), and provides recommendations for further research (section 6.3).

\subsection{Conclusions and discussion}

\subsubsection{Main conclusions}

To what extent do household interactions and changes in household and personal characteristics affect car use for home-based tours?

Different multilevel models were estimated to investigate the variation in car use at the household and individual level. Two waves of the Netherlands Mobility Panel were used to account for the impact of variation in travel mode choice and changes in household and individual characteristics over time. The results of the analysis show that variability between households and individuals accounts for about one-third of the total variation in mode choice of home-based tours. This finding indicates that interactions between household members, resulting in joint (or not) activity patterns, have significantly different outcomes in terms of car use. Also, the impact of interactions between household members on car use is larger in dual-income households, probably because agreements on car use needs to be further organised regarding aspects such as having two work locations instead of one and differences in the accessibility of the work location. 
Moreover, the analysis of other travel-related characteristics shows that household interactions have a significant impact on car use. First, for people who travel together with a household member (i.e. fully joint tours), the odds ratio of using the car is 4.2 times higher compared to single activities. The purpose of a trip is another significant predictor. Travelling to and from work increases the chance of using the car. This implies that in dual-income households where only one car is available, decisions must be made about who gets to use the car. Regarding variation in car use over time, the results show that two life events have a statistically significant impact on car use; both a change in working hours in the previous two years and a change of work location in the same year decreased car use. The negative association between a change in work location and car use suggests better accessibility of the new work location by other means of transport. These findings indicate a delayed effect of changing working hours on mode choice, whereas a change of work location immediately affects mode choice. Furthermore, increasing car preference for commuting increases the chance of travelling by car for home-work-trips. Although only two subsequent waves were analysed, the results already show significant temporal effects. It can therefore be expected that examining the impact of household interactions on changes in mode choice behaviour for a more extended period will reveal more interesting findings.

Do travellers' profiles based on their attitudes towards the car change over time, and are these changes related to life events?

A latent transition model was developed to examine the impact of temporal dynamics in attitudes on transport mode choice using data from two waves of the Netherlands Mobility Panel. Based on attitudes towards car use and ownership and different socio-economic characteristics, four latent classes are identified. The latent classes represent clusters of travellers with different personal values towards the car (i.e. cost-sensitive, car-minded, environmentally aware and social-conscious), while the travel behaviour can be the same. The transitions between the population segments show that traveller's profiles based on attitudes are very stable over time. The share of participants that remained in the same class lies between $72 \%$ (social-conscious travellers) and $85 \%$ (cost-sensitive travellers). This means that the highest transition probabilities were found for less frequent car users and suggests that changes in attitudes are less likely for frequent car users. Another important conclusion is that, based on the frequency of mode choice, the probability of staying in the same class is higher than moving between classes (de Haas et al., 2018; Kroesen and Cranenburgh, 2016). This suggests that attitudes are more stable over time than the frequency of mode use. One possible explanation for fewer observed changes in attitudes is that only two waves of data (2014 and 2016) were used. When conditions change, any subsequent changes in travellers' attitudes may be delayed.

Facing life events increases the likelihood of switching between the latent classes. In particular, the non-car-minded profiles show significantly more movers after the occurrence of a life event. For instance, cost-sensitive travellers are more likely to switch to the carminded profile after starting a new job or moving home. Also, an increase in the number of children results in a substantially higher share of travellers who are environmentally aware and out of social-conscious transition to another class. Moreover, when multiple life events occur within the same year, all profiles show significantly more movers. To that end, these life-changing moments form a trigger for a reconsideration of attitudes towards car use and ownership. It is hypothesised that transitioning to a more car-oriented profile is positively associated with car use and transitioning to a less car-oriented profile is negatively related to car use. However, the findings indicate no significant relationship between changes in attitudes and the frequency of car use for most profiles. The fact that different attitudes 
towards car use and ownership did not directly affect the frequency of car use might reflect that people do not directly change their mode choice behaviour when they become more or less car-oriented. Travellers might postpone changes in the frequency of car use. A more logical explanation is that individuals who switch to a different class already show behaviours that fit with the class that they are moving to. Several studies found that people are more likely to adjust their attitudes to match their behaviour (e.g., Kroesen et al., 2017; NelloDeakin and Brömmelstroet, 2021; van de Coevering et al., 2021).

\section{How do life events affect mode preferences and mode use over time of young adults?}

A cross-lagged panel model was developed to examine the relationship between life events, mode preferences and frequency of mode use over time for young adults. Young adults show very stable behaviour over time. Those who use the car, public transport or bicycle at an above-average level are more likely to use these transport modes at an above-average level across the waves. The stability effects of the frequency of mode use found in this study are higher compared to the stability effects of mode preference. This suggests that young adults are more likely to change their preference towards public transport and cycling than their frequency of public transport or bicycle use. Moreover, in our three-wave panel study, it was found that young adults develop a stronger preference for a particular mode after increasing that mode use over time. In contrast, an increase in mode preference does not necessarily lead to an increase in the frequency of mode use. This implies that changes in travel behaviour are more likely to precede changes in preferences than the other way around. For instance, young adults who start using the car more frequently are more likely to show stronger car preferences later on.

Furthermore, the findings of this study highlight the importance of considering the impact of life events when examining changes in the travel behaviour of young adults. Young adults showed fixed habits regarding mode use and mode preference. However, life events act as a trigger for changes and affect both the travel behaviour and attitudes of young adults. This indicates that a change in frequency of mode use is not only because of a change in attitude towards the car, public transport or bicycle or vice versa but also directly related to life events. The impact of life events on changes in the frequency of mode use and mode preference depends on the type of life event. In particular, car use and car preference among Dutch young adults increased significantly after the birth of a child. At the same time, a negative association is found between the birth of a child and the use of public transport and the bicycle. This result is consistent with other studies about the inertia effects of car use that show car users as the most inert travellers (González et al., 2017). Moving home increases cycling, both the frequency of use and preference, although these effects are not significant at all temporal scopes (i.e. first year or second year of the event). Young adults with a new job showed a negative association with bicycle use and less preference for public transport across all waves. However, this did not result in a significant change in the frequency of the use of this transport mode.

Do changes in teleworking and travel behaviourduring the lockdown influence the intention to reduce car use for commuting after COVID-19

Whereas the previous conclusions concern the situation before the COVID-19 pandemic, this research question focuses on changes in teleworking and car use for commuting during and after COVID-19. Ordinal and binominal logit models were developed to investigate the probability of increasing teleworking and reducing car use. The main factors that influenced teleworking during the lockdown were job characteristics. Office workers and teaching staff were more likely to increase working from home and showed a higher chance of changes in 
daily commuting routines. Also, office workers were more likely to increase working from home after COVID-19. However, this does not apply to teaching staff. This is logical because during the lockdown schools were closed and were obliged to provide online education. It is expected that after the lockdown, most education will proceed offline. In particular, employees with relatively large changes in teleworking during the lockdown expect to work from home more often after COVID-19. This effect is strengthened by positive experiences with teleworking (i.e. more pleasure and higher productivity) and supporting policy measures by the employer, such as sufficient ICT facilities. Furthermore, this study provides evidence that an increase in teleworking leads to a substantial reduction in car use for commuting in the short term and confirms the findings of previous studies before the COVID-19 pandemic (e.g., Choo et al., 2005; Lachapelle et al., 2017). In this way, there is excellent potential for teleworking to reduce transport-related emissions and congestion.

\subsubsection{Discussion}

This thesis aims to provide empirical evidence of the different factors that influence the dynamics in mode choice, the causal relationship between these factors and the directions of these relationships. Several studies have examined the impact of sociodemographic variables, the built environment, attitudes and preferences, trip characteristics and the use of ICT on (changes in) mode choice behaviour (e.g., Clark et al., 2016; Handy et al., 2005; Kuppam et al., 1999; Miskeen et al., 2013; Paulssen et al., 2014; Pawlak et al., 2015). Other research used repeated cross-section or retrospective data to analyse the impact of life-changing moments on travel behaviour (e.g., Clark et al., 2014; Oakil, 2014; Oakil et al., 2016a). In recent years, the availability of new panel data sources created new opportunities to study dynamics in travel behaviour (e.g., González et al., 2016; La Paix Puello et al., 2017; Scheiner, 2016). This thesis complements these studies by providing new empirical evidence from a temporal point of view, using two different sources of large-scale panel data from the Netherlands: the Netherlands Mobility Panel (MPN) and the Dutch Travel Panel (NVP). Because travel behaviour data is collected for three consecutive days over several years (MPN) or continuously (NVP), it is possible to analyse changes in mode choice behaviour over time. Besides, the availability of various background characteristics, such as preferences and attitudes, and the occurrence of life events, allows different causal relationships to be examined while controlling for sociodemographic, spatial and trip characteristics.

The main conclusions of this thesis show that different factors and relationships over time affect mode choice behaviour. The rich datasets from the MPN and NVP allowed the inclusion of different types of determinants that may affect mode choice behaviour over time, and enabled the inter- and intrapersonal variation in mode use to be disentangled. The results show that both attitudes and preferences towards transport modes and the frequency of mode use are relatively stable over time, whereas attitudes and preferences are more stable than the frequency of mode use. In particular, frequent car users show very stable behaviour over time. Life events are a trigger for behavioural changes and have a larger impact on mode choice behaviour than on preferences and attitudes. Also, examining the dynamics in mode choice behaviour over time from different perspectives provides evidence that people are more inclined to adjust their preferences and attitudes so it meets their behaviour instead of the other way around.

From previous research it is known that it takes time to form new habits and to change behaviour (e.g., Verplanken et al., 2008; Kitamura, 1990). The period considered in this thesis, at most three consecutive years, captures most of the behavioural changes because of life events and other contextual changes in someone's life. However, the relatively small 
number of certain life events might require a longer measurement period. At the same time, this raises the question about the optimal duration of a repeated panel. The optimal number of waves or the optimal duration of participation has not yet been determined, mostly because of the limited long-duration panels worldwide and attrition issues. It is argued that al least three time points are required to model patterns of change over time and to capture both direct and indirect effects. (e.g., de Vos et al, 2021; Lui, 2016). Repeating existing research with more waves might provide new insights about habit formation and the relationship with life changing moments. Although, the question is if panel members are willing to participate for a longer continuous period. This is one of main the reasons that the German Mobilty Panel consists of a rotating panel, and panel member participate for a maximum of three years (e.g., Chlond and Kuhnimhof, 2003; Zumkeller and Chlond, 1996).

Previous studies, conducted before the COVID-19 pandemic, found significant changes in commuting behaviour after life events (Mokhtarian et al., 2004; Viana Cerqueira et al., 2020; Zhu, 2013). This is also one of the outcomes examined in this study using COVID-19. During the COVID-lockdown, employees changed their commuting behaviour significantly (i.e. started or increased teleworking), resulting in less commuting trips. Moreover, the results of the COVID-19 study shows that positive experiences with teleworking affected employees' attitudes towards teleworking and increased the likelihood of increasing teleworking and reducing car use after COVID-19, assuming that in the short term commuting distances remain the same. The observed behavioural changes during the COVID-19 pandemic, which can be considered as a 'live experiment', and the examination of the relationship between mode choice behaviour and life events, attitudes and preferences, both demonstrate that experiences with new behaviour, in the short and long term, influence attitudes and preferences. This implies that policymakers should primarily focus on behavioural changes rather than trying to change attitudes and preferences. This is supported by a study by Semenescu et al. (2020), who found that soft interventions had a limited impact on reducing car use. Also, policymakers should focus on people with higher intrapersonal dynamics in mode use variation, as the results of this thesis show that multimodal travellers are more likely to change behaviour compared to, for example, frequent car users.

The COVID-19 pandemic affected daily life in several ways, in particular travel behaviour, such as the decrease in commuting trips because of an increase in teleworking. Over the last year, the government, employers and educational institutions responded rapidly and proactively to these changing circumstances. For instance, municipalities created more space for walking and cycling, and employers made additional investments to facilitate teleworking. These developments have been an extra driver for changes in travel behaviour, as can be concluded from the results in this thesis. To that end, the COVID-19 pandemic is a 'best practice' of how interventions can stimulate future changes in behaviour. Policymakers can use these insights to perpetuate the positive effects of COVID-19 on mobility, such as the reduced congestion and increase in walking and cycling.

This thesis shows that there is a clear distinction between inter- and intrapersonal variation in mode use. In practice, this means that, besides mode use variation between individuals, individuals show variation in mode use during the day, during the week and across years. In this thesis, the focus in the first three chapters was on the dynamics in mode choice behaviour between years. The rich dataset of the MPN (i.e. a yearly 3-day trip diary and additional information about attitudes, preferences and life events) allowed the research questions formulated to be addressed. However, measuring travel behaviour for a longer continuous period (e.g., one, two or six weeks) reveals more detailed information about intrapersonal 
mode use variation (Thomas et al., 2019). This information is needed when a specific period is considered within the same year or when the travel behaviour of a sub-population is of particular interest, for example, mode choice behaviour of multimodal travellers. Therefore, to analyse changes in travel behaviour during the COVID-lockdown, it was necessary to use trip data for more than three consecutive days. For future research, this implies that long-duration panels, such as the MPN, are applicable for investigating dynamics in mode choice behaviour between years. Short-duration panels, such as the NVP, are more appropriate for examining dynamics in mode choice behaviour in specific periods or analysing mode use variation of particular groups.

The conclusions and discussion show that panel data, including detailed background information, helps to understand the dynamics in mode choice behaviour from a temporal point of view and different perspectives. Long- and short-duration panels each have their specific advantages and disadvantages. Therefore, determining in advance which type of panel data is the most appropriate to answer the research objective is necessary. Overall, panel data helps to identify which populations segments change behaviour, the reasons why and when.

\subsection{Implications}

The thesis provides interesting new insights relevant to travel behaviour research. There are several implications (or lessons learned) related to the results of this thesis. First, the research implications are presented. Second, the implications for transport policy are highlighted.

\subsubsection{Research implications}

First, when examining behavioural changes at the individual level, both variation at the household and individual level should be considered to disentangle the inter- and intrapersonal dynamics in mode choice behaviour. It is particularly important to consider this variation in behaviour at different levels and time points as new mobility concepts targeting the use of different mobility services, such as mobility-as-a-service and shared mobility, is become increasingly popular. Insight into mode use variation during the week at the individual and household level becomes even more important when flexible working hours and teleworking increases, which is expected after COVID-19. In this case, one-or three-day travel surveys will not give an adequate representation of the variation in individual travel behaviour during the week, as no day will be the same. Considering inter- and intrapersonal mode use variation over time enables a better understanding of the dynamics in behaviour. The availability of large-scale panel data for a more extended period, both within the same year and across successive years, is necessary to perform this kind of analysis. At the same time, the combination of longitudinal data and detailed information about the respondents and their household members, such as attitudes and preferences, puts high demands on the data collection methods.

Another important implication for the research field is that travel behaviour research over time should consider the bi-directional relationships between preferences, attitudes and travel behaviour. In our three-wave panel study, it is found that after an increase in mode use over time, young adults develop a stronger preference for that mode. In contrast, an increase in mode preference does not necessarily lead to an increase in the frequency of mode use. This implies that changes in travel behaviour are more likely to precede changes in preferences rather than the other way around. This process can be explained by the cognitive dissonance reduction theory, as discussed by Kroesen et al. (2017), who found similar effects in a two- 
wave panel study in the Netherlands. Overall, the findings in this thesis indicate that a dynamic research approach is necessary to study changes in travel behaviour and should include a feedback loop from behaviour to preference.

The availability of enhanced panel data sources offers new opportunities to develop new or to expand existing theories to study dynamics in travel behaviour. Most existing theories to explain changes in travel behaviour are based on cross-section data (see section 1.2). Using panel data and the application of both statistical and qualitative approaches supports the further theoretical conceptualization of the dynamics in travel behaviour (e.g. Scheiner and $\mathrm{Rau}$ ). Moreover, the increasing variation in daily activities, which can be derived from most panel data sources, is becoming more and more relevant to observe changes and examine behavioural dynamics (e.g., Kroesen and Goulias, 2016) and to innovate the theory about dynamics in travel behaviour. With the growing fragmentation of activities, the increasing number of activities conducted online and the increasing availability of on-demand and appdriven forms of transport, panel data is becoming increasingly important in travel behaviour research.

However, examination of bi-directional relationships over time, and also long-term behavioural processes such as habit formation, requires long-duration panel surveys, in particular for attitudes and preferences, as they are very stable over time. One of the reasons there are not many long-term panel surveys, such as the German Mobility Panel (i.e. since 1994) and the Mobility Panel Netherlands (i.e. since 2013) is the high costs of set-up and maintenance of these panels. On the other hand, using GPS tracking to collect trip data continuously offers new opportunities to develop panel surveys for different purposes (i.e. national, regional, local) and different periods (i.e. long-term vs short-term).

In general, traditional traffic and transport models assume homogenous groups in the population and variation in attitudes and preferences towards transport modes, for instance, are not included. Moreover, attitudes and preferences are often assumed to be constant over time. Also, intra- and interpersonal mode use variation are not considered separately. La Paix Puello et al. (2021) show that intrapersonal mode use variation is positively associated with cost sensitivity in the same year. In contrast, variability in mode choice between years decreases cost-sensitiveness for car and public transport modes. Also, Yang and Timmermans (2015) found a significant degree of inertia in car use behaviour in response to increased fuel prices. These findings show that it is essential to distinguish within and between effects. The forecasts obtained from traffic and transport demand models also provide an important basis for the decision-making process by policymakers, for example, whether or not to invest in new road infrastructure. If the dynamics in mode choice behaviour are ignored then an inadequate foundation for these decisions can result. Forecasting based on transport and traffic models can therefore be improved by addressing the behavioural changes over time at the individual level. This might improve, for example, the quality of microsimulation models in generating population synthesizers. These models estimate the activities and travel behaviour at the individual level, and a synthetic population for each forecast year is used. Panel data, including life-changing moments, can improve the estimation of the dynamics in the synthetic population.

\subsubsection{Implications for transport policy}

The findings regarding the dynamics in mode choice behaviour are also useful for policymakers in the field of transportation and for decision-makers in the related authorities. Stimulating sustainable mobility is a high priority for national, regional and local authorities. 
Although changing behaviour is complex and most of our behaviour is habitual, this thesis's results show various changes in mode choice behaviour over time. These changes tend to be concentrated around life-changing moments, interventions, spatial developments or infrastructural changes. Such contextual changes form a trigger to reconsider our behaviour. A contextual change in someone's life can therefore be seen as an essential pre-condition for increasing the effectiveness of policy measures. Moreover, policymakers should focus on behavioural changes to improve the effectiveness of their policy approach for two reasons. Firstly, this thesis shows that attitudes and preferences are more stable over time compared to behaviour. Secondly, the COVID-19 pandemic reveals that experiences with new behaviour increases the intention to change behaviour. This means that policymakers should focus on regulation, pilots and experiments to allow participants hands-on experience with new behaviour, such as testing e-bikes or trial periods using public transport for free. Other policy measures that encourage behavioural changes are changes in the physical environment, for example, investments in walking and cycling infrastructure to stimulate active mobility, or pricing policy, such as pricing depending on car use.

One of the main takeaways from this thesis for policy makers is that attitudinal changes can be expected after a behavioural change. This can help to create public support for travel demand management policies after implementation. Acceptance of measures aiming at the desired change of behaviour through rewarding people for adopting the desired behaviour ("the carrot") or letting them pay for the undesired behaviour ("the stick") can be expected to be positevly induced by gaining a positive experience with the desired behaviour. One well studied example is the successful introduction of the Stockholm Congestion Charge, where public attitdes became dramatically more positive over the years after its introduction, and self-reported changes in behaviour and attitudes considerably underestimated actual changes (Eliasson, 2014). Moreover, this thesis supports the use of experiments as valuable instruments for policy makers to test possible travel behaviour impacts, such as switching to a sustainable mode of transport. In the end this might lead to new habits and changing attitudes and preferences. Also. earlier studies have shown that experiments can help change attitudes, such as trails with free bus tickets for habitual drivers (e.g., Fujii and Kitamura, 2003; AbouZeid et al., 2012) or rewarding car drivers for avoiding peak hours (e.g., Meurs et al., 2015).

Policymakers can use contextual changes, including disruptive events such as the COVID-19 pandemic, as 'windows of opportunity'. A better understanding of how people react in such situations helps policymakers better anticipate these behavioural changes and establish more effective policies to achieve the desired changes. To that end, policy interventions can be more effective when policymakers have a clear understanding of the target group, have insight into the appropriate timing and duration of policy measures, and cooperate with the parties that, in addition to government, can make relevant contributions.

\section{A clear understanding of the target group}

Policymakers need a clear understanding of the target group. An intervention should be designed so that the highest possible effect will be achieved in the selected target group. This means that interventions should match people's motives and specific interests. For instance, a better insight into the sectors in which employees are more likely to telework or intend to increase working from home helps policymakers determine their target population(s). In this respect, it is worth mentioning that behavioural changes are strongly associated with social and cultural aspects. In cultures where companies offer new employees a lease car by default, public transport is not an equal alternative. Policymakers should also consider that in multiperson, and specifically in dual-income households, travel behaviour is more strongly affected 
by relationships between household members. For example, decisions on transport mode also depend on agreements about who will take the children to school before going to work or the commuting distance of the spouse. These household interactions are likely to be reinforced with an expected increase in teleworking after COVID-19. Finally, it is essential to be aware of the behavioural stage of change people are in, also known as the Transtheoretical Model, created by Prochaska and DiClemente (1983). Recognition of the stages of change of the target group is a good starting point for stimulating behavioural changes. For example, stated preference and early adopter studies on mobility innovations, such as bike and car-sharing and mobility-as-a-service, typically find infrequent car users and multi-modal travellers the most likely adopters (Burghard and Dütschke, 2019; Ho et al., 2018). Overall, policymakers should make a well-informed decision about the target group and suitable measures.

\section{Timing and duration are crucial aspects of implementation}

The timing and duration of policy measures are crucial aspects of implementation to achieve structural changes in travel behaviour. Policymakers should focus on the actions that cope with the new deliberation process brought by contextual changes in someone's life. This deliberation process can be anticipated by the individual and household characteristics of the target groups, such as income level, the urbanity of the residential location, gender, composition of the household or first job age. Moreover, the COVID-19 pandemic shows that when people experience with new behaviour over a more extended period, they are more willing to consider structural behavioural changes. In this respect, a free card for one public transport ride will be less effective than discounting a public transport pass for half a year. In this context, policymakers should assess the costs and benefits covered by this type of measure on a long-term basis.

\section{Involve relevant stakeholders: create more awareness of alternatives}

Finally, if possible, policymakers should involve relevant stakeholders, such as other authorities, employers, land register or consultancy agencies. In-depth interviews with young adults in the Netherlands reveal that young adults hardly receive information about transportrelated issues when they are about to relocate, change jobs or become a parent (Berveling et al., 2017). These life-changing moments or other contextual changes offer an excellent opportunity for policymakers and other parties to create more awareness of alternative, more sustainable modes of transport. For instance, local municipalities could issue incentives to new inhabitants, and employers could inform new employees about cycling and public transport options. Also, to stimulate more sustainable modes of transport, alternatives to the car should be put in place in advance in new residential areas. This means offering different forms of shared mobility, operational public transport connections, and installing bicycle infrastructure and attractive pedestrian routes to the bus- and train stations.

\subsection{Recommendations for further research}

This thesis contributes to a better understanding of dynamics in mode choice behaviour regarding household interactions, life events, changing attitudes and preferences, and teleworking. The findings demonstrate the potential of panel data to provide better insight into whose behaviour changes, why and when. Nevertheless, several issues remain to be explored, while other issues encourage future research into changes in travel behaviour, especially from a temporal point of view.

First, this thesis demonstrates some of the new research opportunities provided by large-scale panel data. Both of the panel data sets used in this thesis (i.e. MPN and NVP) contain 
longitudinal travel data, comprehensive information about the respondents' background and other travel-related characteristics, such as the accessibility of the residential and work location. This unique combination of travel data and detailed information of the same persons over time allowed us to analyse differences in weekly and yearly travel patterns at the individual level. In this thesis, panel data from the MPN and NVP were used separately. The strength of the MPN is that it collects relevant information about attitudes and preferences towards transport modes and life events. One of the shortcomings of the MPN is that a threeday trip diary does not capture the total variation in travel behaviour at the individual level. Using real-time and continuous tracking data, such as the NVP, overcomes this problem. However, the NVP lacks data about attitudes and preferences and life events. From a scientific perspective, the combination of MPN- and NVP-data offers unique chances for future research. This combination of real-time panel data and detailed information about the respondents allows researchers to examine the impact of both small (e.g., PT strike, weather alarm) and large (e.g., COVID-19, economic crisis) disruptive events.

Our findings show that life events have a significant impact on changes in travel behaviour. However, the impact of two or more specific related life events is not examined. Some life events coincide, which results in compounded effects. To illustrate, increased car ownership is more likely after a new job or when somebody moves from an urban to a rural area, except if there is a concurrent reduction in household income. It would be interesting in future research to examine these relationships and how these interactions affect travel behaviour. Also, it would be interesting to disentangle the effects of moving between urban and rural areas and moving within the same place. Based on existing research, it is expected that, for example, car use or car preference would decrease after moving from a rural area to a more urban area. Moving to a more urban area could explain the increase in cycling after moving home. However, in our sample, only a relatively small portion (i.e. less than $3 \%$ ) moved to a different area, and consequently, it was not possible to estimate these effects. A possible solution would be to investigate these compounded effects with mixed and/or qualitative approaches. This is in line with Scheiner and Rau (2020), who argue that the infrequent use of qualitative and mixed methods to study mobility and travel behaviour across the life course might be changing.

Another direction for future research is to examine the dynamics in mode choice behaviour for a more extended period. Intriguingly, significant temporal effects were already found when analysing only two or three waves; once data for subsequent years becomes available, more sophisticated panel analyses can be conducted. A more extended period could provide more variation in attitudes and mode use for different population segments over time, and both first-order and second-order effects could be included. It would also be useful to examine if the four identified latent classes reflecting travellers' attitudes towards car use and ownership remain or alter for a longer period. In addition, this would help to investigate contradictory results more in detail, such as tranitions between latent classes in both directions after a life event. Another benefit of the avaialibitly of more subsequent years is that differences in short- and long-term effects can be disentangled. Generally, the short-term effects of life events on travel behaviour are higher than long-term outcomes. In particular, gender differences and the (short- and long-term) effects of childbirth would be interesting to explore. Shortly after becoming parents, young adults spend more time at home and pursue more activities in their neighbourhood, resulting in fewer trips and car use. After a certain period, for example, when parents return to work, preference for the car might increase. Also, the difference between first-time parents and other parents is an exciting direction for future research. As a result of limitations in our dataset, I was not able to make these distinctions. 
With more waves of the MPN, both first- and second-order and short- and long-term effects could be included.

Van Acker and Witlox (2010) raised the question of whether car availability is just a predictor of car use or the result of a specific decision-making process. Exploring this kind of causal relation in both directions using panel data is another interesting research topic for the future. In this thesis, the impact of one variable at time $t$ on the other variable at time $t+1$ is examined. The lead effects between variables (i.e. the impact of one variable at time $t$ on the ther variable at time t-1) should be further analysed. Also, exploring more dimensions than only changes in mode choice or frequency of mode use, such as distance, travel time and the activity duration, would be a challenging and interesting task for future research. Additional models can be developed that not only look at the impacts of, for instance, life events and changes in attitudes on mode choice but also on the distance travelled or travel costs by mode. At the same time, it would be interesting to investigate if new dynamic theories about travel behavioural changes can be developed based on enhanced panel data and confirmatory research (i.e. hypothesis testing).

In this thesis, the impact of COVID-19 on teleworking and car use for commuting in the short term was investigated. However, the long-term effects might be different and should be evaluated in the future. The increase in teleworking has brought significant changes in the way we work, expanding the scope for working from home. A structural increase in teleworking might have consequences for household interactions as people are at home more, and it might also affect attitudes and preferences towards transport modes. Besides, people might reconsider their residential and work location, which can trigger life events such as moving home or changing job (e.g., Viana Cerqueira et al., 2020; Zhu, 2013). In-depth interviews with 26 young adults linving in Australia shows that the long-term effects are more complex and related to upcoming life events (Delbosc and McCarthy, 2021). Future research based on panel data could explore whether the COVID-19 pandemic strengthens existing behaviour and preferences in the long term, or results in structural changes in behaviour, preferences and commuting distance. In this respect, it must be noted that most employees in the Netherlands have access to high quality internet (CBS, 2018). Therefore, the Dutch situation and its extensive opportunities to work from home are not necessarily applicable to countries where the internet is of much lower quality. To that end, a comparative crosscountry study is also an interesting topic for future research.

Travel behaviour research has traditionally had a strong focus on the factors that affect changes in behaviour. This is not surprising as many policy measures aim to change behaviour, for instance stimulating active mobility through new cycling and walking routes. Although panel data offer unique opportunities to provide insight into these (possible) changes in travel behaviour, there is still a large group where behaviour does not change at all. Most of our behaviour, including travel behaviour, is habitual behaviour. This means that most of the time people do not make conscious choices and their behaviour is repetitive. People are often not aware of and do not reconsider their daily decisions (Verplanken et al., 2008). Future research into the characteristics of people who do and do not change behaviour would be useful for policymakers. Segmentation of the population and insight into the dynamics between these segments could help to determine which policy instruments are most effective in a given situation, for a given target group and at which moment during one's life course. 


\section{Acknowledgements}

For chapter 2, 3 and 4, this thesis makes use of data from the Netherlands Mobility Panel (in Dutch: Mobiliteitspanel Nederland, MPN), which is administered by the KIM Netherlands Institute for Transport Policy Analysis. The analyses in chapter 2 and 3 were also supported by the KIM Netherlands Institute for Transport Policy Analysis. Chapter 5 uses data from the Dutch Travel Panel (in Dutch: Nederlands Verplaatsings Panel, NVP), which is administered by DAT.mobility, Kantar, and Mobidot, and a survey commissioned by the Ministry of Infrastructure and Water Management. 


\section{References}

Abdullah, M., Dias, C., Muley, D., Shahin, M. (2020) Exploring the impacts of COVID-19 on travel behavior and mode preferences. Transportation Research Interdisciplinary Perspectives 8, 100255.

Abou-Zeid, M., Witter, R., Bierlaire, M., Kaufmann, V., Ben-Akiva, M., 2012. Happiness and travel mode switching: Findings from a Swiss public transportation experiment. Transport Policy 19, 93-104.

Abrahamse, W., Steg, L., Gifford, R., Vlek, C. (2009) Factors influencing car use for commuting and the intention to reduce it: A question of self-interest or morality? Transportation Research Part F: Traffic Psychology and Behaviour 12, 317-324.

Ajzen, I. (1991) The theory of planned behavior. Organizational Behavior and Human Decision Processes 50, 179-211.

Ajzen, I. (2015) The theory of planned behaviour is alive and well, and not ready to retire: a commentary on Sniehotta, Presseau, and Araújo-Soares. Health Psychology Review 9, 131137.

Gemeente Amsterdam (2020) Amsterdam maakt ruimte: Agenda Amsterdam Autluw. Amsterdam.

Anable, J. (2005) 'Complacent Car Addicts' or 'Aspiring Environmentalists'? Identifying travel behaviour segments using attitude theory. Transport Policy 12, 65-78.

Anable, J. (2013) SEGMENT Survey No 2: Data Evaluation Report - Utrecht. 
Andersen, S.M., Chen, S. (2002) The relational self: An interpersonal social-cognitive theory. Pshychological Review 109, 619-645.

Andreev, P., Salomon, I., Pliskin, N. (2010) Review: State of Teleactivities. Transportation Research Part C-emerging Technologies - TRANSPORT RES C-EMERG TECHNOL 18, 320.

Anggraini, R., Arentze, T., Timmermans, H. (2008) Car Allocation between Household Heads in Car Deficient Households: A Decision Model. European Journal of Transport and Infrastructure Research, 301-319.

Arroyo, R., Ruiz, T., Mars, L., Rasouli, S., Timmermans, H. (2020) Influence of values, attitudes towards transport modes and companions on travel behavior. Transportation Research Part F: Traffic Psychology and Behaviour 71, 8-22.

Auld, J., Zhang, L. (2013) Inter-personal interactions and constraints in travel behavior within households and social networks. Transportation 40, 751-754.

Axhausen, K.W. (2008) Social networks, mobility biographies, and travel: Survey challenges. Environmental and Planning B: Planning and Design 35, 981-996.

Bailey, J. (1984) The meaning of car availability in mode choice decisions. Transportation Planning and Technology 9, 125-134.

Bakk, Z., Tekle, F.B., Vermunt, J.K. (2013) Estimating association between latent class membership and external variables using bias-adjusted three-step approaches. Social Methodology, 272-311.

Bamberg, S. (2006) Is a Residential Relocation a Good Opportunity to Change People's Travel Behavior? Results From a Theory-Driven Intervention Study. Environment and Behavior 38, 820-840.

Bamberg, S., Ajzen, I., Schmidt, P. (2003) Choice of Travel Mode in the Theory of Planned Behavior: The Roles of Past Behavior, Habit, and Reasoned Action. Basic \& Applied Social Psychology 25, 175.

Bamberg, S., Behrens, G., Papendick, M., Bergmeyer, M., Brewitt, K., Rees, J., Zielinski, J. (2015) Development of a theory-driven, web-based behavioral change support system for environmentally friendly mobility behavior. . Social marketing: global perspectives, strategies and effects on consumer behavior ed Evans, W.D., New York, pp. 91-108.

Bamberg, S., Schmidt, P. (2003) Incentives, Morality, Or Habit? Predicting Students' Car Use for University Routes With the Models of Ajzen, Schwartz, and Triandis. Environment and Behavior 35, 264-285.

Beige, S., Axhausen, K. (2006) Long-term mobility decisions during the life course: experiences with a Retrospecitive Survey. Proceedings of IABTR.

Beige, S., Axhausen, K. (2012) Interdependencies between turning points in life and longterm mobility decisions. Transportation 39, 857-872. 
Belzunegui-Eraso, A., Erro-Garcés, A. (2020) Teleworking in the Context of the Covid-19 Crisis. Sustainability 12, 3662.

Berveling, J., Harms, L., Haas, M.d., Scheepers, E., Wust, H. (2017) Levensgebeurtenissen en mobiliteit. Kennisinstituut voor Mobiliteitsbeleid, The Hague, the Netherlands.

Bhat, C.R., Pendyala, R.M. (2005) Modeling intra-household interactions and group decisionmaking. Transportation 32, 443-448.

Bjerkan, K.Y., Nordtømme, M.E. (2014) Car use in the leisure lives of adolescents. Does household structure matter? Transport Policy 33, 1-7.

Borgoni, R., Ewert, U.C., Fürnkranz-Prskawetz, A. (2002) How important are household demographic characteristics to explain private car use patterns? A multilevel approach to Austrian data.

Buehler, R. (2011) Determinants of transport mode choice: a comparison of Germany and the USA. Journal of Transport Geography 19, 644-657.

Bullen, N., Jones, K., Duncan, C. (1997) Modelling complexity: Analysing betweenindividual and between place variation - A multilevel tutorial. Environment Planning A 29, 585-609.

Burghard, U., Dütschke, E. (2019) Who wants shared mobility? Lessons from early adopters and mainstream drivers on electric carsharing in Germany. Transportation Research Part D: Transp. Environ. 71, 96-109.

Burkholder, G.J., Harlow, L.L. (2003) An Illustration of a Longitudinal Cross-Lagged Design for Larger Structural Equation Models. Structural Equation Modeling: A Multidisciplinary Journal 10, 465-486.

Busch-Geertsema, A., Lanzendorf, M. (2017) From university to work life - Jumping behind the wheel? Explaining mode change of students making the transition to professional life. Transportation Research Part A: Policy and Practice 106, 181-196.

CBS (2016) Onderzoek Verplaatsingen in Nederland, 2016. Het Databestand. Statistics Netherlands. The Hague/Heerlen.

CBS (2018) CBS Statline. Statistics Netherlands. The Hague/Heerlen.

CBS (2019) Onderweg in Nederland. Statistisch Netherlands. The Hague/Heerlen: Nederland.

Chatterjee, K., Clark, B., Bartle, C. (2016) Commute mode choice dynamics: Accounting for day-to-day variability in longer term change. European Journal of Transport and Infrastructure Research 16, 713-734.

Chatterjee, K., Scheiner, J. (2015) Understanding travel behaviour over the life course: Contributions from biographical research. 14th International Conference on Travel Behaviour Reserach, Windsor: United Kindom. 
Cherchi, E., Börjesson, M., Bierlaire, M. (2013) A hybrid mode choice model to account for the dynamic effect of inertia over time. International Choice Modelling Conference, Sydney, Australia.

Cherchi, E., Cirillo, C. (2008) A mixed logit mode chioce model on panel data: accounting for systematic and random variations on responses and preferences. Transportation Research Board, Washington.

Cherchi, E., Cirillo, C. (2014) Understanding variability, habit and the effect of long period activity plan in modal choices: a day to day, week to week analysis on panel data. Transportation 41, 1245-1262.

Chlond, B., Lipps, O. (2000) Multimodalität im Personenverkehr im intrapersonellen Längschnitt. Stads Region Land, Institut für Stadtbauwesen der RWTH Aachen, Aachen, Germany.

Chlond, B., Kuhnimhof, T. (2003). Rules of non-response and selectivity: analysing the dropout in the multi-stage recruitment process for the German mobility panel. In Association for European Transport (AET) (Ed.), Conference proceedings of the European Transport Conference (ETC). London: AET.

Choo, S., Mokhtarian, P., Salomon, I. (2005) Does Telecommuting Reduce Vehicle-miles Traveled? An Aggregate Time Series Analysis for the U. S. Transportation 32.

Chung, H., Anthony, J.C., Schafer, J.L. (2011) Latent class profile analysis: An application to stage sequential processes in early onset drinking behaviours. Journal of the Royal Statistical Society. Series A (Statistics in Society) 712, 689-712.

Clark, B., Chatterjee, K., Melia, S. (2014) Life events and travel behaviour: exploring the inter-relationship using the UK household longitudinal study. TRB, Washington.

Clark, B., Chatterjee, K., Melia, S. (2016) Changes to commute mode: the role of life events, spatial context and environmental attitude. Transport Research Part A 89, 89-105.

Cohen, J. (1988) Statistical power analysis for the behavioral sciences. Lawrence Erlbaum Associates, Hillsdale, New Jersey.

Collins, L.M., Hyatt, S.L., Graham, J.W. (2000) Latent transition analysis as a way of testing models of stage-sequential change in longitudinal data. Modeling longitudinal and multilevel data: Practical issues, applied approaches, and specific examples eds Little, T.D., Schnabel, K.U., Baumert, J. Lawrence Erlbaum Associates, New York, pp. 147-161.

Collins, L.M., Lanza, S.T. (2010) Latent class and latent transition analysis: With applications in the social, behavioral, and health sciences. Wiley, New York.

Commins, N., Nolan, A. (2011) The determinants of mode of transport to work in the Greater Dublin Area. Transport Policy 18, 259-268. 
Davis, B., Dutzik, T. (2012) Transportation and the New Generation - Why Young People Are Driving Less and What It Means for Transportation Policy. Frontier Group U.S. PIRG Education Fund.

de Abreu e Silva, J., Melo, P.C. (2018) Does home-based telework reduce household total travel? A path analysis using single and two worker British households. Journal of Transport Geography 73, 148-162.

de Graaff, T., Rietveld, P. (2004) ICT and Substitution Between Out-of-Home and at-Home Work: The Importance of Timing. Environment and Planning A: Economy and Space 36, 879-896.

de Haas, M., Kroesen, M., Chorus, C., Hoogendoorn-Lanser, S., Hoogendoorn, S. (2021). Ebike use groups and substitution effects: evidence from longitudinal travel data in the Netherlands. Transportation.

de Haas, M., Faber, R., Hamersma, M. (2020) How COVID-19 and the Dutch 'intelligent lockdown' change activities, work and travel behaviour: Evidence from longitudinal data in the Netherlands. Transportation Research Interdisciplinary Perspectives 6, 100150.

de Haas, M.C., Scheepers, C.E., Harms, L.W.J., Kroesen, M. (2018) Travel pattern transitions: Applying latent transition analysis within the mobility biographies framework. Transportation Research Part A: Policy and Practice 107, 140-151.

de Jong, G., Gunn, H., Ben-Akiva, M. (2004) A meta-model for passenger and freight transport. European Transport Policy 11, 329-344.

de Vos, J., Singleton, P.A., Gärling, T. (2021). From attitude to satisfaction: introducing the travel mode choice cycle. Transport Reviews, 1-18

de Vos, J., Alemi, F. (2020) Are young adults car-loving urbanites? Comparing young and older adults' residential location choice, travel behavior and attitudes. Transportation Research Part A: Policy and Practice 132, 986-998.

Delbosc, A., McCarthy, L. (2021). Pushed back, pulled forward: Exploring the impact of COVID-19 on young adults' life plans and future mobility. Transport Policy 107, 43-51

Delbosc, A. (2016) Delay or forgo? A closer look at youth driver licensing trends in the United States and Australia. . Transportation, 1-8.

Delbosc, A., Currie, G. (2013) Exploring Attitudes of Young Adults toward Cars and Driver Licensing. Proceedings of Australasian Transport Research Forum, Brisbane, Australia.

Dieleman, F.M., Dijst, M., Burghouwt, G. (2002) Urban form and trabel behaviour: microlevel household attributes and residential context. Urban Studies 39, 507-5527.

Dijst, M., Rietveld, P., Steg, L. (2013) Individual needs, opportunities and travel behaviour: a multidisciplinary perspective based on psychology, economics and geography., The Transport System and Transport Policy eds Wee, B.v., Annema, J.A. Edward Elgar Publishing Limited, Cheltenham, United Kingdom, pp. 19-51. 
Donald, I.J., Cooper, S.R., Conchie, S.M. (2014) An extended theory of planned behaviour model of the psychological factors affecting commuters' transport mode use. Journal of Environmental Psychology 40, 39-48.

Provincie Drenthe (2020) Mobiliteitsprogramma 2021-2030.

Dutzik, T., Baxandall, P. (2013) A New Direction - Our Changing Relationship with Driving and the Implications for America's Future. U.S. PIRG Education Fund Frontier Group.

Eliasson, J., 2014. The role of attitude structures, direct experience and reframing for the success of congestion pricing. Transportation Research Part A: Policy and Practice 67, 81-95

Elldér, E. (2020) Telework and daily travel: New evidence from Sweden. Journal of Transport Geography 86, 102777.

Gemeente Enschede (2021) Fietsvisie Enschede 2030: Leefbaar, Aantrekkelijk en Bereikbaar per fiets. Enschede.

Erikson, E. (1998) The Life Cycle Completed. W.W. Norton \& company, New York, London.

Ettema, D., Schwanen, T., Timmermans, H. (2007) The effect of location, mobility and sociodemographic factors on task and time allocation of households. Transportation 34, 89-105.

Feng, J., Dijst, M., Wissink, B., Prillwitz, J. (2014) Understanding mode choice in the Chinese context: The case of Nanjing metropolitan area. Tijdschrift voor Economische en Sociale Geografie 105, 315-330.

Frey, C.B., Osborne, M.A. (2017) The future of employment: How susceptible are jobs to computerisation? Technological Forecasting and Social Change 114, 254-280.

Fujii, S. (2010) Editorial: Introduction to the special issue on behavior modification for sustainable transportation. International Journal of Sustainable Transportation 4, 249-252.

Fujii, S., Kitamura, R. (2003). What does a one-month free bus ticket do to habitual drivers? An experimental analysis of habit and attitude change. Transportation 30, 81-95 10

Geurs, K.T. (2014) Dynamiek in Mobiliteit en Bereikbaarheid.

Ghisletta, P., Spini, D. (2004) An Introduction to Generalized Estimating Equations and an Application to Assess Selectivity Effects in a Longitudinal Study on Very Old Individuals. Journal of Educational and Behavioral Statistics 29, 421-437.

Gliebe, J.P., Koppelman, F.S. (2005) Modeling household activity-travel interactions as parallel constrained choices. Transportation 32, 449-471.

Golob, T.F., Meurs, H. (1987). A structural model of temporal change in multi-modal travel demand. Transportation Research Part A: General 21, 391-400.

González, R.M., Marrero, Á.S., Cherchi, E. (2017) Testing for inertia effect when a new tram is implemented. Transportation Research Part A: Policy and Practice 98, 150-159. 
González, R.M., Marrero, Á.S., Marrero, G.A. (2016) How the values of travel time change when a panel data around a new tram implementation is used. European Journal of Transport and Infrastructure Research 16, 554-572.

Goulias, K.G. (2000) Repeated measures multilevel analysis of daily time allocation to activities and travel. Citrans Working Paper.

Guell, C., Panter, J., Jones, N.R., Ogilvie, D. (2012) Towards a differentiated understanding of active travel behaviour: using social theory to explore everyday commuting. Soc Sci Med $75,233-239$.

Haddad, H., Lyons, G., Chatterjee, K. (2009) An examination of determinants influencing the desire for and frequency of part-day and whole-day homeworking. Journal of Transport Geography 17, 124-133.

Haggar, P., Whitmarsh, L., Skippon, S.M. (2019) Habit discontinuity and student travel mode choice. Transportation Research Part F: Traffic Psychology and Behaviour 64, 1-13.

Hamaker, E.L. (2012) Why Researchers Should Think“ Within-Person”: A Paradigmatic Rationale.

Hamaker, E.L., Kuiper, R.M., Grasman, R.P. (2015) A critique of the cross-lagged panel model. Psychological Methods 20, 102-116.

Handy, S., Cao, X., Mokhtarian, P. (2005) Correlation or causality between the built environment and travel behavior? Evidence from Northern California. Transportation Research Part D: Transport and Environment 10, 427-444.

Harms, L., Jorritsma, P., Kalfs, N. (2007) Beleving en beeldvorming van mobiliteit. Kennisinstituut voor Mobiliteitsbeleid, The Hague, the Netherlands.

He, S.Y., Hu, L. (2015) Telecommuting, income, and out-of-home activities. Travel Behaviour and Society 2, 131-147.

Hedeker, D. (2007) Multilevel Models for ordinal and nominal variables. Handbook of Multilevel Analysis eds Leeuw, J.d., Meijers, E. Springer, , New York, NY, USA, pp. 341376.

Helminen, V., Ristimäki, M. (2007) Relationships between Commuting Distance, Frequency and Telework in Finland. Journal of Transport Geography 15, 331-342.

Herde, A. (2007) Nachaltige Ernährung im Übergang zur Elternschaft. Technischen Universität Berlin.

Hilbers, H., Snellen, D., Hendriks, A. (2005) De invloed van de werklocatie. Ruimtelijk Planbureau, Rotterdam/The Hague, the Netherlands.

Hjorthol, R., Nossum, Å. (2007) Teleworking - Possible Interaction with Travel Patterns. European Transport Conference, Leiden, The Netherlands. 
Ho, C., Mulley, C. (2013) Tour-based mode choice of joint household travel patterns on weekend and weekday. Transportation 40, 789-811.

Ho, C., Mulley, C. (2015a) Intra-household Interactions in tour-based mode choice: The role of social, temporal, spatial and resource constraints. Transport Policy 38, 52-63.

Ho, C., Mulley, C. (2015b) Intra-household interactions in transport research: a review. Transport Reviews 35, 33-55.

Ho, C.Q., Hensher, D.A., Mulley, C., Wong, Y.Z. (2018) Potential uptake and willingness-topay for mobility as a service (MaaS): a stated choice study. Transportation Research Part A: Policy and Practice 117, 302-318.

Hoogendoorn-Lanser, S., Schaap, N.T.W., OldeKalter, M.J.T. (2015) The Netherlands Mobility Panel: An Innovative Design Approach for Web-based Longitudinal Travel Data Collection. Transportation Research Procedia 11, 311-329.

Hox, J. (2010) Multilevel Analysis: Techniques and Applications, 2nd ed. Routeledge, New York: USA.

Hox, J.J. (2002) Multilevel analysis: Techniques and applications. Lawrence Erblaum Associates, Mahwah, NJ, USA.

Hu, L.T., Bentler, P.M. (1999) Cutoff criteria for fit indexes in covariance structure analysis: Conventional criteria versus new alternatives. Structural Equation Modeling: A Multidisciplinary Journal 6, 1-55.

Irawan, M.Z., Belgiawan, P.F., Joewono, T.B., Bastarianto, F.F., Rizki, M., Ilahi, A. (2021) Exploring activity-travel behavior changes during the beginning of COVID-19 pandemic in Indonesia. Transportation.

İşcan, Ö., Naktiyok, A. (2005) Attitudes towards Telecommuting: The Turkish Case. JIT 20, 52-63.

Janke, J., Handy, S. (2019) How life course events trigger changes in bicycling attitudes and behavior: Insights into causality. Travel Behaviour and Society 16, 31-41.

Jorritsma, P. (2017) Mobiliteitsbeeld 2017. Kennisinstituut voor Mobiliteitsbeleid, The Hague, the Netherlands.

Jorritsma, P., Berveling, J. (2014) Niet autoloos, maar autolater. Voor de generatie Y blijft de auto een aantrekkelijk alternatief. Kennisinstituut voor Mobiliteitsbeleid, The Hague, the Netherlands.

Kaewkluengklom, R., Satiennam, W., Jaensirisak, S., Satiennam, T. (2017) Influence of psychological factors on mode choice behaviour: Case study of BRT in Khon Kaen City, Thailand. Transportation Research Procedia 25, 5072-5082. 
Kim, S.N. (2017) Is telecommuting sustainable? An alternative approach to estimating the impact of home-based telecommuting on household travel. International Journal of Sustainable Transportation 11, 72-85.

Klein, N.J., Smart, M.J. (2017) Millennials and car ownership: Less money, fewer cars. Transport Policy 53, 20-29.

Kloas, J., Kunert, U. (1994) Über die Schwierigkeit, Verkehrsverhalten zu messen. Die drei KONTIV-Erhebungen im Vergleich., Verkehr und Technik. Firmware Entwicklung, Lumino $\mathrm{GmbH}$, Krefeld, Germany.

Klockner, C.A. (2005) Können wichtige Lebensereignisse die gewohnheitsmäBige Nutzung von Verkehrsmitteln verändern? Eine retrospektive Analyse. Umweltpsychologie 9, 28-45.

Klöckner, C.A., Friedrichsmeier, T. (2011) A multi-level approach to travel mode choice How person characteristics and situation specific aspects determine car use in a student sample. Transportation Research Part F: Traffic Psychology and Behaviour 14, 261-277.

Kreft, I., De Leeuw, J. (1998) Introducing Multilevel Modelling. Sage, Thousands Oak: California.

Kroesen, M. (2014) Modeling the behavioral determinants of travel behavior: An application of latent transition analysis. Transportation Research Part A, 56-67.

Kroesen, M. (2015) Do partners influence each other's travel patterns? A new approach to study the role of social norms. Transportation Research Part A: Policy and Practice 78, 489505 .

Kroesen, M., Cranenburgh, S.v. (2016) Revealing transition patterns between mono- and multimodal travel patterns over time: A mover-stayer model. European Journal of Transport and Infrastructure Research 16, 754-771.

Kroesen, M., Goulias, K. G. (2016). Modelling activity-travel behaviour dynamics with panel data: The state-of-the-art. European Journal of Transport and Infrastructure Research, 16(4).

Kroesen, M., Handy, S., Chorus, C. (2017) Do attitudes cause behavior or vice versa? An alternative conceptualization of the attitude-behavior relationship in travel behavior modeling. Transportation Research Part A 101, 190-202.

Kuhnimhof, T., Buehler, R., Dargay, J. (2011) A New Generation: Travel Trends among Young Germans and Britons. Transportation Research Board, Washington.

Kuhnimhof, T., Buehler, R., Wirtz, M., Kalinowska, D. (2012) Travel trends among young adults in Germany: increasing multimodality and declining car use for men. Journal of Transport Geography 24, 443-450.

Kuhnimhof, T., Zumkeller, D., Chlond, B. (2013) Who made peak car, and how? A breakdown of trends over four decades in four countries. Transportation Review 33, 325-352. 
Kuppam, A.R., Pendyala, R.M., Rahman, S. (1999) Analysis of the Role of Traveler Attitudes and Perceptions in Explaining Mode-Choice Behavior. Transportation Reseach Record.

Kuppens, P., Oravecz, Z., Tuerlinckx, F. (2010) Feelings change: accounting for individual differences in the temporal dynamics of affect. Journal Personality Social Pshycology 99, 1042-1060.

La Paix Puello, L., Oakil, A.T.M., Hofman, F., Geurs, K.T. (2021) The influence of panel effects and inertia on travel cost elasticities for car use and public transport. Transportation (article in press).

La Paix Puello, L., Olde-Kalter, M.J., Geurs, K.T. (2017) Measurement of non-random attrition effects on mobility rates using trip diaries data. Transportation Research Part A: Policy and Practice 106, 51-64.

Lachapelle, U., Tanguay, G., Neumark-Gaudet, L. (2017) Telecommuting and sustainable travel: Reduction of overall travel time, increases in non-motorized travel and congestion relief? Urban Studies 55.

Lally, P., Jaarsveld, C.H.M.v., Potts, H.W., Wardle, J. (2010) How are habits formed: Modelling habit formation in the real worldy. European Journal of Social Psychology, 9981009.

Lanza, S.T., Patrick, M.E., Maggs, J.L. (2010) Latent Transition Analysis: Benefits of a Latent Variable Approach to Modeling Transitions in Substance Use. Journal of Drug Issues 40, 93-120.

Lanza, S.T., Tan, X., Bray, B.C. (2013) Latent Class Analysis With Distal Outcomes: A Flexible Model-Based Approach. Structural equation modeling : a multidisciplinary journal $20,1-26$

Lanzendorf, M. (2003) Mobility biographies : A new perspective for understanding travel behaviour. Paper presented at the 10th International Conference on Travel Behaviour Research, Lucerne, August 2003.

Lanzendorf, M. (2010) Key Events and Their Effect on Mobility Biographies: The Case of Childbirth. International Journal of Sustainable Transportation 4, 272 - 292.

Lee, J. H., Davis, A. W., Goulias, K. G. (2017). Triggers of behavioral change: Longitudinal analysis of travel behavior, household composition and spatial characteristics of the residence. Journal of choice modelling, 24, 4-21.

Limtanakool, N., Dijst, M., Schwanen, T. (2006) The influence of socioeconomic characteristics, land use and travel time considerations on mode choice for medium- and longer-distance trips. Journal in Transport Geography 14, 327-341.

Lipps, O., Kunert, U. (2005) Measuring and Explaining the Increase of Travel Distance: a Multilevel Analysis Using Repeated Cross Sectional Travel Surveys. 
Liu, X. (2016) Methods and Applications of Longitudinal Data Analysis. Academic Press, Oxford.

Loo, B.P.Y., Wang, B. (2018) Factors associated with home-based e-working and e-shopping in Nanjing, China. Transportation 45, 365-384.

Lorenzo-Seva, U., ten Berge, J.M.F. (2006) Tucker's congruence coefficient as a meaningful index of factor similarity. Methodology: European Journal of Research Methods for the Behavioral and Social Sciences 2, 57-64.

Maat, K., Timmermans, H.J.P. (2009) Influence of the residential and work environment on car use in dual-earner households. Transportation Research Part A: Policy and Practice 43, 654-664.

Magidson, J. (2013) Using Mixture Latent Markov Models for Analyzing Change with Longitudinal Data. Modern Modeling Methods, University of Connecticut.

Magidson, J., Vermunt, J.K. (2004) Latent Class Models. The Sage Handbook of Quantitative Methodology for the Social Sciences, pp. 175-198.

MarketResponse (2020) Mobiliteit van Nederlanders tijdens COVID-19: mate van thuiswerken nu en in de toekomst, tweede herhaalmeting. In opdracht van: Ministerie van Infrastructuur en Waterstaat, the Hague.

Masyn, K. (2013) Latent class and finite mixture modeling. Oxford Handbook of quantitative method ed Little, T.D. Oxford Press, Oxford, pp. 551-611.

McBride, E., Lee, J. H., Lundberg, A. M., Davis, A. W., Goulias, K. G. (2016). Behavioural micro-dynamics of car ownership and travel in the Seattle metropolitan region from 1989 to 2002. European Journal of Transport and Infrastructure Research, 16(4).

Meurs, H., Stelling, C., Haaijer, R. (2015). Belonen voor spitsmijden: effecten van mobiliteitsprojecten. Tijdschrift Vervoerswetenschap 51, 63-86

Meurs, H. (2007) Longitudinal data in transport research. MuConsult, Amersfoort, the Netherlands.

Meurs, H., Van Wissen, L.J.G., Visser, J. (1989) Measurement biases in panel data. Transportation 16, 175-194.

Miller, E.J., Roorda, M.J., Carrasco, J.A. (2005) A tour-based model of travel mode choice. Transportation 32, 399-422.

Miskeen, M.A.A., Alhodairi, A.M., Rahmat, R.A.A.O.K. (2013) Modeling a Multinomial Logit Model of Intercity Travel Mode Choice Behavior for All Trips in Libya. International Journal of Civil, Architectural, Structural and Construction Engineering 7, 308-217.

Miskeen, M.A.A., Alhodairi, A.M., Rahmat, R.A.A.O.K. (2014) Modeling of intercity travel mode choice behavior for non-business trips within Libya. Research Journal of Applied Sciences, Engineering and Technology 7, 442-453. 
Mokhtarian, P., Collantes, G., Gertz, C. (2004) Telecommuting, Residential Location, and Commute-Distance Traveled: Evidence from State of California Employees. Environment and Planning A 36, 1877-1897.

Mokhtarian, P.L., Bagley, M.N., Salomon, I. (1998) The impact of gender, occupation, and presence of children on telecommuting motivations and constraints. Journal of the American Society for Information Science 49, 1115-1134.

Mokhtarian, P.L., Salomon, I. (1994) Modeling the Choice of Telecommuting: Setting the Context. Environment and Planning A: Economy and Space 26, 749-766.

Molin, E., Mokhtarian, P., Kroesen, M. (2016) Multimodal travel groups and attitudes: A latent class cluster analysis of Dutch travelers. Transportation Research Part A: Policy and Practice 83, 14-29.

Molloy, J., Schatzmann, T., Schoeman, B., Tchervenkov, C., Hintermann, B., Axhausen, K.W. (2021) Observed impacts of the Covid-19 first wave on travel behaviour in Switzerland based on a large GPS panel. Transport Policy 104, 43-51.

Müggenburg, H., Busch-Geertsema, A., Lanzendorf, M. (2015) Mobility biographies: A review of achievements and challenges of the mobility biographies approach and a framework for further research. Journal of Transport Geography 46, 151-163.

Müller, S., Tscharaktschiew, S., Haase, K. (2008) Travel-to-school mode choice modelling and patterns of school choice in urban areas. Journal of Transport Geography 16, 342-357.

Nello-Deakin, S., Brömmelstroet, M.t. (2021) Scaling up cycling or replacing driving? Triggers and trajectories of bike-train uptake in the Randstad area. Transportation.

Nguyen, M.H. (2021) Factors influencing home-based telework in Hanoi (Vietnam) during and after the COVID-19 era. Transportation.

Niemeier, D.A., Mannering, F.L. (1994) Factors Influencing Changes in Mode Choice and Workplace Location: Some Empirical Evidence, Washington, DC.

Nijland, H., Meerkerk, J.v., Hoen, A. (2015) Effecten van autodelen op mobiliteit en CO2uitstoot. Planbureau voor de Leefomgeving, The Hague, the Netherlands.

Non, M., Dinkova, M., Dahmen, B. (2021) Skill up or get left behind? Digital skills and labor market outcomes in the Netherlands. CPB Netherlands Bureau for Economic Policy Analysis, The Hague, the Netherlands.

Nunnally, J.C. (1978) Psychometric theory, 2nd ed. McGraw-Hill, New York.

Nurul Habib, K.M., Sasic, A., Zaman, H. (2012) Investigating Telecommuting Considerations in the Context of Commuting Mode Choice. International Journal of Sustainable Transportation 6, 362-383.

Nylund, K.L. (2007) Latent Transition Analysis: Modeling Extensions and an Application to Peer Victimization. University of California. 
O'Keefe, P., Caulfield, B., Brazil, W., White, P. (2016) The impacts of telecommuting in Dublin. Research in Transportation Economics 57, 13-20.

Oakil, A.T.M., Ettema, D., Arentze, T., Timmermans, H. (2011). A longitudinal analysis of the dependence of the commute mode switching decision on mobility decisions and life cycle events. In Transport dynamics: Proceedings of 16th International Conference of Hong Kong Society for Transportation Studies (HKSTS). Hong Kong Society for Transportation Studies, Hong Kong.

Oakil, A.T.M. (2014) Changing household car ownership level and life cycle events: An action in anticipation or an action on occurrence. Transportation 41, 889-904.

Oakil, A.T.M., Ettema, D., Arentze, T., Timmermans, H. (2016a) Bicycle commuting in the Netherlands: An Analysis of modal shift and its dependence on life cycle and mobility events. International Journal of Sustainable Transportation 10, 376-384.

Oakil, A.T.M., Manting, D., Nijland, H. (2016b) Dynamics in car ownership: the role of entry into parenthood. European Journal of Transport and Infrastructure Research 16, 661-673.

Olde Kalter, M.J.T., Geurs, K.T., Hoogendoorn-Lanser, S. (2015) Vervoerwijzekeuze in woon-werkverkeer. Eerste analyses met het nieuwe Mobiliteitspanel Nederland. Tijdschrift Vervoerwetenschap 51, 107-127.

Olde Kalter, M.J.T., Geurs, K.T., Hoogendoorn-Lanser, S., Beek, v.P. (2014) Mode-choice behaviour for home-based work trips: The first results of the new Netherlands Mobility Panel 10th International Conference on Survey Methods in Transport, Leura: Australia.

Olde Kalter, M.J.T., La Paix Puello, L., Geurs, K.T. (2020) Do changes in travellers' attitudes towards car use and ownership over time affect travel mode choice? A latent transition approach in the Netherlands. Transportation Research Part A: Policy and Practice 132, 1-17.

Olde Kalter, M.J.T., La Paix Puello, L., Geurs, K.T. (2021) Exploring the relationship between life events, mode preferences and mode use of young adults: A 3-year cross-lagged panel analysis in the Netherlands. Travel Behaviour and Society 24, 195-204.

Ortúzar, J.d.D., Armoogum, J., Madre, J.-L., Potier, F. (2011) Continuous Mobility Surveys: The State of Practice. Transport Reviews 31, 293 - 312.

Ouellette, J., Wood, W. (1998) Habit and Intention in Everyday Life: The Multiple Processes by Which Past Behavior Predicts Future Behavior. Psychological Bulletin - PSYCHOL BULL $124,54-74$.

Paulssen, M., Temme, D., Vij, A., Walker, J. (2014) Values, attitudes and travel behavior: a hierarchical latent variable mixed logit model of travel mode choice. Transportation 41, 873888 .

Pawlak, J., Polak, J.W., Sivakumar, A., Gann, D. (2015) Investigating Diffusion of Relationships between ICT and Travel Behaviour by Pooling Independent Cross-Sectional Data across Time. Transportation Research Board, Washington. 
Pendyala, R., Goulias, K., Kitamura, R. (1991) Impact of Telecommuting on Spatial and Temporal Patterns of Household Travel. Transportation 18, 383-409.

Peters, P., Tijdens, K.G., Wetzels, C. (2004) Employees' opportunities, preferences, and practices in telecommuting adoption. Information \& Management 41, 469-482.

Popuri, Y., Bhat, C. (2003) On Modeling Choice and Frequency of Home-Based Telecommuting. Transportation Research Record 1858, 55-60.

Prillwitz, J., Barr, S. (2011) Moving towards sustainability? Mobility styles, attitudes and individual travel behaviour. Journal of Transport Geography 19, 1590-1600.

Prochaska, J.O., DiClemente, C.C. (1983) Stages and processes of self-change of smoking: Toward an integrative model of change. Journal of Consulting and Clinical Psychology 51, 390-395.

Raftery, A.E. (1995) Bayesian model selection in social research. Sociological Methodology 25, 111-163.

Rau, H., Manton, R. (2015) Mobility Biographies: A Study of Life Events and Mobility Milestones in Ireland.

Rau, H., Manton, R. (2016) Life Events and Mobility Milestones: Advances in mobility biography theory and research. Journal in Transport Geography, 51-60.

Rauws, R., Lierop, D.v. (2020) Returning to Public Transit after an Epidemic. Transport Findings.

Riggs, W. (2020) Telework and Sustainable Travel During the COVID-19 Era. Social Science Research Network (SSRN).

Rosseel, Y. (2012) lavaan: An R Package for Structural Equation Modeling. Journal of Statistical Software 48, 36.

Rubin, O., Mulder, C.H., Bertolini, L. (2014) The determinants of mode choice for familiy visits - evidence from Dutch panel data. Journal of Transport Geography 38, 137-147.

Schäfer, M., Jaeger-Erben, M., Bamberg, S. (2012) Life Events as Windows of Opportunity for Changing Towards Sustainable Consumption Patterns? Journal of Consumer Policy 35, 65-84.

Scheiner, J. (2016) Time use and the life course: a study of key events in the lives of men and women using panel data. European Journal of Transport and Infrastructure Research 16, $638-660$

Scheiner, J., Chatterjee, K., Heinen, E. (2016) Key events and multimodality: A life course approach. Transportation Research Part A: Policy and Practice 91, 148-165. 
Scheiner, J., Holz-Rau, C. (2013) A comprehensive study of life course, cohort, and period effects on changes in travel mode use. Transportation Research Part A: Policy and Practice $47,167-181$.

Scheiner, J., Rau, H. (2020) Mobility and Travel Behaviour Across the Life Course: Qualitative and Quantitative Approached. Edwar Elgar Publishing, Cheltenham: United Kindom.

Schoenduwe, R., Mueller, M.G., Peters, A., Lanzendorf, M. (2015) Analysing mobility biographies with the life course calendar: a retrospective survey methodology for longitudinal data collection. Journal of Transport Geography 42, 98-109.

Schwanen, T. (2011) Car Use and Gender: The Case of Dual-Earner Families in Utrecht, The Netherlands. Auto Motives, pp. 151-171.

Schwanen, T., Banister, D., Anable, J. (2012) Rethinking habits and their role in behaviour change: the case of low-carbon mobility. Journal of Transport Geography 24, 522-532.

Schwanen, T., Dieleman, F.M., Dijst, M. (2004) The Impact of Metropolitan Structure on Commute Behavior in the Netherlands: A Multilevel Approach. Growth \& Change 35, 304333.

Schwanen, T., Ettema, D., Timmermans, H. (2007) If you pick up the children, I'll do the groceries: spatial differences in between-partner interactions in out-of-home household activities. Environment and Planning A 39, 2754-2773.

Schwartz, S.H. (1977) Normative influences on altruism Academic Press, San Diego, pp. 221-279., Advances in Experimental Social Psychology ed Berkowitz, L. Academic Press, San Diego.

Selig, J.P., Little, T.D. (2012) Autoregressive and cross-lagged panel analysis for longitudinal data. Handbook of development research methods eds Laursen, B., Little, T.D., Card, N.A., pp. 265-278.

Semanjski, I., Gautama, S. (2016) Crowdsourcing mobility insights - Reflection of attitude based segments on high resolution mobility behaviour data. Transportation Research Part C: Emerging Technologies 71, 434-446.

Semenescu, A., Gavreliuc, A., Sârbescu, P. (2020) 30 Years of soft interventions to reduce car use - A systematic review and meta-analysis. Transportation Research Part D: Transport and Environment 85, 102397.

Sener, I.N., Reeder, P.R. (2012) An Examination of Behavioral Linkages across ICT Choice Dimensions: Copula Modeling of Telecommuting and Teleshopping Choice Behavior. Environment and Planning A: Economy and Space 44, 1459-1478.

Shabanpour, R., Golshani, N., Tayarani, M., Auld, J., Mohammadian, A. (2018) Analysis of telecommuting behavior and impacts on travel demand and the environment. Transportation Research Part D: Transport and Environment 62, 563-576. 
Shakibaei, S., de Jong, G.C., Alpkökin, P., Rashidi, T.H. (2021) Impact of the COVID-19 pandemic on travel behavior in Istanbul: A panel data analysis. Sustainable cities and society $65,102619$.

Shamshiripour, A., Rahimi, E., Shabanpour, R., Mohammadian, A. (2020) How is COVID-19 reshaping activity-travel behavior? Evidence from a comprehensive survey in Chicago. Transportation Research Interdisciplinary Perspectives 7, 100216.

Singh, P., Paleti, R., Jenkins, S., Bhat, C.R. (2013) On modeling telecommuting behavior: option, choice, and frequency. Transportation 40, 373-396.

Sourd, R.C.d., Calastri, C. (2020) Effect of respondent engagement on data quality in travel behaviour and retrospective mobility surveys. Mobility and Travel Behaviour Across the Life Course eds Scheiner, J., Rau, H. Edward Elgar Publishing, Cheltenham: United Kingdom, pp. 67-81.

Steg, L., Kalfs, N. (2000) Altijd weer die auto. Sociaal en Cultureel Planbureau / Adviesdienst Verkeer en Vervoer, The Hague, the Netherlands.

Steg, L., Vlek, C., Slotegraaf, G. (2001) Instrumental-reasoned and symbolic-affective motives for using a motor car. Transportation Research Part F: Traffic Psychology and Behaviour 4, 151-169.

Stopher, P., Hartgen, D., Li, Y. (1996) SMART: simulation model for activities, resources and travel. Transportation 23, 293-312.

Stopher, P.R., Zhang, Y. (2011) The repetitiveness of daily travel. Proceedings of Transportation Research Board Annual Meeting, Washington, January 2011.

Susilo, Y.O., Liu, C., Börjesson, M. (2019) The changes of activity-travel participation across gender, life-cycle, and generations in Sweden over 30 years. Transportation 46, 793-818.

Swiers, R., Pritchard, C., Gee, I. (2017) A cross sectional survey of attitudes, behaviours, barriers and motivators to cycling in University students. Journal of Transport \& Health 6 , 379-385.

Taale, H., Turpijn, B. (2020). Een fundamentele relatie in coronatijd. Bijdrage Colloquium Vervoersplanologisch Speurwerk, Corona editie 2020.

Thøgersen, J. (2006) Understanding repetitive travel mode choices in a stable context: A panel study approach. Transportation Research Part A: Policy and Practice 40, 621-638.

Thomas, G.O., Fisher, R., Whitmarsh, L., Milfont, T.L., Poortinga, W. (2018a) The impact of parenthood on environmental attitudes and behaviour: a longitudinal investigation of the legacy hypothesis. Population and Environment 39, 261-276.

Thomas, T., Geurs, K.T., Bijlsma, M. (2018b) Automatic Trip Detection with the Dutch Mobile Mobility Panel: Towards Reliable Multiple-Week Trip Registration for Larger Samples. Journal of Urban Technology 25, 1-19. 
Thomas, T., Puello, L.L.P., Geurs, K. (2019) Intrapersonal mode choice variation: Evidence from a four-week smartphone-based travel survey in the Netherlands. Journal of Transport Geography 76, 287-300.

Thompson, S., Michaelson, J., Abdallah, S., Johnson, V., Morris, D., Riley, K., Simms, A. (2011) Moments of change' as opportunities for influencing behaviour. Department of Environment. Food and Rural Affairs, Londen.

Thulin, E., Vilhelmson, B., Johansson (2019) New Telework, Time Pressure and Time Use Control in Everyday Life. Sustainability 11, 3067.

Timmermans, H. (2009) Household Decision Making in Travel Behaviour Analysis., The Expanding Sphere of Travel Behaviour Research Emerald Group Publishing, Bingley, UK, pp. 159-185.

Timmermans, H.J.P., Zhang, J. (2009) Modeling household activity travel behavior: Examples of state of the art modeling approaches and research agenda. Transportation Research Part B: Methodological 43, 187-190.

Toger, M., Kourtit, K., Nijkamp, P., Östh, J. (2021) Mobility during the COVID-19 Pandemic: A Data-Driven Time-Geographic Analysis of Health-Induced Mobility Changes. Sustainability 13, 4027.

Tourangeau, R., Zimowski, M., Ghadialy, R. (1997) An introduction to panel surveys in transportation studies. Federal Highway Administration, Chicago.

Gemeente Utrecht (2021) Mobiliteitsplan 2040: Jouw straat en onze stad gezond, aantrekkelijk en bereikbaar voor iedereen. Utrecht.

Provincie Utrecht (2019) Mobiliteitsprogramma 2019-2023: Overstappen.

Van Acker, V., Witlox, F. (2010) Car ownership as a mediating variable in car travel behaviour research using a structural equation modelling approach to identify its dual relationship. Journal of Transport Geography 18, 65-74.

van de Coevering, P., Maat, K., van Wee, B. (2021) Causes and effect between attitudes, the built environment and car klimetres: A longitudinal analysis. Journal of Transport Geography 91.

van der Drift, S., Wismans, L., Olde Kalter, M.J.T. (2021) Changing mobility patterns in the Netherlands during COVID-19 outbreak. Journal of Location Based Services, 1-24.

Vermunt, J.K. (2010) Latent class modeling with covariates: Two improved three-step approaches. . Political Analysis 1818.

Vermunt, J.K., Tran, B., Magidson, J. (2008) Latent Class Models in Longitudinal Research. Handbook of Longitudinal Research: Design, Measurement, and Analysis ed Menard, S. Elsevier, Burlington, pp. 373-385. 
Verplanken, B., Aarts, H., van Knippenberg, A., Moonen, A. (1998) Habit versus planned behaviour: A field experiment. British Journal of Social Psychology 37, 111-128.

Verplanken, B., Walker, I., Davis, A., Jurasek, M. (2008) Context change and travel mode choice: Combining the habit discontinuity and self-activation hypotheses. Journal of Environmental Psychology 28, 121-127.

Verplanken, B., Wood, W. (2006) Interventions to Break and Create Consumer Habits. Journal of Public Policy \& Marketing 25, 90-103.

Viana Cerqueira, E., Motte-Baumvol, B., Belton Chevallier, L., Bonin, O. (2020) Does working from home reduce $\mathrm{CO} 2$ emissions? An analysis of travel patterns as dictated by workplaces. Transportation Research Part D: Transport and Environment 83, 102338.

Vij, A., Carrel, A., Walker, J.L. (2013) Incorporating the influence of latent modal preferences on travel mode choice behavior. Transportation Research Part A: Policy and Practice 54, 164-178.

Vilhelmson, B., Thulin, E. (2016) Who and where are the flexible workers? Exploring the current diffusion of telework in Sweden. New Technology, Work and Employment 31, 77-96.

Vovsha, P., Petersen, E. (2005) Escorting children to school: Statistical analysis and applied modeling approach. Transportation Research Record: Journal of Transportation Research Board 1921, 131-140.

Vovsha, P., Petersen, E., Donnelly, R. (2007) Explicit modeling of joint travel by household members: statistical evidence and applied approach. Transportation Research Record, 1-10.

Wang, D., Li, J. (2009) A model of household time allocation taking into consideration of hiring domestic helpers. Transportation Research Part B: Methodological 43, 204-216.

Ministerie van Infrastructuur en Waterstaat (2021) Nationaal Toekomstbeeld Fiets, The Hague, the Netherlands.

Xianyu, J., Rasouli, S., Timmermans, H. (2017) Analysis of variability in multi-day GPS imputed activity-travel diaries using multi-dimensional sequence alignment and panel effects regression models. Transportation 44, 533-553.

Yáñez, M.F., Cherchi, E., Ortúzar, J.d.D., Heydecker, B.G. (2009) Inertia and schock effects on mode choice panel data: implications of the Transsantiago Implementation. International Conference on Travel Behaviour Research, Jaipur, India.

Yang, D., Timmermans, H. (2015) Analysis of consumer response to fuel price fluctuations applying sample selection model to GPS panel data: Dynamics in individuals' car use. Transportation Research Part D: Transport and Environment 38, 67-79.

Yarlagadda, A., Srinivasan, S. (2008) Modeling children's school travel mode and parential escort decisions. Transportation 35, 201-218. 
Yen, J.R. (2000) Interpreting employee telecommuting adoption: An economics perspective. Transportation 27, 149-164.

Zarabi, Z., Manaugh, K., Lord, S. (2019) The impacts of residential relocation on commute habits: A qualitative perspective on households' mobility behaviors and strategies. Travel Behaviour and Society 16, 131-142.

Zeger, S.L., Liang, K.-Y. (1992) An overview of methods for the analysis of longitudinal data. Statistics in Medicine 11, 1825-1839.

Zhang, J., Yu, B., Chikaraishi, M. (2014) Interdependences between household residential and car ownership behavior: a life history analysis. Journal of Transport Geography 34, 165-174.

Zhu, P. (2013) Telecommuting, Household Commute and Location Choice. Urban Studies 50, 2441-2459.

Zmud, J., Green, L., Kuhnimhof, T., Le Vine, S., Polak, J., Phelps, P. (2017) Still going... and going: the emerging travel patterns of older adults. Institute for Mobility Research.

Zumkeller, D., Chlond, B. (1996). The Usefulness of Panel Data to Understand Changes - The German Approach. In PTRC seminar proceedings P: Vol. 404. Transportation planning methods. London: PTRC Education and Research Services on behalf of the Planning and Transport Research and Computation International Association. 


\section{Summary}

In the Netherlands over 17 billion trips are made annually. More than half of them are car trips, and until 2020 the number of kilometres driven by car was increasing every year. To reverse the worrying long-term trends of growing mobility, such as congestion, increasing oil consumption and $\mathrm{CO}_{2}$ emissions, air pollution and inefficient use of public spaces, policymakers try to encourage the use of more sustainable modes of transport, such as the bicycle and public transport. Therefore, better insight is needed into the motivations and barriers of different modes of transport and the underlying reasons for behavioural changes. An essential question in this regard is why, when and how mode preferences and mode choice change during the life course. A better understanding of what influences mode choice behaviour will help decision-makers develop and implement better and more effective policy approaches to achieve the (desired) behavioural changes.

Examining the factors that affect mode choice behaviour has been a major field in travel behaviour research in the past decades. In general, five groups of determinants that influence mode choice are distinguished: household and individual characteristics, motivational factors, built environment variables, trip characteristics and ICT use. However, most studies on mode choice behaviour focus on only one group of determinants, as including all types of determinants is too demanding on the data. Geographers typically focus on built environment factors, economists concentrate on the travel costs and preferences of individuals, and psychologists are particularly interested in the motivational factors that influence travel behaviour. Besides, most research on mode choice behaviour is based on cross-sectional travel surveys, which is insufficient to capture inter- and intra-personal mode use variation. Day-to-day, week-to-week and year-to-year information about travellers' mode choice provides a better insight into behavioural changes at the individual level. Also, traffic and transport demand models and new mobility concepts, such as mobility-as-a-service and shared mobility, require insight into mode use variation on a more disaggregated level. These observations highlight the need for more longitudinal studies to examine the dynamics in 
mode choice behaviour and the different determinants that affect mode choice over time, and also to disentangle intrapersonal- and interpersonal mode use variation.

Despite the vast amount of studies conducted to analyse the dynamics in mode choice behaviour, there are still significant research gaps. First, the impact of changes in personal and household characteristics on household interactions and travel behaviour over time has hardly been investigated. Most studies have focused on the individual decision-making process probably because of the absence of longitudinal household surveys. Second, although previous studies have examined the impact of life events and an individual's preference for transport modes on travel behaviour, most of these studies assume that mode preferences do not change during the life event. However, mode preferences may also change over time and these changes may also affect travel behaviour. Furthermore, in most research, it is assumed that attitudes affect behaviour. This follows from the basic principle that people's behaviour can be derived from their intentions, and that attitudes determine intentions. Consequently, the impact of temporal dynamics in attitudes on transport mode choice has been much less studied. Finally, the literature has identified teleworking as a cost-effective measure to reduce (car) commuting trips, but with small overall impact. Existing research provides insight into teleworking adaption and the relationship with mode choice for commuting before COVID19. The COVID-19 pandemic offers the opportunity to gain new insights into experiences with teleworking as a major part of the working population worked from home, and the impact of these behavioural changes on future commuting behaviour.

The availability of panel data provides researchers with new opportunities to examine the identified research gaps and to increase our understanding of the temporal dynamics in mode choice behaviour. In the Netherlands, two large-scale panel data are available and were used in this thesis: the Netherlands Mobility Panel (in Dutch: Mobiliteitspanel Nederland, MPN) and the Dutch Mobility Panel (in Dutch: Nederlands Verplaatsings Panel, NVP). Since 2013, the MPN has recorded the travel behaviour of a representative sample of the Dutch population with a 3-day trip diary yearly. Additional information about, for instance, attitudes, preferences, and life events was collected through questionnaires. In this thesis, MPN-data was used to explore the impact of household interactions, mode preferences, life events and attitudes on mode choice behaviour over time. The NVP, started in 2019, measures the travel behaviour of the participants continuously through GPS tracking. In this thesis, NVP data and an additional questionnaire about changes in teleworking were used to examine the impact of COVID-19 on future changes in commuting behaviour.

The aim of this thesis was to provide empirical evidence of the different factors that influence the dynamics in mode choice behaviour, the causal relationships between these factors and the directions of these relationships over time, based on large-scale panel data from the Netherlands. Research on travel behaviour covers a large variety of topics, including factors that influence people's travel choices, building new or improving analytical modelling approaches for forecasting travel behaviour, and the analysis of the impacts of future scenarios on travel behaviour. This thesis focused on the factors that influence people's travel mode choices and the changes in mode choice behaviour over time. For each of the four identified research gaps (i.e. household interactions, life events and preferences, attitudes, and teleworking), panel analyses were conducted, using different panel modelling techniques.

Chapter 2 provides empirical insight into the impact of inter- and intrahousehold interactions and changes in individual and household characteristics, such as life events and changing preferences, on car use for home-based tours. A multilevel framework is used to investigate 
mode choice behaviour at tour, individual and household level to account for the impact of individual and household characteristics on travel mode choice, the interdependencies of individuals within their households and variation in individual travel mode choice and other characteristics over time. This chapter shows that variability between households and individuals accounts for about one-third of the total variation in mode choice of home-based tours. The findings indicate that interactions between household members, resulting in joint (or not) activity patterns, have significantly different outcomes in terms of car use. Intrahousehold interactions have a more significant effect on car use in dual-income households, probably because there are more aspects to consider that impact car use. For instance, having two work locations with different commuting distances. Policymakers should consider that in multi-person and specifically dual-income households, car use is strongly affected by relationships between household members.

Chapter 3 examines how changes in travellers' attitudes towards car use and ownership change over time and how these changes influence car use. A latent transition model was developed to investigate the transitions between different population segments and used the attitudes towards car use and ownership to identify these segments. Four latent classes were identified (i.e. cost-sensitive, car-minded, environmentally aware and socially-conscious), representing clusters of travellers with different personal values about car use and ownership. Most of the travellers remained in the same class between 2014 and 2016, which suggests that attitudes towards car use and ownership are stable over time. Also, the results indicate that car use and ownership may be less widespread among younger adults. When younger adults face life events, such as moving home, starting a job or becoming parents, transitioning to more car-oriented profiles appears more likely. Changes in attitudes towards car use and car ownership do not significantly affect car use (number of trips per day), except for the sociallyconscious travellers who switched to the car-minded class. This suggests that, in most cases, a more positive or negative attitude towards car use and ownership does not directly affect the frequency of car use.

Chapter 4 provides empirical insight into the relationship between frequency of mode use and mode preference over time and the impact of life events on young adults' mode preference and mode frequency. Cross-lagged structural equation panel models were estimated to examine the longitudinal relationship between life events, mode preferences and mode use. Young adults show very stable behaviour over time: frequency of mode use and mode preference are good predictors of frequency of mode use and mode preference in the future. Frequent car users are the most stable in their behaviour, compared to public transport and bicycle users. Concerning the relationship between mode preference and mode use, one of the main conclusions of this study is that young adults whose use of the car, public transport or bicycle increases are more likely to develop a more positive attitude towards this mode. Changes in mode preference seem to have less influence on the frequency of mode use, in particular for public transport users. In addition, young adults subjected to life events are more likely to change travel behaviour. These life-changing moments could offer a window of opportunity for policymakers and other parties to create more awareness of alternative, more sustainable modes of transport.

Chapter 5 provides evidence from large-scale GPS tracking and survey data on the relationship between changes in teleworking and daily travel behaviour during the first lockdown and the intention to change commuting behaviour after COVID-19. Ordinal and binominal logit models were developed to investigate the odds to increase teleworking and reduce car use. The main factors that influenced teleworking during the lockdown are job 
characteristics. Office workers and teaching staff were more likely to increase working from home and show a higher chance of changes in daily commuting routines. Office workers are also more likely to express an intention to increase working from home after COVID-19. In particular, employees with relatively large changes in teleworking during the lockdown expect to work from home more often after COVID-19. This effect is strengthened further by positive experiences with teleworking (i.e. more pleasure and higher productivity) and supporting policy measures by the employer, such as sufficient ICT facilities. Furthermore, this study provides evidence that employees who substantially increased teleworking during COVID-19 are more likely to increase teleworking after COVID-19, resulting in a reduction of car trips for employees in specific job sectors and functions. Teleworking can contribute in this way to the reduction of transport-related emissions and congestion.

In conclusion, this thesis contributes to a better understanding of the dynamics in mode choice behaviour regarding household interactions, life events, changing attitudes and preferences, and teleworking. The findings show the potential of panel data to provide better insight into intra- and interpersonal changes in mode preferences and mode choice and the relationship with life events. The unique combination of travel data and detailed information of the same persons over time allowed us to analyse differences and changes in weekly and yearly travel patterns at the individual level. The analysis of changes in mode choice behaviour between subsequent years demonstrates that especially contextual changes in someone's life are a trigger for behavioural changes. A first major result from this study is that attitudes and preferences are more stable over time than mode choice behaviour. A second major result is that changes in behaviour often precede changes in attitudes and preferences than vice versa. This is because people are more inclined to change attitudes and preferences to match their behaviour (or changes in behaviour). The third major result is that the analysis of the behavioural changes during the COVID-19 pandemic reveals a similar picture. Employees adapted to teleworking on a large scale, resulting in large changes in commuting behaviour. At the same time, during the lockdown, employees developed a more positive attitude towards working from home (i.e. more pleasure, higher productivity).

The main difference between the COVID-study and the other analyses in this thesis is that during the COVID-19 pandemic, employees were more or less 'forced' to change their behaviour. In contrast, contextual changes in someone's life, such as life events, are triggers to reconsider behaviour. The COVID-19 pandemic shows that when people experience new behaviour for a more extended period, the intention to change behaviour is more likely. The main takeaway for policymakers from this thesis is that they should focus on experiments, pilots, and interventions aimed directly at the desired behavioural changes. Acceptance of measures aiming at the desired change of behaviour through rewarding people for adopting the desired behaviour ("the carrot") or letting them pay for the undesired behaviour ("the stick") can be expected to be positively induced by gaining a positive experience with the desired behaviour. Examples of policy measures that encourage behavioural changes are trails with free bus tickets, changes in the physical environment, for example investments in walking and cycling infrastructure to stimulate active mobility, or pricing policy, such as pricing depending on car use.

Another important outcome from this thesis is that the dynamics in mode choice behaviour is relevant at various levels: household vs individual, interpersonal vs intrapersonal, within a year vs between years. The availability of large-scale longitudinal data, both long-duration and short-duration panels, enables a distinction to be made between these different types of mode use variation. At the same time, the availability of new and more sophisticated panel 
data offers several opportunities for further research into the dynamics in mode choice behaviour. For example, future research based on panel data is relevant in order to examine whether the COVID-19 pandemic, in the long term, strengthens existing behaviour and preferences or results in structural changes in behaviour, preferences and commuting distance. 


\section{Samenvatting}

In Nederland worden jaarlijks meer dan 17 miljard verplaatsingen gemaakt. Meer dan de helft van alle verplaatsingen zijn autoritten, en tot 2020 steeg het aantal gereden autokilometers jaarlijks. De toename van het autoverkeer heeft negatieve effecten op onder andere de congestie, olie consumptie, luchtkwaliteit, CO2-emissises en ruimtegebruik in steden, zowel op de korte als lange termijn. Het stimuleren van het gebruik van duurzame vervoermiddelen, zoals de fiets en het openbaar vervoer, is nodig om de negatieve effecten te verminderen. Daarvoor is echter inzicht nodig in de motivaties en belemmeringen voor het gebruik van verschillende vervoermiddelen en de onderliggende redenen om wel of niet van gedrag te veranderen. Een antwoord op de vraag waarom, wanneer en op welke manier mensen hun voorkeur en keuze voor vervoermiddelen veranderen is daarvoor essentieel. Een beter inzicht in de factoren die de vervoerwijzekeuze van mensen beïnvloeden helpt beleidsmakers bij het ontwikkelen en implementeren van effectieve beleidsmaatregelen om de (gewenste) gedragsverandering te bereiken.

Onderzoek naar de factoren die de vervoerwijzekeuze beïnvloeden kent een lange en rijke historie. In het algemeen worden vijf type factoren onderscheiden die van invloed zijn op de vervoerwijzekeuze: huishoud- en persoonskenmerken, de houding ten aanzien van vervoerwijzen, ruimtelijke kenmerken, verplaatsingskenmerken en het gebruik van ICT. Het meenemen van al deze kenmerken in een onderzoek stelt hoge eisen aan de data en dataverzameling. De meeste onderzoeken naar vervoerwijzekeuze nemen daarom niet al deze type factoren mee, maar beperken zich vaak tot één of meerdere typen. De gekozen focus is afhankelijk van de wetenschappelijke discipline van de onderzoekers. Geografen focussen zich voornamelijk op de relatie tussen ruimtelijke kenmerken en de vervoerwijzekeuze, economen kijken vooral naar de reiskosten en voorkeuren van reizigers, en psychologen zijn meer geïnteresseerd in de onderliggende motivaties en belemmeringen om een bepaalde vervoerwijze wel of niet te kiezen. Daarnaast zijn de meeste onderzoeken naar vervoerwijzekeuze gebaseerd op cross-sectie onderzoeken, waarmee de variatie in het gebruik van verschillende vervoermiddelen, zowel van één persoon als tussen personen, niet gemeten 
kan worden. Gegevens over de vervoerwijzekeuze van dezelfde persoon van dag-tot-dag, week-tot-week en jaar-tot-jaar, geven een beter inzicht in de gedragsveranderingen op individueel niveau. Ook voor verkeersmodellen en het analyseren van nieuwe mobiliteitsconcepten zoals mobility-as-a-service en deelmobiliteit zijn individuele gegevens over de variatie in vervoermiddelgebruik noodzakelijk. Kortom, er is dus meer longitudinaal onderzoek nodig naar de dynamiek in vervoerwijzekeuze en de factoren die van invloed zijn op veranderingen in de vervoerwijzekeuze, ook om meer grip te krijgen op de inter- en intrapersonele verschillen in vervoermiddelgebruik.

Hoewel er al veel onderzoek is gedaan naar de dynamiek in vervoerwijzekeuze, zijn er nog steeds een aantal kennis lacunes. In de eerste plaats is de invloed van veranderingen in de persoonlijke of huishoudelijke sfeer op huishoudinteracties en veranderingen in mobiliteitsgedrag nog nauwelijks onderzocht. De meeste onderzoeken richten zich op het individuele keuzeproces binnen huishoudens, mede ingegeven door het feit dat er weinig longitudinale data op huishoudniveau beschikbaar is. Hoewel er al veel onderzoek is gedaan naar de invloed van levensgebeurtenissen op de mobiliteit, wordt in de meeste studies ervan uitgegaan dat voorkeuren voor vervoermiddelen niet gelijktijdig met een levensgebeurtenis mee veranderen. Voorkeuren kunnen echter wel degelijk veranderen, en wijzigingen van voorkeuren kunnen ook weer van invloed zijn op het mobiliteitsgedrag. Ook wordt in de meeste onderzoeken verondersteld dat attitudes van invloed zijn op ons gedrag. Dit volgt uit het basisprincipe dat het gedrag van mensen afgeleid kan worden van de intenties die mensen hebben en dat intenties worden bepaald door onze attitudes. Als gevolg daarvan is minder vaak onderzoek gedaan naar de invloed van veranderende attitudes op de vervoerwijzekeuze. Tenslotte, telewerken wordt al enige tijd als een potentiële en effectieve maatregel gezien om de woon-werk mobiliteit, en dan vooral het aantal autoritten, te verminderen. Bestaand onderzoek, gebaseerd op de situatie voor COVID-19, geeft vooral inzicht in de factoren die van invloed zijn op telewerken en de relatie met de vervoermiddelkeuze voor woon-werk verplaatsingen. De coronacrisis biedt de mogelijkheid om nieuwe inzichten op te doen over de ervaringen die in deze periode zijn opgedaan met telewerken, aangezien een zeer groot deel van de werkende bevolking thuis werkte, en de invloed van deze gedragsveranderingen op de toekomstige woon-werk mobiliteit.

De beschikbaarheid van panel data biedt nieuwe mogelijkheden om de genoemde kennis lacunes te onderzoeken en geeft een beter inzicht in de dynamiek in de vervoerwijzekeuze. In Nederland lopen op dit moment twee omvangrijke panel onderzoeken die in dit proefschrift zijn gebruikt: het Mobiliteitspanel Nederland (MPN) en het Nederlands Verplaatsingspanel (NVP). Het MPN meet sinds 2013 jaarlijks het verplaatsingsgedrag van een representatieve steekproef van de Nederlandse bevolking met een 3-daags dagboekje. Aanvullende informatie over onder andere attitudes, voorkeuren en levensgebeurtenissen wordt via vragenlijsten verzameld. Voor het onderzoeken van de invloed van huishoudinteracties, levensgebeurtenissen en attitudes op de veranderingen in de vervoerwijzekeuze is gebruik gemaakt van MPN-data. Het NVP meet sinds 2019 continu het verplaatsingsgedrag van ongeveer 9,000 Nederlanders via GPS tracking. NVP-data en een enquête over telewerken ingevuld door deelnemers aan het NVP zijn gebruikt om de invloed van COVID-19 op toekomstige veranderingen in de woon-werk mobiliteit te onderzoeken.

Het doel van dit proefschrift is het vaststellen van de invloed van verschillende factoren op de dynamiek in vervoerwijzekeuze, de causale verbanden tussen deze factoren en de ontwikkeling door de tijd, op basis van empirische gegevens. Daarvoor is gebruik gemaakt van twee omvangrijke panel studies uit Nederland. Onderzoek naar mobiliteitsgedrag richt 
zich in het algemeen op een van de volgende drie onderwerpen: (1) factoren die ons reisgedrag en de keuzes die we hierin maken beïnvloeden, (2) het ontwikkelen of verbeteren van modellen om ons reisgedrag te voorspellen, en (3) het analyseren van de effecten van verschillende toekomstscenario's. In dit proefschrift ligt de focus op het eerste onderwerp: de factoren die de vervoerwijzekeuze en veranderingen daarin beïnvloeden. Voor elk van de onderwerpen waar kennis lacunes bestaan (i.e. huishoudinteracties, levensgebeurtenissen en voorkeuren, attitudes, en telewerken) zijn panel analyses uitgevoerd, waarbij gebruik is gemaakt van verschillende modelleringstechnieken.

Hoofdstuk 2 geeft empirische inzichten in de invloed van inter- en intra-huishoud interacties en veranderingen in persoonlijke en huishoudkenmerken, zoals levensgebeurtenissen en veranderende voorkeuren, op het autogebruik voor huisgebonden verplaatsingen. Met een multilevel analyse is de vervoerwijzekeuze op individueel en huishoudniveau onderzocht, waarbij rekening is gehouden met de invloed van (veranderende) persoons- en huishoudkenmerken, afhankelijkheden tussen huishoudleden en de variatie in vervoerwijzekeuze. Dit hoofdstuk laat zien dat variatie tussen huishoudens en personen ongeveer een derde van de totale variatie in vervoerwijzekeuze voor huisgebonden verplaatsingen verklaart. De bevindingen tonen aan dat interacties tussen huishoudleden, resulterend in wel of geen gezamenlijke activiteiten, een significant effect hebben op het autogebruik. Binnen huishoudens met tweeverdieners hebben interacties tussen huishoudleden een groter significant effect op het individuele autogebruik, waarschijnlijk omdat meer rekening moet worden gehouden met andere aspecten die de keuze voor de auto beïnvloeden. In een huishouden met tweeverdieners moet bijvoorbeeld rekening worden gehouden met twee werklocaties met verschillende woon-werk afstanden. Beleidsmakers moeten rekening houden met het feit dat in meerpersoonshuishouden, en specifiek tweeverdieners, het autogebruik sterk beïnvloed wordt door de afhankelijkheden die bestaan tussen huishoudleden.

Hoofdstuk 3 onderzoekt hoe attitudes van reizigers ten aanzien van autogebruik en autobezit veranderen door de tijd en hoe deze veranderingen van invloed zijn op het autogebruik. Een latent transitie model is ontwikkeld om de verschuivingen tussen verschillende segmenten te analyseren. Binnen dit model zijn de verschillende attitudes ten aanzien van autogebruik en autobezit gebruikt om deze segmenten te classificeren. De vier geïdentificeerde segmenten (i.e. kosten-gevoelig, auto-minded, milieubewust en omgevingsbewust) representeren clusters van reizigers die dezelfde persoonlijke waarden hebben ten aanzien van autobezit en autogebruik. De meeste reizigers blijven in hetzelfde segment tussen 2014 en 2016. Dit suggereert dat attitudes ten aanzien van autogebruik en autobezit stabiel zijn door de tijd. De resultaten laten ook zien dat autogebruik en autobezit minder belangrijk zijn onder jongvolwassenen. Alleen bij bepaalde levensgebeurtenissen, zoals verhuizen, starten met een baan, het krijgen van een kind, verschuiven jongvolwassenen vaker naar een meer op de auto georiënteerd segment. Veranderingen in de attitudes ten aanzien van autogebruik en autobezit hebben geen significant effect op het autogebruik (aantal autoverplaatsingen per dag), behalve voor de omgevingsbewuste reizigers, die opschuiven naar het auto-minded segment. De resultaten wijzen erop dat een meer positieve of negatieve houding ten aanzien van autogebruik en autobezit in de meeste gevallen niet direct leidt tot meer of minder autogebruik.

Hoofdstuk 4 geeft empirische inzichten in de relatie tussen het gebruik van en de voorkeur voor een vervoermiddel door de tijd en de invloed van levensgebeurtenissen op het gebruik van en de voorkeur voor een vervoermiddel van jongvolwassenen. Cross-lagged structurele 
vergelijkingsmodellen zijn geschat om te longitudinale relatie tussen levensgebeurtenissen, voorkeur voor en het gebruik van vervoermiddelen te onderzoeken. Jongvolwassenen laten door de tijd een stabiel gedrag zien: de frequentie van het gebruik van en de mate waarin iemand een voorkeur heeft voor een vervoermiddel zijn goede voorspellers voor de frequentie van gebruik en mate van voorkeur in de toekomst. Frequente autogebruikers vertonen het meest stabiele gedrag, vergeleken met frequente openbaar vervoer gebruikers en fietsers. Ten aanzien van de relatie tussen voorkeur en gebruik, is een belangrijke conclusie uit dit onderzoek dat jongvolwassenen die vaker de auto, het openbaar vervoer of de fiets gaan gebruiken, een grotere voorkeur voor deze vervoermiddelen ontwikkelen. Veranderende voorkeuren lijken een minder grote invloed te hebben op het gebruik, dit geldt in het bijzonder voor openbaar vervoer gebruikers. Daarnaast zijn jongvolwassen die een levensgebeurtenis hebben meegemaakt meer geneigd hun mobiliteitsgedrag aan te passen. Het moment waarop deze ingrijpende veranderingen in het leven van jongvolwassenen plaatsvinden bieden beleidsmakers een aangrijpingspunt om meer bewustzijn te creëren voor alternatieven en meer duurzame vervoerwijzen.

Hoofdstuk 5 levert op basis van omvangrijke GPS tracking data en een enquête bewijs over de relatie tussen veranderingen in telewerken en het dagelijkse reisgedrag gedurende de eerste lockdown en de intentie om woon-werk mobiliteit te veranderen na COVID-19. Ordinale en binominale logit modellen zijn geschat om te bepalen hoe groot de kans is dat telewerken toeneemt en het autogebruik in het woon-werk verkeer afneemt. De belangrijkste factoren die telewerken hebben beïnvloed tijdens de lockdown zijn kenmerken van de baan. Kantoormedewerkers en onderwijspersoneel zijn vaker gaan thuiswerken en hebben een grotere kans op veranderingen in hun dagelijkse woon-werkverkeer. Kantoormedewerkers hebben ook een grotere kans om na COVID-19 vaker thuis te werken. Vooral werknemers die tijdens de lockdown veel meer zijn gaan telewerken, verwachten vaker thuis te weken na COVID-19. Dit effect wordt verder versterkt door positieve ervaringen met telewerken (i.e. meer plezier, hogere productiviteit) en ondersteunende maatregelen van de werkgever, zoals voldoende ICT-faciliteiten. Deze studie bewijst ook dat een verwachte toename in telewerken leidt tot een substantiële afname van het autogebruik in het woon-werk verkeer, ervan uitgaande dat de woon-werk afstanden op de korte termijn niet veranderen. Dit betekent dat telewerken in potentie een belangrijke bijdrage kan leveren aan de reductie van transport gerelateerde emissies en de congestie.

Samenvattend levert dit proefschrift nieuwe empirische inzichten over de dynamiek in vervoerwijzekeuze als het gaat om huishoudinteracties, levensgebeurtenissen, veranderende attitudes en voorkeuren en telewerken. De resultaten laten de potentie van panel data zien om het inzicht in gedragsveranderingen te vergroten. De unieke combinatie van verplaatsingsdata en uitgebreide achtergrondinformatie van dezelfde personen gedurende een langere periode biedt de mogelijkheid om individuele verschillen en veranderingen in de wekelijkse en jaarlijkse reispatronen te analyseren. De analyse van veranderingen in vervoerwijzekeuze tussen opeenvolgende jaren laat zien dat vooral veranderingen in de persoonlijke leefomgeving een prikkel vormen voor gedragsveranderingen. Een eerste belangrijke conclusie van dit proefschrift is dat attitudes en voorkeuren stabieler door de tijd zijn dan de vervoerwijzekeuze. Een tweede belangrijke conclusie is dat veranderingen in de vervoerwijzekeuze vaker voorafgaan aan veranderingen in attitudes en voorkeuren dan andersom. Dit komt doordat mensen eerder geneigd zijn hun attitudes en voorkeuren aan te passen zodat het past bij het gedrag dat ze toch al vertonen. De derde belangrijke conclusie van dit proefschrift is dat de analyse van de gedragsveranderingen tijdens de COVID-19 pandemie een vergelijkbaar beeld laten zien. Werknemers werkten veel vaker thuis, hetgeen 
resulteerde in grote veranderingen in het woon-werkverkeer. Tegelijkertijd, werden werknemers tijdens de lockdown steeds positiever over telewerken (i.e. meer plezier, hogere productiviteit).

Het grote verschil tussen de COVID-19 studie en de andere analyses in dit proefschrift is dat tijdens de COVID-19 pandemie werknemers min of meer werden gedwongen om hun gedrag aan te passen, terwijl veranderingen in de leefomgeving van iemand eerder een trigger zijn om na te denken over ander gedrag. De COVID-pandemie laat zien dat wanneer mensen ervaringen opdoen met andere gedrag voor een langere periode, de intentie om ook daadwerkelijk het gedrag aan te passen groter is. De belangrijkste boodschap voor beleidsmakers is dan ook dat ze vooral gebruik moeten maken van experimenten, pilots en interventies die direct ingrijpen op de gewenste gedragsveranderingen. Acceptatie van maatregelen die gericht zijn op de gewenste gedragsverandering via belonen ("wortel") of straffen ("azijn") kan positief gestimuleerd worden door positieve ervaringen met het gewenste gedrag. Voorbeelden van beleidsmaatregelen die ander gedrag 'uitlokken' zijn een gratis proefperiode met het $\mathrm{OV}$, aanpassingen in de fysieke leefomgeving, bijvoorbeeld investeringen in de loop- en fietsinfrastructuur om actieve mobiliteit te stimuleren, of prijsbeleid, zoals betalen voor autogebruik.

Een andere belangrijke uitkomst van dit proefschrift is dat de dynamiek in vervoerwijzekeuze zich manifesteert op verschillende niveaus: huishoudens vs individueel, interpersoonlijk vs intrapersoonlijk, binnen een jaar vs tussen jaren. De beschikbaarheid van omvangrijke longitudinale data, zowel langdurige als kortdurende panels, biedt de mogelijkheid om onderscheid te maken tussen deze verschillende vormen van variatie in vervoerwijzekeuze. Tegelijkertijd biedt de beschikbaarheid van nieuwe en meer geavanceerde panel data verschillende mogelijkheden voor vervolgonderzoek. Toekomstige studies gebaseerd op panel data zijn bijvoorbeeld relevant om de lange termijneffecten te onderzoeken van COVID-19 op ons mobiliteitsgedrag en onze voorkeuren voor de verschillende vervoerwijzen. Maar ook of op de lange termijn mensen langere woonwerk afstanden accepteren omdat ze minder vaak naar het werk hoeven te reizen. 


\section{About the author}

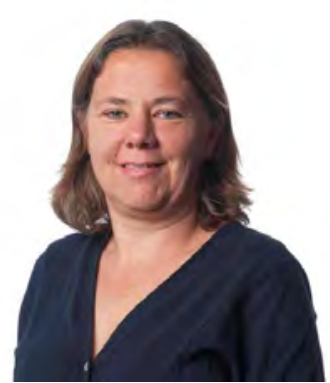

Marie-José Olde Kalter was born on the $16^{\text {th }}$ of August 1974. She grew up in Oldenzaal, the Netherlands. She obtained her VWO diploma at the Twents Carmel Lyceum in Oldenzaal. In 1992 she started to study Civil Engineering and Management at the University of Twente. In this period, she combined her study at the University with playing for the Dutch National Women's Soccer Team. She was granted with the "Stheemanbokaal", a yearly award given to students who combine sport performances on top level with good academic study results. After graduation, Marie-José started working at Goudappel as a research consultant. In 2005 she moved to Rijkswaterstaat, part of the Ministry of Infrastructure and Water Management, and in 2006 she started working at the KIM Netherlands Institute for Transport Policy Analysis as a scientific researcher. In 2010 she returned to Goudappel as a consultant at the Research \& Development department. In 2014 she started, parallel to her work as a consultant, a PhD project at the University of Twente, Centre for Transport Studies. She still works at Goudappel, mainly on research projects related to evaluation and policy research. Since 2019 she is hired by the Ministry of Infrastructure and Water Management to support and advice the different departments regarding monitoring and evaluation of their policy.

In her spare time, she likes to travel around the world with her husband and two children. Backpacking in South-East Asia and visiting historical cities in Europe are favourite. Other hobbies are reading, skiing, hiking, soccer, drinks with friends and family, photography and playing board games. 


\section{Author's publications}

\section{Journal publications}

Olde Kalter, M.J.T., La Paix Puello, L., Geurs, K.T. (2021). Exploring the relationship between life events, mode preferences and mode use of young adults: a 3-year cross-lagged panel analysis in the Netherlands. Travel Behaviour and Society, 24, 195-204

Van der Drift, S., Wismans, L., Olde Kalter, M.J.T. (2020). Changing mobility patterns in the Netherlands during COVID-19 outbreak. Journal of Location Based Services, 1-24

Olde Kalter, M.J.T., La Paix Puello, L., Geurs, K.T. (2020). Do changes in travellers' attitudes towards car use and ownership over time affect travel mode choice? A latent transition approach in the Netherlands. Transportation Research Part A: Policy and Practice, $132,1-17$

La Paix Puello, L., Olde Kalter, M.J.T., Geurs, K.T. (2017). Measurement of non-random attrition effects on mobility rates using trip diaries data. Transportation Research Part A: Policy and Practice, 160, Supplement C, 51-64

Olde Kalter, M.J.T., Geurs, K.T. (2016). Exploring the impact of household interactions on car use for home-based tours: a multilevel analysis of mode choice using data from the first two waves of the Netherlands Mobility Panel. European Journal of Transport and Infrastructure Research, 16(4), 698-712

Olde Kalter, M.J.T., Geurs, K.T., Hoogendoorn-Lanser, S. (2015). Vervoerwijzekeuze in woon-werkverkeer. Eerste analyses met het nieuwe Mobiliteitspanel Nederland. Tijdschrift Vervoerwetenschap, 51(4), 107-127

Arentze, T., Timmermans, H., Jorritsma, P., Olde Kalter, M.J.T. \& Schoemakers, A. (2008). More Grey Hair - But For Whom? Scenario Based Simulations of Elderly Activity Patterns in 2020. Transportation, 35, 613-627.

\section{Peer reviewed conference preceedings}

Hoogendoorn-Lanser, S., Schaap, N., Olde Kalter, M.J.T. (2015). The Netherlands Mobility Panel: An innovative design approach for web-based longitudinal travel data collection. Transportation Research Procedia, 11, 311-329

Hoogendoorn-Lanser, S., Olde Kalter, M.J.T., Schaap, N.T.W. (2015). Impact of different shopping stages on shopping-related travel behaviour: Analyses of the Netherlands Mobility Panel data. Transportation, 46, 341-371

Olde Kalter, M.J.T., Harms, L.W.J., Jorritsma, P. (2009). Changing travel patterns of women in the Netherlands. Women's Issues in Transportation, 2, 179-190 


\section{TRAIL Thesis Series}

The following list contains the most recent dissertations in the TRAIL Thesis Series. For a complete overview of more than 275 titles see the TRAIL website: www.rsTRAIL.nl.

The TRAIL Thesis Series is a series of the Netherlands TRAIL Research School on transport, infrastructure and logistics.

Olde Kalter, M.J.T., Dynamics in Mode Choice Behaviour, T2021/27, November 2021, TRAIL Thesis Series, the Netherlands

Los, J., Solving Large-Scale Dynamic Collaborative Vehicle Routing Problems: an AuctionBased Multi-Agent Approach, T2021/26, November 2021, TRAIL Thesis Series, the Netherlands

Khakdaman, M., On the Demand for Flexible and Responsive Freight Transportation Services, T2021/25, September 2021, TRAIL Thesis Series, the Netherlands

Wierbos, M.J., Macroscopic Characteristics of Bicycle Traffic Flow: a bird's-eye view of cycling, T2021/24, September 2021, TRAIL Thesis Series, the Netherlands

Qu, W., Synchronization Control of Perturbed Passenger and Freight Operations, T2021/23, July 2021, TRAIL Thesis Series, the Netherlands

Nguyen, T.T., Highway Traffic Congestion Patterns: Feature Extraction and Pattern Retrieval, T2021/22, July 2021, TRAIL Thesis Series, the Netherlands

Pudāne, B., Time Use and Travel Behaviour with Automated Vehicles, T2021/21, July 2021, TRAIL Thesis Series, the Netherlands

Gent, P. van, Your Car Knows Best, T2021/20, July 2021, TRAIL Thesis Series, the Netherlands

Wang, Y., Modeling Human Spatial Behavior through Big Mobility Data, T2021/19, June 2021, TRAIL Thesis Series, the Netherlands

Coevering, P. van de, The Interplay between Land Use, Travel Behaviour and Attitudes: a quest for causality, T2021/18, June 2021, TRAIL Thesis Series, the Netherlands

Landman, R., Operational Control Solutions for Traffic Management on a Network Level, T2021/17, June 2021, TRAIL Thesis Series, the Netherlands

Zomer, L.-B., Unravelling Urban Wayfinding: Studies on the development of spatial knowledge, activity patterns, and route dynamics of cyclists, T2021/16, May 2021, TRAIL Thesis Series, the Netherlands

Núñez Velasco, J.P., Should I Stop or Should I Cross? Interactions between vulnerable road users and automated vehicles, T2021/15, May 2021, TRAIL Thesis Series, the Netherlands 
Duivenvoorden, K., Speed Up to Safe Interactions: The effects of intersection design and road users' behaviour on the interaction between cyclists and car drivers, T2021/14, April 2021, TRAIL Thesis Series, the Netherlands

Nagalur Subraveti, H.H.S., Lane-Specific Traffic Flow Control, T2021/13, March 2021, TRAIL Thesis Series, the Netherlands

Beirigo, B.A., Dynamic Fleet Management for Autonomous Vehicles: Learning- and optimization-based strategies, T2021/12, March 2021, TRAIL Thesis Series, the Netherlands

Zhang, B., Taking Back the Wheel: Transition of control from automated cars and trucks to manual driving, T2021/11, February 2021, TRAIL Thesis Series, the Netherlands

Boelhouwer, A., Exploring, Developing and Evaluating In-Car HMI to Support Appropriate use of Automated Cars, T2021/10, January 2021, TRAIL Thesis Series, the Netherlands

Li, X., Development of an Integrity Analytical Model to Predict the Wet Collapse Pressure of Flexible Risers, T2021/9, February 2021, TRAIL Thesis Series, the Netherlands

Li, Z., Surface Crack Growth in Metallic Pipes Reinforced with Composite Repair System, T2021/8, January 2021, TRAIL Thesis Series, the Netherlands

Gavriilidou, A., Cyclists in Motion: From data collection to behavioural models, T2021/7, February 2021, TRAIL Thesis Series, the Netherlands

Methorst, R., Exploring the Pedestrians Realm: An overview of insights needed for developing a generative system approach to walkability, T2021/6, February 2021, TRAIL Thesis Series, the Netherlands

Walker, F., To Trust or Not to Trust? Assessment and calibration of driver trust in automated vehicles, T2021/5, February 2021, TRAIL Thesis Series, the Netherlands

Schneider, F., Spatial Activity-travel Patterns of Cyclists, T2021/4, February 2021, TRAIL Thesis Series, the Netherlands

Madadi, B., Design and Optimization of Road Networks for Automated Vehicles, T2021/3, January 2021, TRAIL Thesis Series, the Netherlands

Krabbenborg, L.D.M., Tradable Credits for Congestion Management: support/reject?, T2021/2, January 2021, TRAIL Thesis Series, the Netherlands

Castelein, B., Accommodating Cold Logistics Chains in Seaport Clusters: The development of the reefer container market and its implications for logistics and policy, T2021/1, January 2021, TRAIL Thesis Series, the Netherlands

Huang, B., The Influence of Positive Interventions on Cycling, T2020/20, December 2020, TRAIL Thesis Series, the Netherlands

Xiao, L., Cooperative Adaptive Cruise Control Vehicles on Highways: Modelling and Traffic Flow Characteristics, T2020/19, December 2020, TRAIL Thesis Series, the Netherlands 

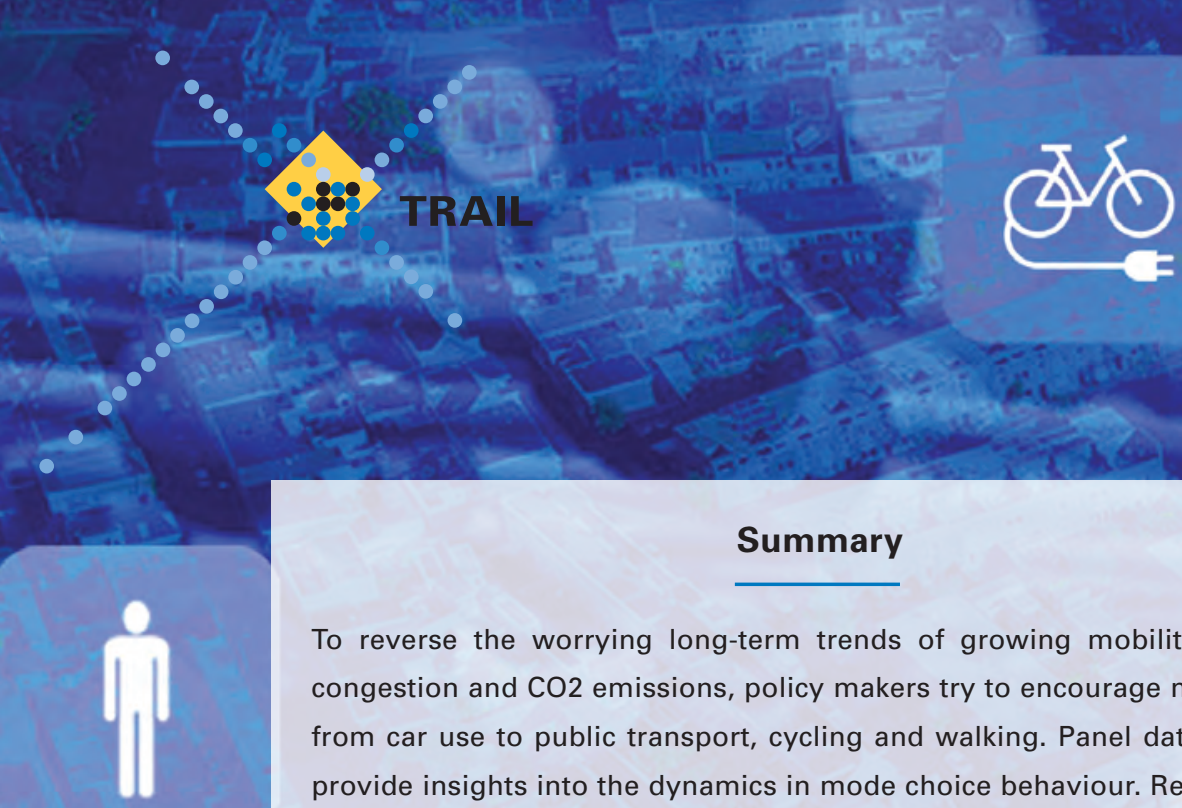

\section{Summary}

To reverse the worrying long-term trends of growing mobility, such as congestion and $\mathrm{CO} 2$ emissions, policy makers try to encourage mode shifts from car use to public transport, cycling and walking. Panel data analyses provide insights into the dynamics in mode choice behaviour. Results show that behavioural changes often precede changes in attitudes and preferences. Therefore, policy makers should focus on interventions aimed directly at the desired behavioural changes.

\section{About the Author}

Marie-José Olde Kalter carried out, parallel to her work as a consultant at Goudappel, her PhD research from 2014-2021 at the Centre of Transport Studies, University of Twente. Her research focus is dynamics in travel behaviour.

TRAIL Research School ISBN 978-90-5584-302-2

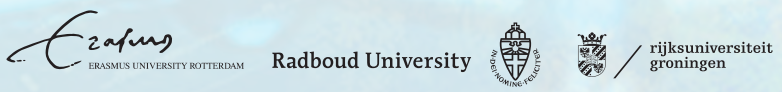

